ACS Chemical Biology - Letter

SUPPORTING INFORMATION

\title{
3-Oxo- $\beta$-Sultam as a Sulfonylating Chemotype for Inhibition of Serine Hydrolases and Activity-Based Protein Profiling
}

Luís A. R. Carvalho, ${ }^{a}$ Vanessa T. Almeida, ${ }^{\text {b }}$ José A. Brito, ${ }^{\mathrm{b}}$ Kenneth M. Lum, ${ }^{\mathrm{c}}$ Tânia F. Oliveira, ${ }^{\mathrm{b} \dagger}$ Rita C. Guedes, ${ }^{\mathrm{a}}$ Lídia M. Gonçalves, ${ }^{a}$ Susana D. Lucas, ${ }^{a}$ Benjamin F. Cravatt, ${ }^{c}$ Margarida Archer, ${ }^{b}$ Rui Moreira*a

a. Department of Medicinal Chemistry, Research Institute for Medicines (iMed.ULisboa), Faculdade de Farmacia, Universidade de Lisboa Av. Prof. Gama Pinto, 1649-003 Lisboa (Portugal). E-mail: rmoreira@ff.ulisboa.pt.

b. Biological Chemistry Division, Instituto de Tecnologia Química e Biológica António Xavier, Universidade Nova de Lisboa (ITQB NOVA) Av. da República, 2780-157 Oeiras (Portugal).

c. Department of Chemistry, The Scripps Research Institute, La Jolla, CA 92037 (US).

$\$$ These authors contributed equally to this work.

$\dagger$ Deceased

\begin{abstract}
3-oxo- $\beta$-sultams are four-membered ring ambident electrophiles that can react with nucleophiles either at the carbonyl carbon or at the sulfonyl sulfur atoms, and that have been reported to inhibit serine hydrolases via acylation of the activesite serine residue. We have developed a panel of 3-oxo- $\beta$-sultam inhibitors and show, through crystallographic data, that they are regioselective sulfonylating electrophiles, covalently binding to the catalytic serine of human and porcine elastases through the sulfur atom. Application of 3-oxo- $\beta$-sultam-derived activity-based probes in a human proteome revealed their potential to label disease-related serine hydrolases and proteasome subunits. Activity-based protein profiling applications of 3-oxo- $\beta$-sultams should open up new opportunities to investigate these classes of enzymes in complex proteomes and expand the toolbox of available sulfur-based covalent protein modifiers in chemical biology.
\end{abstract}




\section{Table of Contents}

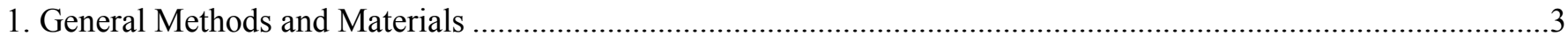

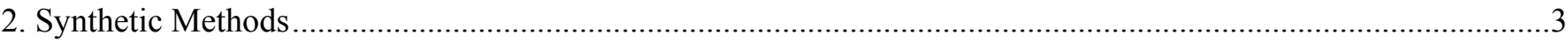

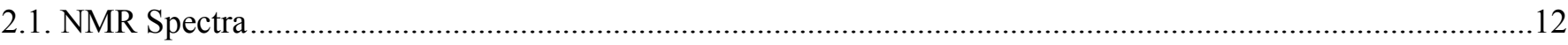

3. X-Ray Crystallography - Crystallization, Structure Determination and Refinement .........................................32

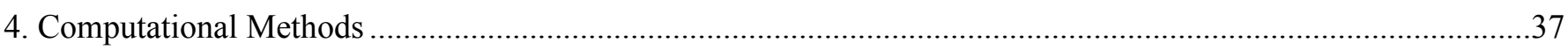

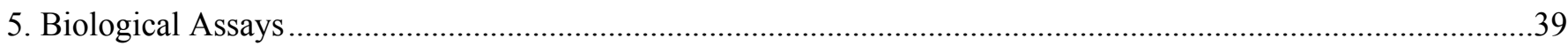

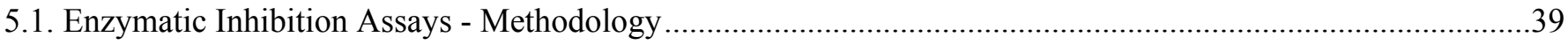

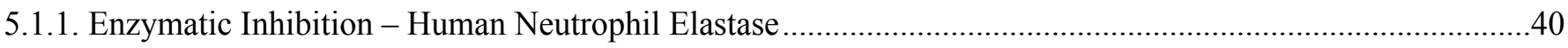

5.1.2. Enzymatic Inhibition - Biochemical Selectivity Evaluation Results...........................................................4

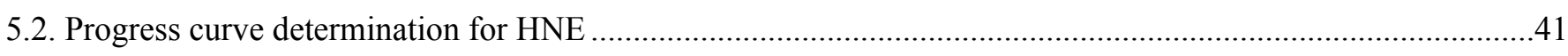

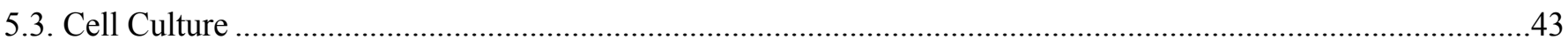

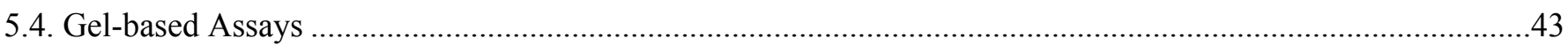

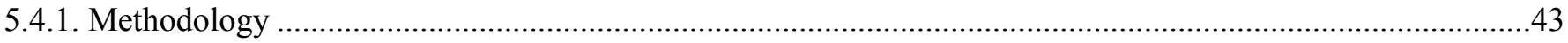

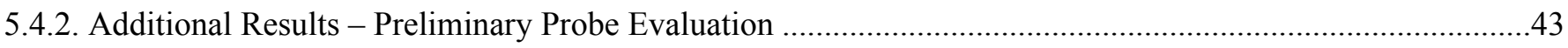

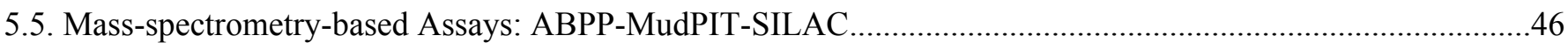

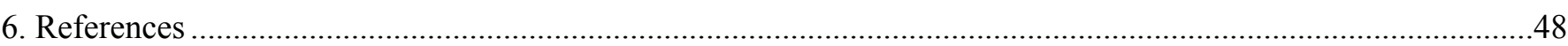




\section{General Methods and Materials}

All chemical reagents and solvents were purchased from reputable commercial vendors and used without further purification. Nuclear magnetic resonance experiments $\left({ }^{1} \mathrm{H}\right.$ and ${ }^{13} \mathrm{C}$ NMR) were recorded on a Bruker Avance $300(300$ and $75 \mathrm{MHz}$, respectively). Chemical shifts are reported in the $\delta$ scale in ppm. Solvent residual signals were used as internal standard. Coupling constants $J$ are given in Hz using the abbreviations: $\mathrm{s}=$ singlet, $\mathrm{d}=$ doublet, $\mathrm{t}=$ triplet, $\mathrm{q}=$ quartet, quint $=$ quintet, $\mathrm{m}=$ multiplet. Chemical reactions were followed by thin layer chromatography (TLC) using Merck aluminium backed sheets coated with $60 \mathrm{~F}_{254}$ silica gel and visualized in a UV lamp $\left(\lambda_{\max }=254 \mathrm{~nm}\right)$. When indicated, flash chromatography was performed in a Combi Flash RF-200 instrument from Teledyne Isco with RediSep normal-phase silica flash columns. High resolution ESI positive mode mass spectra were obtained from a QqTOF Impact II ${ }^{\mathrm{TM}}$ mass spectrometer (Bruker Daltonics) operating in high resolution mode. Samples were analyzed by flow injection analysis (FIA) using a isocratic gradient $30 \mathrm{~A}: 70 \mathrm{~B}$ of $0.1 \%$ formic acid in water (A) and $0.1 \%$ of formic acid in acetonitrile (B), at a $10 \mu \mathrm{L} \mathrm{min}{ }^{-1}$ flow rate over $15 \mathrm{~min}$. The TOF analyser was calibrated in the $\mathrm{m} / \mathrm{z}$ range $100-1500$ using an internal calibration standard (Tunemix solution) supplied from Agilent. The full scan mass spectra were acquired over a mass range of $100-1350 \mathrm{~m} / \mathrm{z}$ at a spectra rate of $1 \mathrm{~Hz}$. Data was processed using Data Analysis 4.2 software. Protein separations by SDS-PAGE were performed using $10 \%$ acrylamide gels at $300 \mathrm{~V}$ and samples were visualized by in-gel fluorescence (broad green excitation [LED] and emission filter 605/50 nm) scanning using a ChemiDoc MP system (Bio-Rad). The resulting data was processed using the Image Lab (5.2.1) software (Bio-Rad). Gel image contrast and brightness was optimized in the same software. Culture media and supplements for cell culture were purchased from Life Technologies. Reagents and probes for cell treatment were prepared as stock solutions (1000x) in DMSO and stored at $-20^{\circ} \mathrm{C}$.

\section{Synthetic Methods}

The synthesis of the 3-oxo- $\beta$-sultam (1,2-thiazetidin-3-one 1,1-dioxide) library was adapted from previously published procedures. ${ }^{I-3}$ A general description of our strategy is presented in scheme S1. Briefly, an appropriate anhydride is reacted with sulfuric acid to introduce the sulfonic acid. Basic treatment results in a disodium salt. Reaction with thionyl chloride converts the carboxylic and sulfonic acids into their chloride derivatives. Reaction with an amine results in cyclization and formation of the 3-oxo- $\beta$-sultam ring. Propargyl derivatives were synthesized and derivatization via CuAAC click chemistry resulted in the library of compounds.
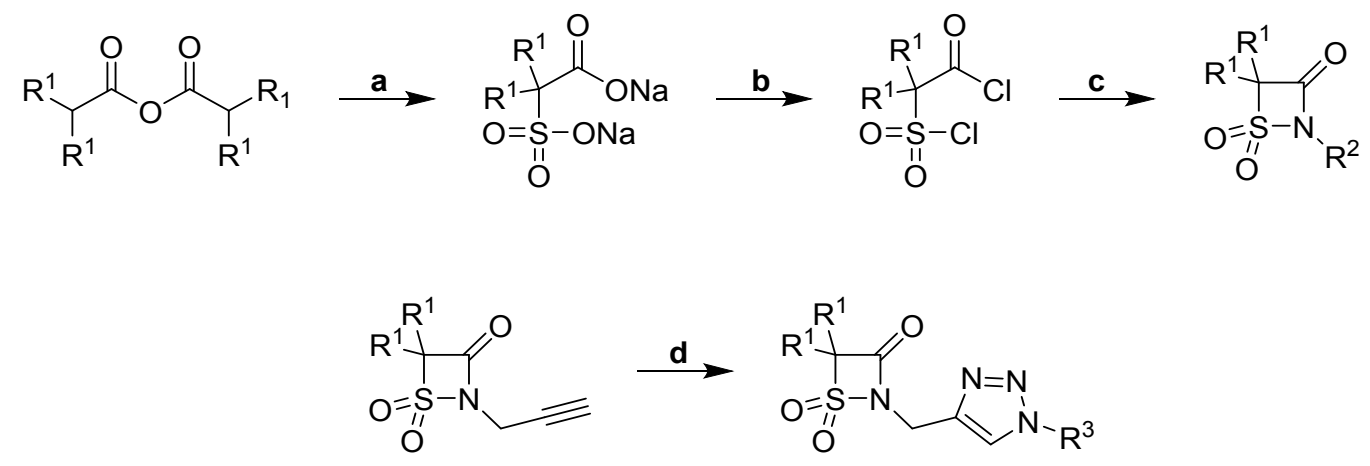

Scheme S1. a. $1 . \mathrm{H}_{2} \mathrm{SO}_{4}, 90{ }^{\circ} \mathrm{C}, 14 \mathrm{~h}, 2 . \mathrm{NaOH}$ (aq). b. $\mathrm{SOCl}_{2}(10$ eq ), DMF (cat), 5 h; c. NH-R (1.1 eq), TEA (2 eq), Diethyl Ether, $2 \mathrm{~h}, 0{ }^{\circ} \mathrm{C}$; d. $\mathrm{CuSO}_{4}(1 \%$ mol eq, aq. $)$, Sodium Ascorbate (2\% mol eq, aq.), N $3-\mathrm{R}(1.1$ eq), DMSO, $24 \mathrm{~h}$. 


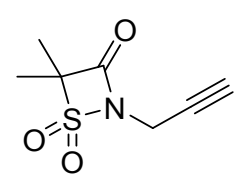

\section{(3) 4,4-Dimethyl-2-(prop-2-yn-1-yl)-1,2-thiazetidin-3-one 1,1-dioxide.}

2-(chlorosulfonyl)-2-methylpropanoyl chloride $(1,568 \mathrm{~g}, 6,6 \mathrm{mmol})$ was stirred in dry diethyl ether $(17 \mathrm{~mL})$ at $0{ }^{\circ} \mathrm{C}$ under nitrogen atmosphere. Propargylamine $(0.508 \mathrm{~mL}, 7.9 \mathrm{mmol})$ in dry diethyl ether $(9 \mathrm{~mL})$ was slowly added dropwise. The reaction was stirred at $0{ }^{\circ} \mathrm{C}$ for 30 minutes and then triethylamine $(2.114 \mathrm{~mL}, 15.2 \mathrm{mmol})$ in dry ether $(9 \mathrm{~mL})$ was slowly added. The reaction was allowed to reach room temperature and stirred overnight. The precipitate that formed was filtered and washed with diethyl ether. Evaporation of the filtrate yielded the alkyne derived 3-oxo- $\beta$-sultam 3 as white crystals (920 mg, 4.9 mmol, 74\%). ${ }^{1} \mathrm{H}$ NMR (300 MHz, DMSO- $\left.d_{6}\right) \delta 4.40$ (d, $\left.J=2.6 \mathrm{~Hz}, 2 \mathrm{H}\right), 3.47$ (t, $\left.J=2.6 \mathrm{~Hz}, 1 \mathrm{H}\right), 1.65$ (s, 6H). ${ }^{13} \mathrm{C}$ NMR $\left(75 \mathrm{MHz}, \mathrm{DMSO}-d_{6}\right) \delta 163.8,83.6,76.3,75.6,29.3,17.6$. HRMS (ESI) $\mathrm{m} / \mathrm{z}[\mathrm{M}]+$ calcd for $\mathrm{C}_{7} \mathrm{H}_{9} \mathrm{NO}_{3} \mathrm{~S}: 188.0374$, found: 188.0376 .

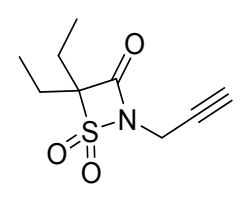

\section{(4) 4,4-Diethyl-2-(prop-2-yn-1-yl)-1,2-thiazetidin-3-one 1,1-dioxide.}

2-(chlorosulfonyl)-2-ethylbutanoyl chloride $(1.08 \mathrm{~g}, 4.6 \mathrm{mmol})$ was stirred in dry diethyl ether $(10 \mathrm{~mL})$ at $0{ }^{\circ} \mathrm{C}$ under nitrogen atmosphere. Propargylamine $(0.330 \mathrm{~mL}, 5.2 \mathrm{mmol})$ in dry diethyl ether $(10 \mathrm{~mL})$ was very slowly added dropwise. The reaction was stirred at $0{ }^{\circ} \mathrm{C}$ for 30 minutes and then triethylamine $(1.36 \mathrm{~mL}, 9.8 \mathrm{mmol})$ in dry ether $(10 \mathrm{~mL})$ was slowly added. The reaction was allowed to reach room temperature and stirred overnight. The precipitate that formed was filtered and washed with diethyl ether. The filtrate was evaporated, concentrated under reduced pressure and purified by combi flash chromatography to obtain the product 4 as a colorless oil $\left(0.63 \mathrm{~g}, 2.9 \mathrm{mmol}, 63 \%\right.$ yield). ${ }^{1} \mathrm{H}$ NMR (300 MHz, DMSO$\left.d_{6}\right) \delta 4.42(\mathrm{~d}, J=2.5 \mathrm{~Hz}, 2 \mathrm{H}), 3.46(\mathrm{t}, J=2.6 \mathrm{~Hz}, 1 \mathrm{H}), 2.18-2.00(\mathrm{~m}, 4 \mathrm{H}), 1.04(\mathrm{t}, J=7.5 \mathrm{~Hz}, 6 \mathrm{H}) .{ }^{13} \mathrm{C} \mathrm{NMR}(75 \mathrm{MHz}$, DMSO- $\left.d_{6}\right) \delta 163.1,91.0,76.7,76.1,29.6,22.5,8.7$. HRMS (ESI) $\mathrm{m} / \mathrm{z}[\mathrm{M}]+$ calcd for $\mathrm{C}_{9} \mathrm{H}_{13} \mathrm{NO}_{3} \mathrm{~S}: 216.0679$, found: 216.0689 .

General method for the synthesis of benzylic azides (A): $1 \mathrm{mmol}$ of selected halogenated benzylic compounds was dissolved in DMSO (30 mL). Sodium Azide (1.1 - $1.5 \mathrm{eq})$ was added and the reaction was stirred overnight at room temperature under nitrogen atmosphere. Full conversion of the starting material was observed by TLC and a single new chemical entity was observed. $50 \mathrm{~mL}$ of water were added to the solution and the product was extracted with diethyl ether $(3 \times 10 \mathrm{~mL})$. The organic fractions were combined, dried with anhydrous sodium sulfate and filtered. $1 \mathrm{~mL}$ of DMSO was added to the solution and the diethyl ether was evaporated under reduced pressure, resulting in a solution of the respective azide in DMSO. The azides were stored as DMSO solutions and used without further purification to avoid concentration of potentially explosive azides. A quantitative yield was assumed for the calculation of the concentration of azide solutions.

(Az1) (azidomethyl)benzene. The compound was purchased from Sigma-Aldricht. (Az2) 1-(azidomethyl)-4chlorobenzene. Synthesized from 1-chloro-4-(chloromethyl)benzene using the general method A. (Az3) 1-(azidomethyl)4-bromobenzene. Synthesized from 1-bromo-4-(bromomethyl)benzene using the general method A. (Az4) 1(azidomethyl)-4-nitrobenzene. Synthesized from 1-(chloromethyl)-4-nitrobenzene using the general method A. (Az5) 1(azidomethyl)-3-nitrobenzene. Synthesized from 1-(chloromethyl)-3-nitrobenzene using the general method A. (Az6) 1(azidomethyl)-2-nitrobenzene. Synthesized from 1-(bromomethyl)-2-nitrobenzene using the general method A. (Az7) 1(azidomethyl)-4-methoxybenzene. Synthesized from 1-(chloromethyl)-4-methoxybenzene using the general method A. 


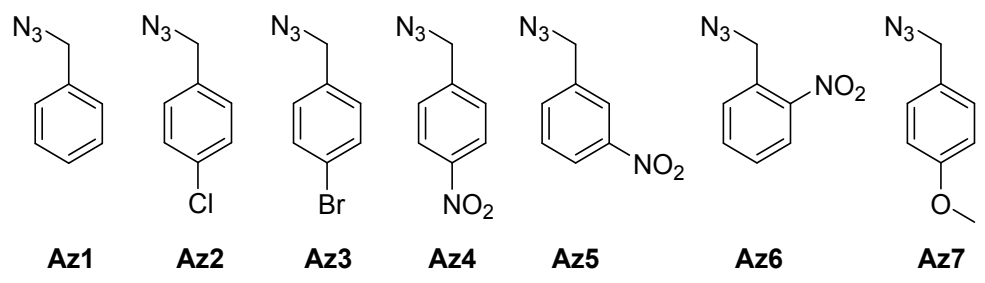

Figure S1. Azides synthesized for the click chemistry reactions.

General method for the derivatization of 3-oxo- $\beta$-sultams by CuAAC (B): An alkyne-derived 3-oxo- $\beta$-sultam (3 or 4$)$ was dissolved in DMSO $\left(1 \mathrm{~mL}\right.$ ) and stirred at room temperature. $\mathrm{CuSO}_{4}$ (aq. $0.1 \mathrm{M}, 1 \% \mathrm{~mol} \mathrm{eq}$ ) and Sodium Ascorbate (aq. 0.2 $\mathrm{M}, 2 \% \mathrm{~mol}$ eq) were added. After 10 minutes the corresponding azide was added. The reaction was stirred overnight at room temperature under nitrogen atmosphere.<smiles>[R]C1C(=O)N(Cc2cn([R])nn2)S1(=O)=O</smiles>

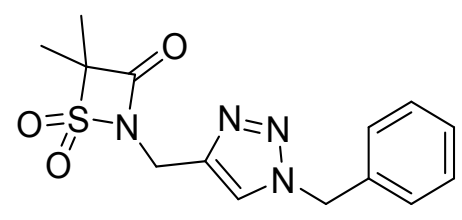

(11) 2-((1-Benzyl-1H-1,2,3-triazol-4-yl)methyl)-4,4-dimethyl-1,2-thiazetidin-3-one 1,1-dioxide.

From the general method B using alkyne 3 ( $70 \mathrm{mg}, 0.37 \mathrm{mmol}$ ) and azide Az1 (60 mg, $0.45 \mathrm{mmol}$ ). After stirring overnight, the product was precipitated in the reaction medium by adding $5 \mathrm{~mL}$ of water. The solid was filtered and washed with water, yielding 11 as a white solid (48 mg, $0.15 \mathrm{mmol}, 40 \%) .{ }^{1} \mathrm{H}$ NMR $\left(300 \mathrm{MHz}, \mathrm{DMSO}-d_{6}\right) \delta 8.20(\mathrm{~s}, 1 \mathrm{H}), 7.46-7.15(\mathrm{~m}, 5 \mathrm{H})$, $5.62(\mathrm{~s}, 2 \mathrm{H}), 4.74(\mathrm{~s}, 2 \mathrm{H}), 1.64(\mathrm{~s}, 6 \mathrm{H}) .{ }^{13} \mathrm{C}$ NMR $\left(75 \mathrm{MHz}, \mathrm{DMSO}-d_{6}\right) \delta 164.2,140.2,136.0,128.8,128.2,127.8,124.2$, 83.4, 52.8, 35.2, 17.7. HRMS (ESI) $\mathrm{m} / \mathrm{z}[\mathrm{M}]+$ calcd for $\mathrm{C}_{14} \mathrm{H}_{16} \mathrm{~N}_{4} \mathrm{O}_{3} \mathrm{~S}: 321.1012$, found: 321.1016 .<smiles>CC1(C)C(=O)N(Cc2cn(-c3ccc(Br)cc3)nn2)S1(=O)=O</smiles>

\section{(12) 2-((1-(4-Bromophenyl)-1H-1,2,3-triazol-4-yl)methyl)-4,4-dimethyl-1,2-thiazetidin-3-one 1,1-dioxide.}

From the general method B using alkyne $3(70 \mathrm{mg}, 0.37 \mathrm{mmol})$ and azide 1-azido-4-bromobenzene (79 $\mathrm{mg}, 0.4 \mathrm{mmol})$. After stirring overnight, a white solid precipitated in the reaction medium. $5 \mathrm{~mL}$ of water were added, leading to further precipitation of the solid. The solid was filtered, washed with water, and recrystallized from acetonitrile and water, yielding 12 as a white solid (36 mg, $0.093 \mathrm{mmol}, 25 \%) .{ }^{1} \mathrm{H}$ NMR (300 MHz, DMSO- $\left.d_{6}\right) \delta 8.88(\mathrm{~s}, 1 \mathrm{H}), 7.96-7.71(\mathrm{~m}, 4 \mathrm{H}), 4.84$ 
(s, 2H), $1.67(\mathrm{~s}, 6 \mathrm{H}) .{ }^{13} \mathrm{C}$ NMR $\left(75 \mathrm{MHz}, \mathrm{DMSO}-d_{6}\right) \delta 164.6,141.8,136.1,133.3,122.6,122.5,122.0,84.0,35.4,18.2$. HRMS (ESI) $\mathrm{m} / \mathrm{z}[\mathrm{M}]+$ calcd for $\mathrm{C}_{13} \mathrm{H}_{13} \mathrm{BrN}_{4} \mathrm{O}_{3} \mathrm{~S}: 384.9960$, found: 384.9964 .

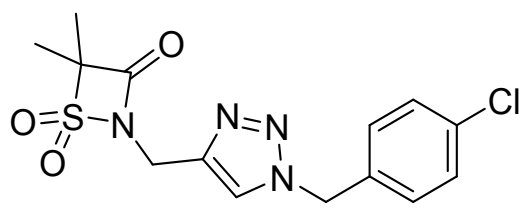

\section{(5) 2-((1-(4-Chlorobenzyl)-1H-1,2,3-triazol-4-yl)methyl)-4,4-dimethyl-1,2-thiazetidin-3-one 1,1-dioxide.}

From the general method B using alkyne 3 ( $80 \mathrm{mg}, 0.43 \mathrm{mmol}$ ) and azide Az2 (86 mg, $0.51 \mathrm{mmol}$ ). After stirring overnight, a white solid precipitated in the reaction medium. $5 \mathrm{~mL}$ of water were added, leading to further precipitation of the solid. The solid was filtered, washed with water, and recrystallized from ethyl acetate and hexane, yielding $\mathbf{5}$ as a white solid (71 $\mathrm{mg}, 0.20 \mathrm{mmol}, 47 \%) .{ }^{1} \mathrm{H}$ NMR $(300 \mathrm{MHz}, \mathrm{DMSO}) \delta 8.22(\mathrm{~s}, 1 \mathrm{H}), 7.45(\mathrm{~d}, J=8.6 \mathrm{~Hz}, 2 \mathrm{H}), 7.32(\mathrm{~d}, J=8.6 \mathrm{~Hz}, 2 \mathrm{H}), 5.63$ $(\mathrm{s}, 2 \mathrm{H}), 4.75(\mathrm{~s}, 2 \mathrm{H}), 1.64(\mathrm{~s}, 6 \mathrm{H}) .{ }^{13} \mathrm{C}$ NMR $(75 \mathrm{MHz}$, Acetone) $\delta 164.9,141.7,135.9,134.5,130.6,129.7,124.5,84.1$, 53.4, 36.1, 18.3. HRMS (ESI) $\mathrm{m} / \mathrm{z}[\mathrm{M}]+$ calcd for $\mathrm{C}_{14} \mathrm{H}_{15} \mathrm{ClN}_{4} \mathrm{O}_{3} \mathrm{~S}: 354.2176$, found: 354.2186 .

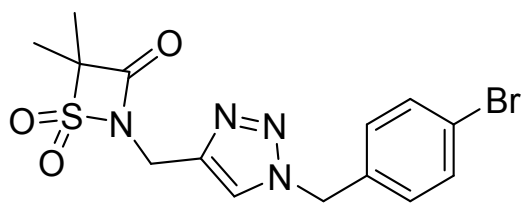

(6) 2-((1-(4-Bromobenzyl)-1H-1,2,3-triazol-4-yl)methyl)-4,4-dimethyl-1,2-thiazetidin-3-one 1,1-dioxide.

From the general method B using alkyne $3(80 \mathrm{mg}, 0.43 \mathrm{mmol}$ ) and azide Az3 (109 mg, $0.52 \mathrm{mmol})$. After reacting overnight, $25 \mathrm{~mL}$ of water were added. The product was extracted with ethyl acetate $(3 \times 10 \mathrm{~mL})$. The organic fractions were combined, dried with anhydrous sodium sulfate and concentrated under reduced pressure. The product was recrystallized from acetonitrile and water, yielding 6 as a white solid $(176 \mathrm{mg}, 0.817 \mathrm{mmol}, 60 \%) .{ }^{1} \mathrm{H}$ NMR $(300 \mathrm{MHz}, \mathrm{DMSO}) \delta 8.21(\mathrm{~s}, 1 \mathrm{H})$, $7.57(\mathrm{~d}, J=8.4 \mathrm{~Hz}, 2 \mathrm{H}), 7.24(\mathrm{~d}, J=8.4 \mathrm{~Hz}, 2 \mathrm{H}), 5.61(\mathrm{~s}, 2 \mathrm{H}), 4.75(\mathrm{~s}, 2 \mathrm{H}), 1.64(\mathrm{~s}, 6 \mathrm{H}) .{ }^{13} \mathrm{C}$ NMR $\left(75 \mathrm{MHz}, \mathrm{DMSO}-d_{6}\right) \delta$ 164.2, 140.3, 135.4, 131.7, 130.1, 124.2, 121.5, 83.4, 52.1, 35.2, 17.7. HRMS (ESI) m/z [M]+ calcd for $\mathrm{C}_{14} \mathrm{H}_{15} \mathrm{BrN}_{4} \mathrm{O}_{3} \mathrm{~S}$ : 399.0120, found: 399.0121 .

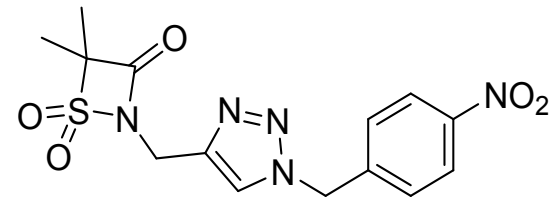

\section{(7) 4,4-Dimethyl-2-((1-(4-nitrobenzyl)-1H-1,2,3-triazol-4-yl)methyl)-1,2-thiazetidin-3-one 1,1-dioxide.}

From the general method B using alkyne $3(70 \mathrm{mg}, 0.37 \mathrm{mmol})$ and azide Az4 (69 mg, $0.39 \mathrm{mmol})$. After reacting overnight, $25 \mathrm{~mL}$ of water were added to the reaction. The product was extracted with ethyl acetate $(3 \mathrm{x} 10 \mathrm{~mL})$. The organic fractions were combined, dried with anhydrous sodium sulfate and concentrated under reduced pressure. The product was recrystallized from acetonitrile and water, yielding 7 as a white solid (16 mg, 0.044 mmol, 12\%). ${ }^{1} \mathrm{H}$ NMR (300 MHz, DMSO) $\delta 8.29$ (s, 1H), $8.23(\mathrm{~d}, J=8.8 \mathrm{~Hz}, 2 \mathrm{H}), 7.50(\mathrm{~d}, J=8.8 \mathrm{~Hz}, 2 \mathrm{H}), 5.81$ (s, 2H), 4.77 (s, 2H), 1.64 (s, 6H). ${ }^{13} \mathrm{C}$ NMR (75 MHz, Acetone) $\delta 164.9,148.7,144.3,141.9,129.7,125.0,124.7,84.1$, 53.3, 36.1, 18.3. HRMS (ESI) $\mathrm{m} / \mathrm{z}$ [M]+ calcd for $\mathrm{C}_{14} \mathrm{H}_{15} \mathrm{~N}_{5} \mathrm{O}_{5} \mathrm{~S}: 366.0865$, found: 366.0867 . 


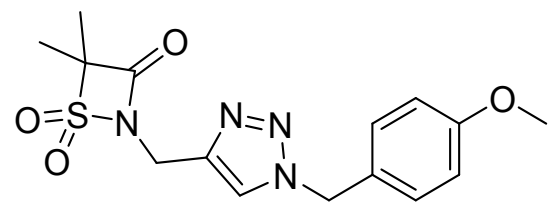

(13) 2-((1-(4-Methoxybenzyl)-1H-1,2,3-triazol-4-yl)methyl)-4,4-dimethyl-1,2-thiazetidin-3-one 1,1-dioxide.

From the general method B using alkyne $3(80 \mathrm{mg}, 0.43 \mathrm{mmol})$ and azide $\mathbf{A z 7}(82 \mathrm{mg}, 0.5 \mathrm{mmol})$. After reacting overnight, $25 \mathrm{~mL}$ of water were added. The product was extracted with ethyl acetate $(3 \times 10 \mathrm{~mL})$. The organic fractions were combined, dried with anhydrous sodium sulfate and concentrated under reduced pressure. The product was recrystallized from acetonitrile and water, yielding 13 as a white solid $(95 \mathrm{mg}, 0.27 \mathrm{mmol}, 63 \%){ }^{1} \mathrm{H}$ NMR $\left(300 \mathrm{MHz}, \mathrm{DMSO}-d_{6}\right) \delta 8.14(\mathrm{~s}$, $1 \mathrm{H}), 7.27(\mathrm{~d}, J=8.7 \mathrm{~Hz}, 2 \mathrm{H}), 6.92(\mathrm{~d}, J=8.7 \mathrm{~Hz}, 2 \mathrm{H}), 5.52(\mathrm{~s}, 2 \mathrm{H}), 4.73(\mathrm{~s}, 2 \mathrm{H}), 3.73(\mathrm{~s}, 3 \mathrm{H}), 1.63(\mathrm{~s}, 6 \mathrm{H}) .{ }^{13} \mathrm{C}$ NMR $(75$ $\mathrm{MHz}, \mathrm{DMSO}) \delta 164.2,159.2,140.2,129.5,127.9,123.8,114.1,83.4,55.1,52.4,35.2,17.7$. HRMS (ESI) $\mathrm{m} / \mathrm{z}[\mathrm{M}]+$ calcd for $\mathrm{C}_{15} \mathrm{H}_{18} \mathrm{~N}_{4} \mathrm{O}_{4} \mathrm{~S}: 351.1122$, found: 351.1124 .

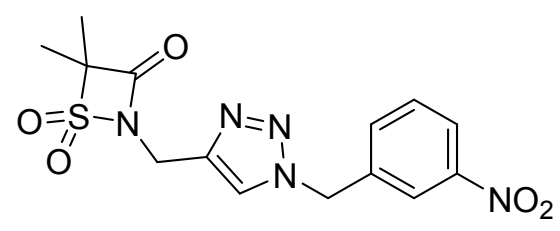

(14) 4,4-Dimethyl-2-((1-(3-nitrobenzyl)-1H-1,2,3-triazol-4-yl)methyl)-1,2-thiazetidin-3-one 1,1-dioxide.

From the general method B using alkyne 3 ( $80 \mathrm{mg}, 0.43 \mathrm{mmol}$ ) and azide Az5 (92 mg, $0.52 \mathrm{mmol}$ ). After reacting overnight, $5 \mathrm{~mL}$ of water were added to the reaction, causing a white solid to precipitate. The solid was filtered, washed with water, and recrystallized from acetonitrile and water, yielding 14 as a white solid $(94 \mathrm{mg}, 0.26 \mathrm{mmol}, 60 \%) .{ }^{1} \mathrm{H} \mathrm{NMR}(300 \mathrm{MHz}$, DMSO) $\delta 8.31(\mathrm{~s}, 1 \mathrm{H}), 8.23-8.17(\mathrm{~m}, 2 \mathrm{H}), 7.76-7.64(\mathrm{~m}, 2 \mathrm{H}), 5.81(\mathrm{~s}, 2 \mathrm{H}), 4.77(\mathrm{~s}, 2 \mathrm{H}), 1.64(\mathrm{~s}, 6 \mathrm{H}) .{ }^{13} \mathrm{C}$ NMR $(75$ MHz, DMSO) $\delta 164.6,148.3,140.8,138.6,135.1,130.9,124.9,123.6,123.2,83.9,52.2,35.6,18.1$. HRMS (ESI) $\mathrm{m} / \mathrm{z}$ $[\mathrm{M}]+$ calcd for $\mathrm{C}_{14} \mathrm{H}_{15} \mathrm{~N}_{5} \mathrm{O}_{5} \mathrm{~S}: 366.0866$, found: 366.0867 .<smiles>CC1(C)C(=O)N(Cc2cn(Cc3ccccc3[N+](=O)[O-])nn2)S1(=O)=O</smiles>

(15) 4,4-Dimethyl-2-((1-(2-nitrobenzyl)-1H-1,2,3-triazol-4-yl)methyl)-1,2-thiazetidin-3-one 1,1-dioxide.

From the general method B using alkyne 3 ( $80 \mathrm{mg}, 0.43 \mathrm{mmol}$ ) and azide Az6 (92 mg, $0.52 \mathrm{mmol}$ ). After reacting overnight, $5 \mathrm{~mL}$ of water were added to the reaction, causing a white solid to precipitate. The solid was filtered, washed with water, and recrystallized from acetonitrile and water, yielding 15 as a white solid (69 mg, $0.19 \mathrm{mmol}, 44 \%) .{ }^{1} \mathrm{H} \mathrm{NMR}(300 \mathrm{MHz}$, DMSO) $\delta 8.22(\mathrm{~s}, 1 \mathrm{H}), 8.15(\mathrm{~d}, J=7.8 \mathrm{~Hz}, 1 \mathrm{H}), 7.67(\mathrm{dt}, J=25.6,7.3 \mathrm{~Hz}, 2 \mathrm{H}), 6.94(\mathrm{~d}, J=7.5 \mathrm{~Hz}, 1 \mathrm{H}), 6.00(\mathrm{~s}, 2 \mathrm{H}), 4.80$ (s, 2H), $1.64(\mathrm{~s}, 6 \mathrm{H}) .{ }^{13} \mathrm{C}$ NMR (75 MHz, DMSO) $\delta 164.1,147.4,140.2,134.2,131.0,129.60,129.55,125.02,124.95,83.3$, 50.0, 35.2, 17.6. HRMS (ESI) $\mathrm{m} / \mathrm{z}$ [M]+ calcd for $\mathrm{C}_{14} \mathrm{H}_{15} \mathrm{~N}_{5} \mathrm{O}_{5} \mathrm{~S}: 366.0866$, found: 366.0867 . 


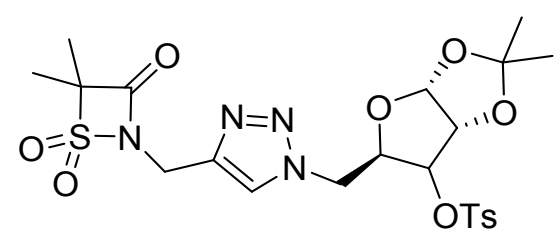

(16) $(3 \mathrm{a} R, 5 R, 6 \mathrm{a} R)-5$-((4-((4,4-dimethyl-1,1-dioxido-3-oxo-1,2-thiazetidin-2-yl)methyl)-1H-1,2,3-triazol-1-yl)methyl)2,2-dimethyl-tetrahydrofuro[2,3-d][1,3]dioxol-6-yl 4-methylbenzenesulfonate.

From the general method B using alkyne $3(72 \mathrm{mg}, 0.38 \mathrm{mmol})$ and the azide (3aR,6aR)-5-(azidomethyl)-2,2dimethyltetrahydrofuro[2,3-d][1,3]dioxol-6-yl 4-methylbenzenesulfonate (170 $\mathrm{mg}, 0.46 \mathrm{mmol})$. After reacting overnight $25 \mathrm{~mL}$ of water were added. The product was extracted with ethyl acetate $(3 \times 10 \mathrm{~mL})$. The organic layers were combined, dried with anhydrous sodium sulfate and concentrated under reduced pressure. The product was purified by combi flash chromatography (hexane: ethyl acetate gradient, $100 \%$ hexane to $100 \%$ ethyl acetate), yielding $\mathbf{1 6}$ as a white solid $(77 \mathrm{mg}, 0.14 \mathrm{mmol}, 36 \%) .{ }^{1} \mathrm{H}$ NMR $\left(300 \mathrm{MHz}, \mathrm{CDCl}_{3}\right) \delta 7.82(\mathrm{~d}, J=7.4 \mathrm{~Hz}, 2 \mathrm{H}), 7.73(\mathrm{~s}, 1 \mathrm{H}), 7.40(\mathrm{~d}, J=6.9 \mathrm{~Hz}$, 2H), $5.93(\mathrm{~s}, 1 \mathrm{H}), 4.88(\mathrm{~s}, 1 \mathrm{H}), 4.76-4.63(\mathrm{~m}, 3 \mathrm{H}), 4.58-4.31(\mathrm{~m}, 3 \mathrm{H}), 2.47(\mathrm{~s}, 3 \mathrm{H}), 1.71(\mathrm{~s}, 6 \mathrm{H}), 1.38(\mathrm{~s}, 3 \mathrm{H}), 1.25(\mathrm{~s}$, $3 \mathrm{H}) .{ }^{13} \mathrm{C}$ NMR $\left(75 \mathrm{MHz}, \mathrm{CDCl}_{3}\right) \delta 164.1,146.2,140.5,132.4,130.5,128.0,124.3,113.0,104.9,83.4,83.3,81.8,77.5$, 49.2, 35.9, 26.6, 26.3, 21.9, 18.5. HRMS (ESI) m/z [M]+ calcd for $\mathrm{C}_{22} \mathrm{H}_{28} \mathrm{~N}_{4} \mathrm{O}_{9} \mathrm{~S}_{2}:$ 557.1372, found: 557.1370.

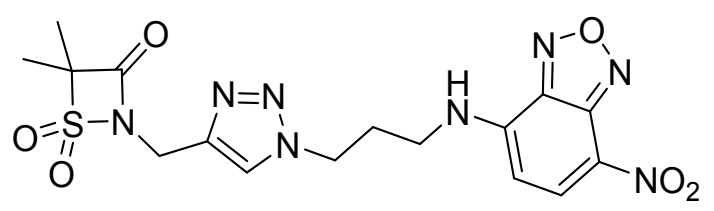

(17) 4,4-Dimethyl-2-((1-(3-((7-nitrobenzo[c][1,2,5]oxadiazol-4-yl)amino)propyl)-1H-1,2,3-triazol-4-yl)methyl)-1,2thiazetidin-3-one 1,1-dioxide. From the general method B using alkyne 3 (100 mg, $0.53 \mathrm{mmol})$ and $\mathrm{N}$-(3-azidopropyl)7-nitrobenzo[c][1,2,5]oxadiazol-4-amine $(167 \mathrm{mg}, 0.64 \mathrm{mmol})$. After reacting overnight, an orange solid precipitated in the reaction media. The solid was filtered and washed with water, yielding 17 as an orange solid $(174 \mathrm{mg}, 0.39 \mathrm{mmol}, 72 \%)$. ${ }^{1} \mathrm{H}$ NMR $(300 \mathrm{MHz}, \mathrm{DMSO}) \delta 9.52(\mathrm{~s}, 1 \mathrm{H}), 8.50(\mathrm{~d}, \mathrm{~J}=8.9 \mathrm{~Hz}, 1 \mathrm{H}), 8.19(\mathrm{~s}, 1 \mathrm{H}), 6.33(\mathrm{~d}, \mathrm{~J}=8.5 \mathrm{~Hz}, 1 \mathrm{H}), 4.74(\mathrm{~s}, 2 \mathrm{H})$, 4.52 (t, J = 6.9 Hz, 2H), 3.48 (broad, 2H), 2.24 (q, 2H), 1.64 (s, 6H). ${ }^{13} \mathrm{C}$ NMR (75 MHz, DMSO) $\delta 164.1,145.0,144.4$, 144.1, 139.9, 137.8, 124.1, 121.0, 99.1, 83.4, 47.2, 35.2, 28.3, 17.7. HRMS (ESI) m/z [M]+ calcd for $\mathrm{C}_{16} \mathrm{H}_{18} \mathrm{~N}_{8} \mathrm{O}_{6} \mathrm{~S}$ : 451.1143, found: 451.1143 .<smiles>CCC1(CC)C(=O)N(Cc2cn(-c3ccc(Br)cc3)nn2)S1(=O)=O</smiles>

(18) 2-((1-(4-Bromophenyl)-1H-1,2,3-triazol-4-yl)methyl)-4,4-diethyl-1,2-thiazetidin-3-one 1,1-dioxide.

From the general method B using alkyne $4(100 \mathrm{mg}, 0.46 \mathrm{mmol})$ and using azide 1-azido-4-bromobenzene (110 $\mathrm{mg}, 0.56$ $\mathrm{mmol})$. After reacting overnight, $25 \mathrm{~mL}$ of water were added. The product was extracted with ethyl acetate $(3 \mathrm{x} 10 \mathrm{~mL})$. The organic layers were combined, dried with anhydrous sodium sulfate and concentrated under reduced pressure, yielding a green oil. Washing of the crude oil with diethyl ether led to precipitation of $\mathbf{1 8}$ as a white solid (74 $\mathrm{mg}, 0.18 \mathrm{mmol}$, 39\%). ${ }^{1} \mathrm{H}$ NMR (300 MHz, Chloroform- $d$ ) $\delta 8.06(\mathrm{~s}, 1 \mathrm{H}), 7.73-7.51(\mathrm{~m}, 4 \mathrm{H}), 4.85(\mathrm{~s}, 2 \mathrm{H}), 2.18(\mathrm{qd}, J=7.5,1.6 \mathrm{~Hz}, 4 \mathrm{H})$, $1.14(\mathrm{t}, J=7.5 \mathrm{~Hz}, 6 \mathrm{H}) .{ }^{13} \mathrm{C}$ NMR $(75 \mathrm{MHz}$, Chloroform- $d$ ) $\delta 163.4,135.8,133.0,132.8,122.8,122.1,120.8,91.1,35.5$, 22.6, 8.5. HRMS (ESI) m/z [M]+ calcd for $\mathrm{C}_{15} \mathrm{H}_{17} \mathrm{BrN}_{4} \mathrm{O}_{3} \mathrm{~S}: 413.0280$, found: 413.0277 . 


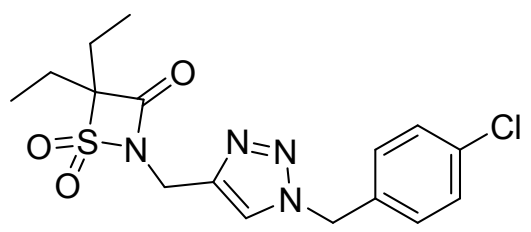

(19) 2-((1-(4-Chlorobenzyl)-1H-1,2,3-triazol-4-yl)methyl)-4,4-diethyl-1,2-thiazetidin-3-one 1,1-dioxide.

From the general method B using alkyne $4(100 \mathrm{mg}, 0.46 \mathrm{mmol})$ and using azide Az2 (93 mg, $0.55 \mathrm{mmol})$. After reacting overnight, $25 \mathrm{~mL}$ of water were added. The product was extracted with ethyl acetate $(3 \mathrm{x} 10 \mathrm{~mL})$. The organic layers were combined, dried with anhydrous sodium sulfate and concentrated under reduced pressure, yielding a colorless oil. Washing of the crude oil with diethyl ether led to precipitation of 19 as a white solid (66 mg, $0.19 \mathrm{mmol}, 40 \%) .{ }^{1} \mathrm{H} \mathrm{NMR} \mathrm{(300} \mathrm{MHz,}$ Chloroform- $d$ ) $\delta 7.56(\mathrm{~s}, 1 \mathrm{H}), 7.35(\mathrm{~d}, J=8.5 \mathrm{~Hz}, 2 \mathrm{H}), 7.18(\mathrm{~d}, J=8.5 \mathrm{~Hz}, 2 \mathrm{H}), 5.51(\mathrm{~s}, 2 \mathrm{H}), 4.75(\mathrm{~s}, 2 \mathrm{H}), 2.14(\mathrm{qd}, J=$ 7.5, $1.8 \mathrm{~Hz}, 4 \mathrm{H}), 1.10(\mathrm{t}, J=7.5 \mathrm{~Hz}, 6 \mathrm{H}) .{ }^{13} \mathrm{C}$ NMR $(75 \mathrm{MHz}$, Chloroform- $d$ ) $\delta 163.3,135.0,133.0,129.6,129.5,129.4$, 122.9, 91.0, 53.6, 35.7, 22.6, 8.5. HRMS (ESI) $\mathrm{m} / \mathrm{z}$ [M]+ calcd for $\mathrm{C}_{16} \mathrm{H}_{19} \mathrm{ClN}_{4} \mathrm{O}_{3} \mathrm{~S}: 383.0939$, found: 383.0940 .

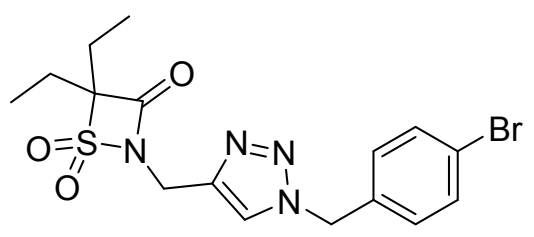

\section{(8) 2-((1-(4-Bromobenzyl)-1H-1,2,3-triazol-4-yl)methyl)-4,4-diethyl-1,2-thiazetidin-3-one 1,1-dioxide.}

From the general method B using alkyne 4 (148 $\mathrm{mg}, 0.69 \mathrm{mmol})$ and using azide Az3 (175 mg, $0.83 \mathrm{mmol})$. After reacting overnight, $25 \mathrm{~mL}$ of water were added. The product was extracted with ethyl acetate $(3 \mathrm{x} 10 \mathrm{~mL})$. The organic layers were combined, dried with anhydrous sodium sulfate and concentrated under reduced pressure, yielding a colorless oil. Washing of the crude oil with diethyl ether led to precipitation of 8 as a white solid $(176 \mathrm{mg}, 0.41 \mathrm{mmol}, 60 \%) .{ }^{1} \mathrm{H} \mathrm{NMR}(300 \mathrm{MHz}$, Chloroform- $d$ ) $\delta 7.78(\mathrm{~s}, 1 \mathrm{H}), 7.50(\mathrm{~d}, J=8.0 \mathrm{~Hz}, 2 \mathrm{H}), 7.11(\mathrm{~d}, J=8.2 \mathrm{~Hz}, 2 \mathrm{H}), 5.49(\mathrm{~s}, 2 \mathrm{H}), 4.74(\mathrm{~s}, 2 \mathrm{H}), 2.27-1.91(\mathrm{~m}$, $4 \mathrm{H}), 1.10(\mathrm{t}, J=7.4 \mathrm{~Hz}, 6 \mathrm{H}) .{ }^{13} \mathrm{C}$ NMR $(75 \mathrm{MHz}$, Chloroform- $d$ ) $\delta 163.4,133.4,132.4,129.7,123.2,91.1,54.0,35.7,22.7$, 8.57. HRMS (ESI) $\mathrm{m} / \mathrm{z}[\mathrm{M}]+$ calcd for $\mathrm{C}_{16} \mathrm{H}_{19} \mathrm{BrN}_{4} \mathrm{O}_{3} \mathrm{~S}: 427.0435$, found: 427.0434 .

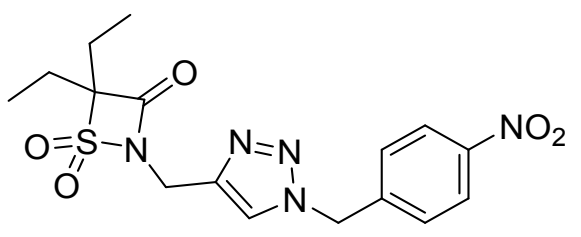

(20) 4,4-Diethyl-2-((1-(4-nitrobenzyl)-1H-1,2,3-triazol-4-yl)methyl)-1,2-thiazetidin-3-one 1,1-dioxide.

From the general method B using alkyne 4 (100 mg, $0.46 \mathrm{mmol}$ ) and using azide Az4 (98 mg, $0.55 \mathrm{mmol})$. After reacting overnight, $25 \mathrm{~mL}$ of water were added. The product was extracted with ethyl acetate $(3 \times 10 \mathrm{~mL})$. The organic layers were combined, dried with anhydrous sodium sulfate and concentrated under reduced pressure, yielding a brown oil. Washing of the crude oil with diethyl ether led to precipitation of $\mathbf{2 0}$ as a light brown solid ( $86 \mathrm{mg}, 0,22 \mathrm{mmol}, 51 \%) .{ }^{1} \mathrm{H}$ NMR (300 MHz, Chloroform- $d$ ) $\delta 8.21(\mathrm{~d}, J=8.3 \mathrm{~Hz}, 2 \mathrm{H}), 7.72(\mathrm{~s}, 1 \mathrm{H}), 7.37$ (d, $J=8.4 \mathrm{~Hz}, 2 \mathrm{H}), 5.66(\mathrm{~s}, 2 \mathrm{H}), 4.77$ (s, 2H), 2.14 (qd, $J=7.4,1.7 \mathrm{~Hz}, 4 \mathrm{H}), 1.10(\mathrm{t}, J=7.4 \mathrm{~Hz}, 6 \mathrm{H}) .{ }^{13} \mathrm{C} \mathrm{NMR}(75 \mathrm{MHz}$, Chloroform- $d$ ) $\delta 163.3,148.2,141.5,128.6,124.5,91.2$, 53.4, 35.7, 22.7, 8.5. HRMS (ESI) $\mathrm{m} / \mathrm{z}$ [M]+ calcd for $\mathrm{C}_{16} \mathrm{H}_{19} \mathrm{~N}_{5} \mathrm{O}_{5} \mathrm{~S}: 394.1183$, found: 394.1180 . 


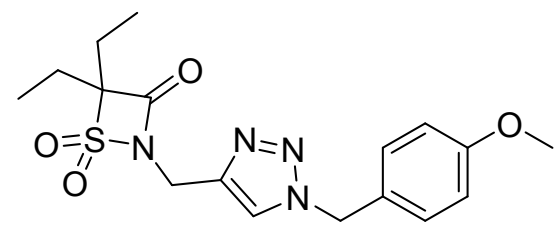

(21) 4,4-Diethyl-2-((1-(4-methoxybenzyl)-1H-1,2,3-triazol-4-yl)methyl)-1,2-thiazetidin-3-one 1,1-dioxide.

From the general method B using alkyne $4(100 \mathrm{mg}, 0.46 \mathrm{mmol})$ and using azide Az7 (90 mg, $0.55 \mathrm{mmol})$. After reacting overnight, $25 \mathrm{~mL}$ of water were added. The product was extracted with ethyl acetate $(3 \times 10 \mathrm{~mL})$. The organic layers were combined, dried with anhydrous sodium sulfate and concentrated under reduced pressure, yielding an orange oil. Washing of the crude oil with diethyl ether led to precipitation of $\mathbf{2 1}$ as a light yellow solid (74 mg, $0.18 \mathrm{mmol}, 41 \%) .{ }^{1} \mathrm{H}$ NMR $(300$ MHz, Chloroform- $d$ ) $\delta 7.51(\mathrm{~s}, 1 \mathrm{H}), 7.21(\mathrm{~d}, J=8.7 \mathrm{~Hz}, 2 \mathrm{H}), 6.89(\mathrm{~d}, J=8.7 \mathrm{~Hz}, 2 \mathrm{H}), 5.46(\mathrm{~s}, 2 \mathrm{H}), 4.73(\mathrm{~s}, 2 \mathrm{H}), 3.80(\mathrm{~s}$, $3 \mathrm{H}), 2.14(\mathrm{qd}, J=7.4,1.9 \mathrm{~Hz}, 4 \mathrm{H}), 1.10(\mathrm{t}, J=7.5 \mathrm{~Hz}, 6 \mathrm{H}) .{ }^{13} \mathrm{C} \mathrm{NMR}\left(75 \mathrm{MHz}, \mathrm{CDCl}_{3}\right) \delta 163.3,160.0,129.8,129.7,126.4$, 122.7, 114.6, 90.9, 55.4, 53.9, 35.7, 22.6, 8.5. HRMS (ESI) m/z [M]+ calcd for $\mathrm{C}_{17} \mathrm{H}_{22} \mathrm{~N}_{4} \mathrm{O}_{4} \mathrm{~S}: 379.1435$, found: 379.1435 .<smiles>CCC1(CC)C(=O)N(Cc2cn(CCCNc3ccc([N+](=O)[O-])c4nonc34)nn2)S1(=O)=O</smiles>

(22) 4,4-Diethyl-2-((1-(3-((7-nitrobenzo[c][1,2,5]oxadiazol-4-yl)amino)propyl)-1H-1,2,3-triazol-4-yl)methyl)-1,2thiazetidin-3-one 1,1-dioxide.

From the general method B using alkyne 4 (100 mg, $0.46 \mathrm{mmol})$ and using $N$-(3-azidopropyl)-7nitrobenzo[c][1,2,5]oxadiazol-4-amine $(135 \mathrm{mg}, 0.51 \mathrm{mmol})$. After reacting overnight, $25 \mathrm{~mL}$ of water were added. The product was extracted with ethyl acetate $(4 \times 10 \mathrm{~mL})$. The organic layers were combined, dried with anhydrous sodium sulfate and concentrated under reduced pressure, yielding an orange oil. Washing of the crude oil with diethyl ether led to precipitation of 22 as an orange solid (178 mg, $0.37 \mathrm{mmol}, 80 \%) .{ }^{1} \mathrm{H}$ NMR $(500 \mathrm{MHz}$, Chloroform- $d$ ) $\delta 8.45(\mathrm{~d}, J=8.6 \mathrm{~Hz}$, $1 \mathrm{H}), 7.75(\mathrm{~s}, 1 \mathrm{H}), 6.97(\mathrm{~s}, 1 \mathrm{H}), 6.16(\mathrm{~d}, J=8.6 \mathrm{~Hz}, 1 \mathrm{H}), 4.80(\mathrm{~s}, 2 \mathrm{H}), 4.59(\mathrm{t}, J=6.4 \mathrm{~Hz}, 2 \mathrm{H}), 3.58(\mathrm{~d}, J=6.5 \mathrm{~Hz}, 2 \mathrm{H}), 2.51$ $-2.35(\mathrm{~m}, 2 \mathrm{H}), 2.16(\mathrm{qd}, J=7.5,4.8 \mathrm{~Hz}, 4 \mathrm{H}), 1.12(\mathrm{t}, J=7.5 \mathrm{~Hz}, 6 \mathrm{H}) .{ }^{13} \mathrm{C}$ NMR $(75 \mathrm{MHz}$, Chloroform- $d$ ) $\delta 163.3,144.4$, 144.3, 144.0, 136.8, 123.6, 99.1, 91.2, 47.9, 41.0, 40.9, 35.7, 28.7, 22.6, 8.5. HRMS (ESI) m/z [M]+ calcd for $\mathrm{C}_{18} \mathrm{H}_{22} \mathrm{~N}_{8} \mathrm{O}$. 479.1461, found: 479.1556 .<smiles></smiles>

(9) 4,4-Diethyl-3-oxo- $\beta$-sultam-Triazole-PEG3-Rhodamine.

From the general method B using alkyne 4 (30 mg, $0.14 \quad \mathrm{mmol})$ and using $\mathbf{N}-(\mathbf{9 - ( 2 - ( 2 - ( 2 - ( 2 - ( 2 - )}$ azidoethoxy)ethoxy)ethoxy)ethyl)carbamoyl)phenyl)-6-(diethylamino)-3 $\mathrm{H}$-xanthen-3-ylidene)- $\mathrm{N}$ ethylethanaminium ( $88 \mathrm{mg}, 0.14 \mathrm{mmol})$. After reacting overnight, $25 \mathrm{~m} \mathrm{~L}$ of water were added. The product was extracted 
with ethyl acetate $(3 \times 10 \mathrm{~mL})$. The organic fractions were combined, dried with anhydrous sodium sulfate and concentrated under reduced pressure, resulting in a pink oil. The compound was purified using preparative thin layer chromatography (ethyl acetate: methanol - 9:1 eluent). Compound 9 was obtained as a pink solid (18 mg, $0.02 \mathrm{mmol}, 15 \%)$. ${ }^{1} \mathrm{H}$ NMR (300 $\mathrm{MHz}, \mathrm{CDCl} 3) \delta 7.78-7.74(\mathrm{~m}, 1 \mathrm{H}), 7.69(\mathrm{~s}, 1 \mathrm{H}), 7.33-7.28(\mathrm{~m}, J=5.6,3.1 \mathrm{~Hz}, 2 \mathrm{H}), 6.97-6.92(\mathrm{~m}, 1 \mathrm{H}), 6.33(\mathrm{~s}, 1 \mathrm{H})$, $6.30(\mathrm{~s}, 1 \mathrm{H}), 6.26(\mathrm{~d}, J=2.5 \mathrm{~Hz}, 2 \mathrm{H}), 6.15(\mathrm{dd}, J=8.9,2.6 \mathrm{~Hz}, 2 \mathrm{H}), 4.63(\mathrm{~s}, 2 \mathrm{H}), 4.39(\mathrm{t}, J=5.0 \mathrm{~Hz}, 2 \mathrm{H}), 3.68(\mathrm{t}, J=12.8$, $7.9 \mathrm{~Hz}, 2 \mathrm{H}), 3.43(\mathrm{~s}, 4 \mathrm{H}), 3.39-3.31(\mathrm{~m}, 2 \mathrm{H}), 3.31-3.15(\mathrm{~m}, 12 \mathrm{H}), 3.05(\mathrm{t}, J=7.3 \mathrm{~Hz}, 2 \mathrm{H}), 2.09-1.98(\mathrm{~m}, J=14.8,7.5$, $1.9 \mathrm{~Hz}, 4 \mathrm{H}), 1.09-0.94(\mathrm{~m}, 18 \mathrm{H})$. HRMS (ESI) m/z [M]+ calcd for $\mathrm{C}_{45} \mathrm{H}_{60} \mathrm{~N}_{7} \mathrm{O}_{8} \mathrm{~S}:$ 858.4216, found: 858.4219.<smiles>CCC1(CC)C(=O)N(Cc2cn(CCOCCOCCNC(=O)CCCC[C@H]3SC[C@@H]4NC(=O)N[C@@H]43)nn2)S1(=O)=O</smiles>

\section{(10) 4,4-Diethyl-3-oxo- $\beta$-sultam-Triazole-PEG2-Biotin.}

From the general method B using alkyne $4(25 \mathrm{mg}, 0.12 \mathrm{mmol})$ and using a commercially available biotin azide (TCI) (47 $\mathrm{mg}, 0.12 \mathrm{mmol}) .25 \mathrm{~mL}$ of distilled water were added. The product was extracted with ethyl acetate $(3 \mathrm{x} 10 \mathrm{~mL})$. The organic fractions were combined, dried with anhydrous sodium sulfate and concentrated under reduced pressure, resulting in a colorless oil. Washing of the crude oils with diethyl ether resulted in the pure product $\mathbf{1 0}$ as a colorless oil $(65 \mathrm{mg}, 0.11$ mmol, 91\%); ${ }^{1} \mathrm{H}$ NMR (500 MHz, Chloroform- $\left.d\right) \delta 7.84(\mathrm{~s}, 1 \mathrm{H}), 6.63(\mathrm{~s}, 1 \mathrm{H}), 6.14(\mathrm{~s}, 1 \mathrm{H}), 5.21(\mathrm{~s}, 1 \mathrm{H}), 4.77(\mathrm{~s}, 2 \mathrm{H}), 4.56$ $(\mathrm{t}, J=5.0 \mathrm{~Hz}, 2 \mathrm{H}), 4.51-4.45(\mathrm{~m}, 1 \mathrm{H}), 4.35-4.27(\mathrm{~m}, 1 \mathrm{H}), 3.88(\mathrm{t}, J=5.0 \mathrm{~Hz}, 2 \mathrm{H}), 3.59(\mathrm{~d}, J=3.3 \mathrm{~Hz}, 7 \mathrm{H}), 3.55(\mathrm{t}, J=$ $5.1 \mathrm{~Hz}, 2 \mathrm{H}), 3.46-3.39(\mathrm{~m}, 2 \mathrm{H}), 3.18-3.10(\mathrm{~m}, 1 \mathrm{H}), 2.90(\mathrm{~d}, J=11.6 \mathrm{~Hz}, 1 \mathrm{H}), 2.73(\mathrm{~d}, J=12.8 \mathrm{~Hz}, 1 \mathrm{H}), 2.26-2.12(\mathrm{~m}$, $6 \mathrm{H}), 1.80(\mathrm{~s}, 2 \mathrm{H}), 1.72-1.62(\mathrm{~m}, 3 \mathrm{H}), 1.49-1.37(\mathrm{~m}, 2 \mathrm{H}), 1.12(\mathrm{t}, J=7.5 \mathrm{~Hz}, 6 \mathrm{H}) .{ }^{13} \mathrm{C}$ NMR $(75 \mathrm{MHz}$, Chloroform- $d$ ) $\delta$ 173.3, 163.5, 163.3, 140.4, 124.0, 90.9, 70.5, 70.1, 70.0, 69.3, 61.8, 60.1, 55.5, 50.5, 41.0, 40.5, 39.2, 35.9, 35.6, 28.1, 25.5, 22.6, 8.4. HRMS (ESI) m/z [M]+ calcd for $\mathrm{C}_{25} \mathrm{H}_{41} \mathrm{~N}_{7} \mathrm{O}_{7} \mathrm{~S}_{2}:$ : 616.2582, found: 616.2591 . 


\subsection{NMR Spectra}
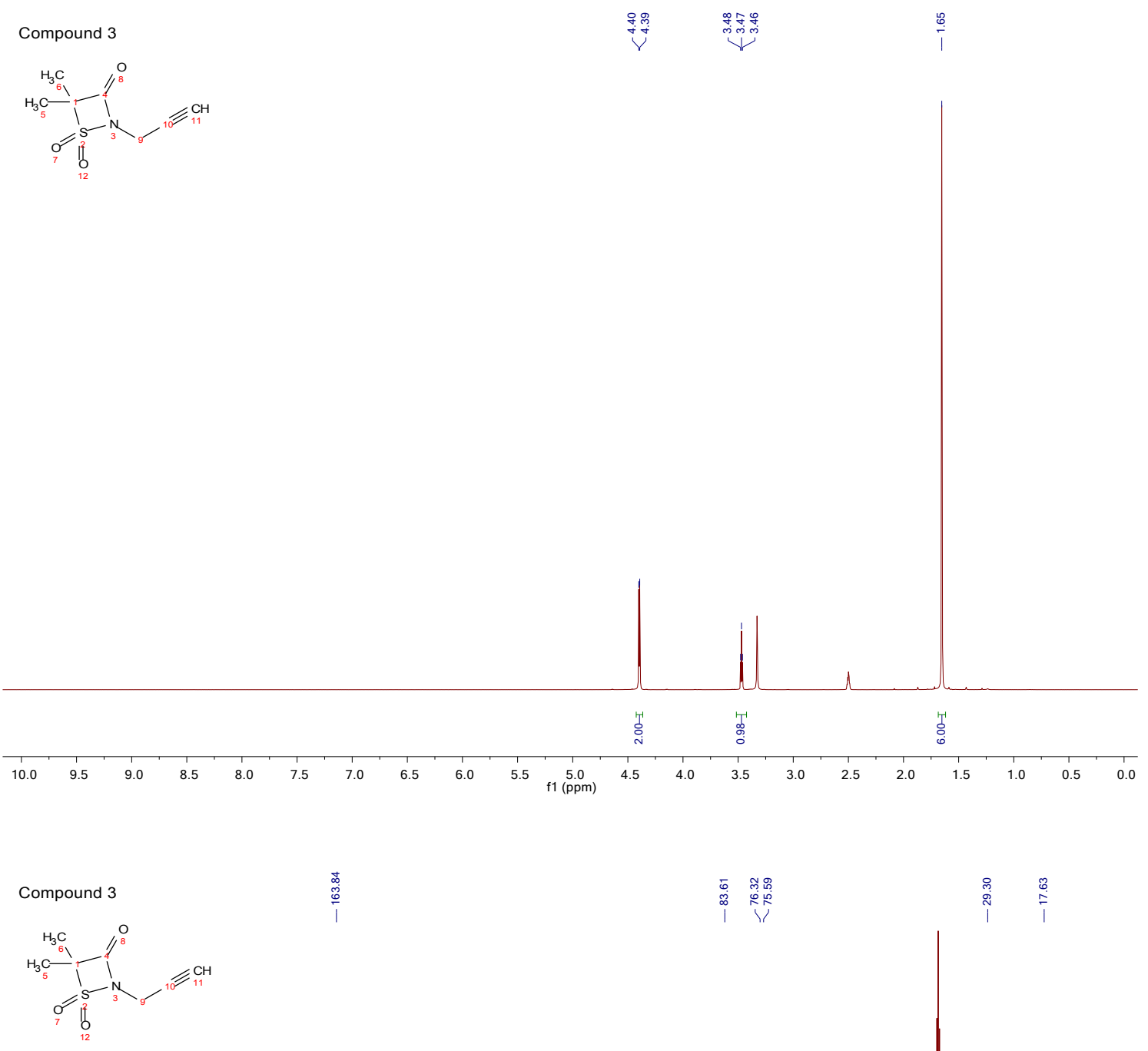

$\begin{array}{llllllllllllllllllllllllllllllll}1 & 230 & 220 & 210 & 200 & 190 & 180 & 170 & 160 & 150 & 140 & 130 & 120 & 110 & 100 & 90 & 80 & 70 & 60 & 50 & 40 & 30 & 20 & 10 & 0\end{array}$

Figure S.2. $\mathrm{H}^{1} \mathrm{NMR}$ and $\mathrm{C}^{13} \mathrm{NMR}$ of compound 3. 
Compound 4<smiles>C#CNN1C(=O)C(SC)(SC)S1(=O)=O</smiles>

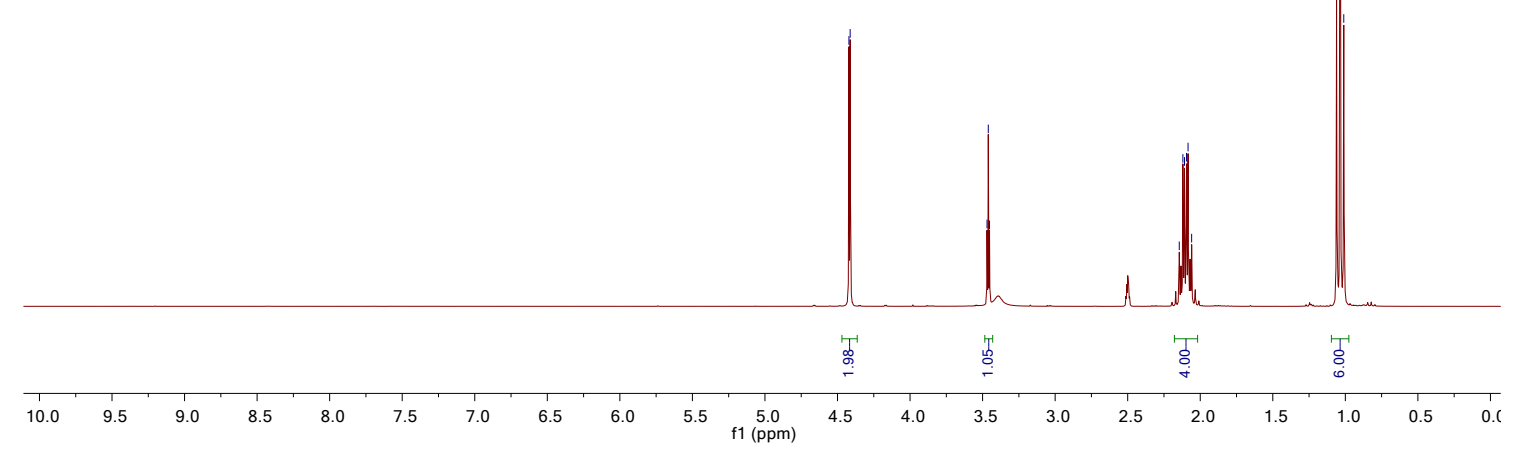<smiles>C#CN1C(=O)C(SC)(SC)S1(=O)=O</smiles>

Figure S.3. $\mathrm{H}^{1} \mathrm{NMR}$ and $\mathrm{C}^{13} \mathrm{NMR}$ of compound 4. 

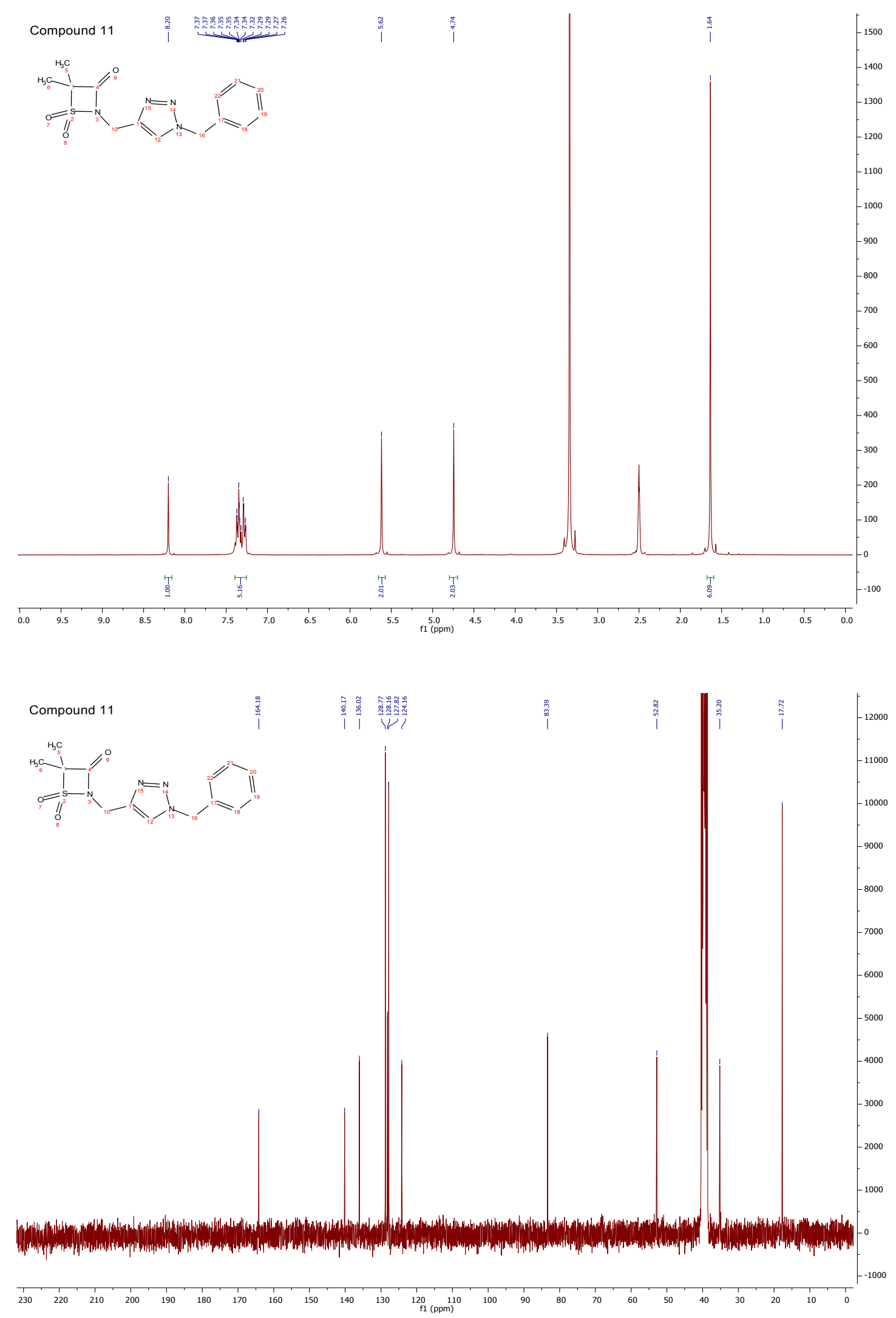

Figure S.4. $\mathrm{H}^{1} \mathrm{NMR}$ and $\mathrm{C}^{13} \mathrm{NMR}$ of compound 11. 

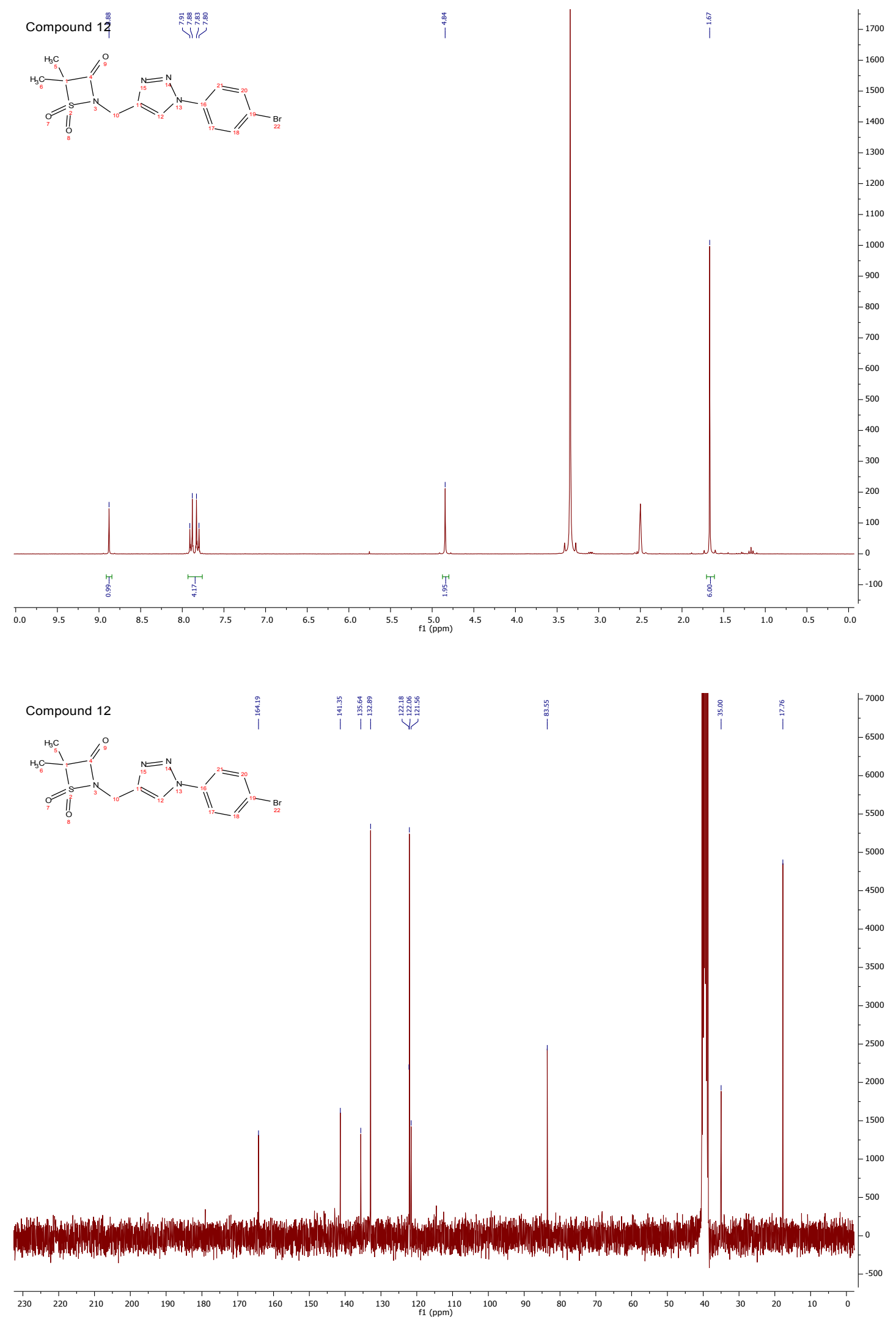

Figure S.5. $\mathrm{H}^{1} \mathrm{NMR}$ and $\mathrm{C}^{13} \mathrm{NMR}$ of compound 12 . 

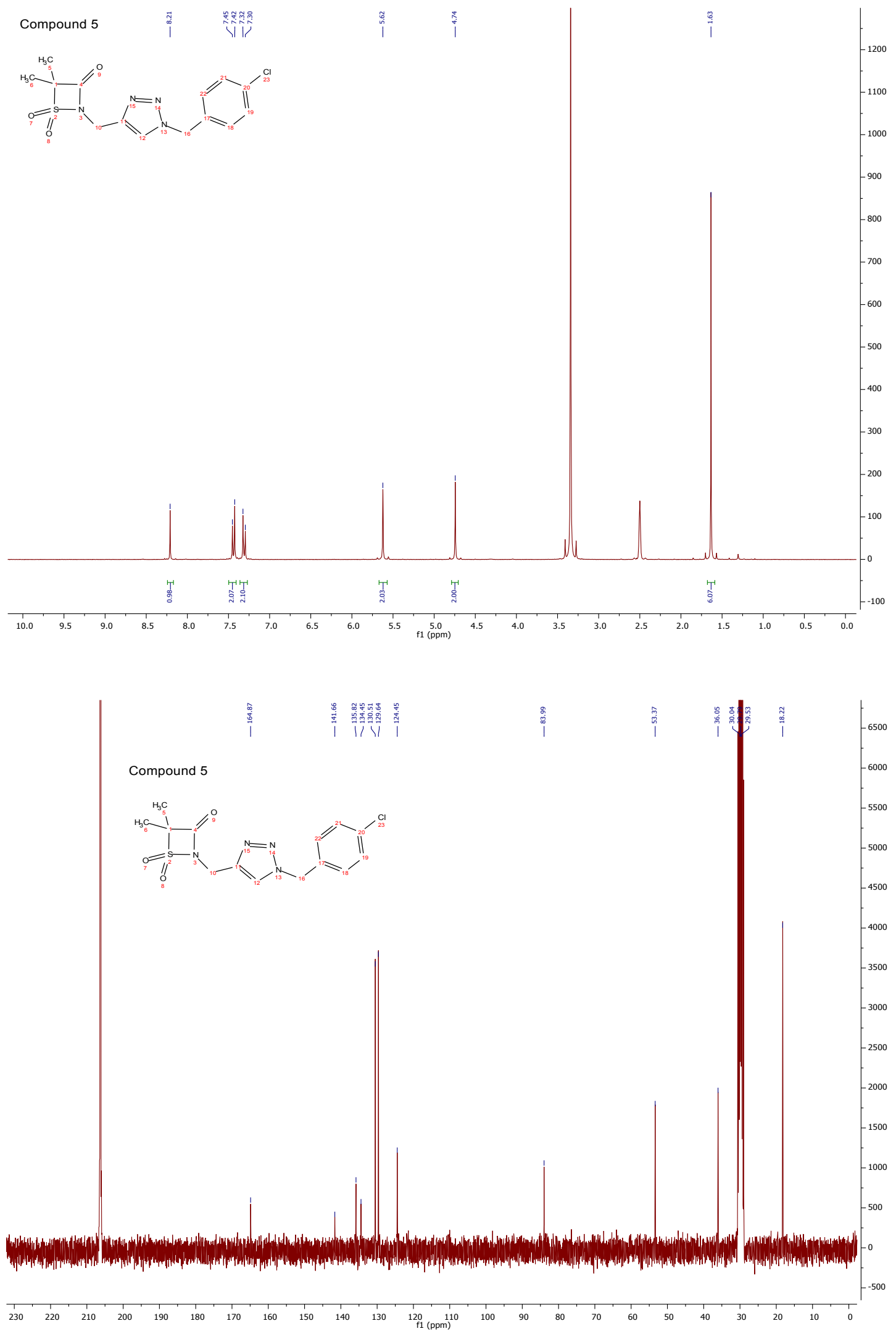

Figure S.6. $\mathrm{H}^{1} \mathrm{NMR}$ and $\mathrm{C}^{13} \mathrm{NMR}$ of compound 5.

S16 

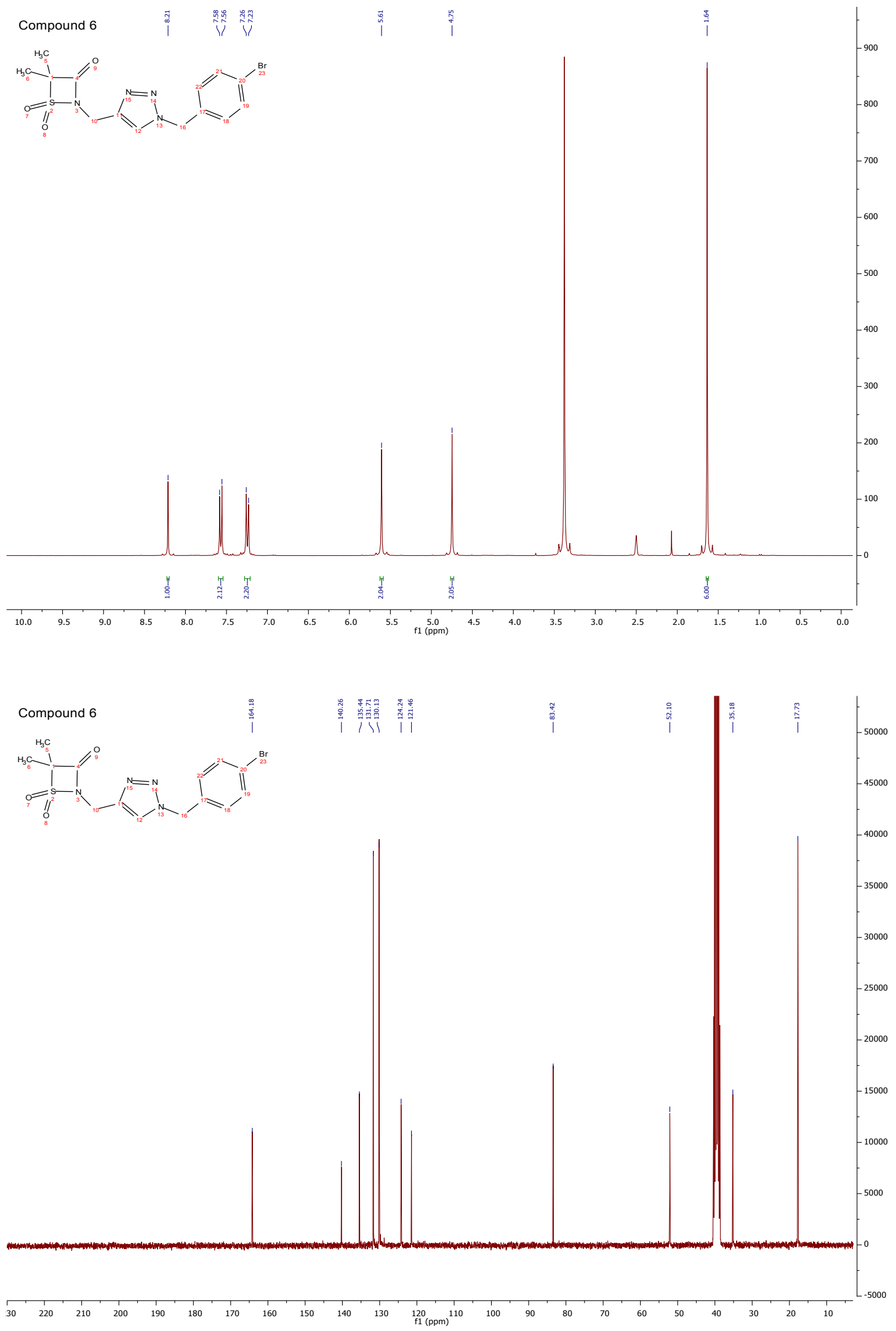

Figure S.7. $\mathrm{H}^{1} \mathrm{NMR}$ and $\mathrm{C}^{13} \mathrm{NMR}$ of compound 6.

S17 

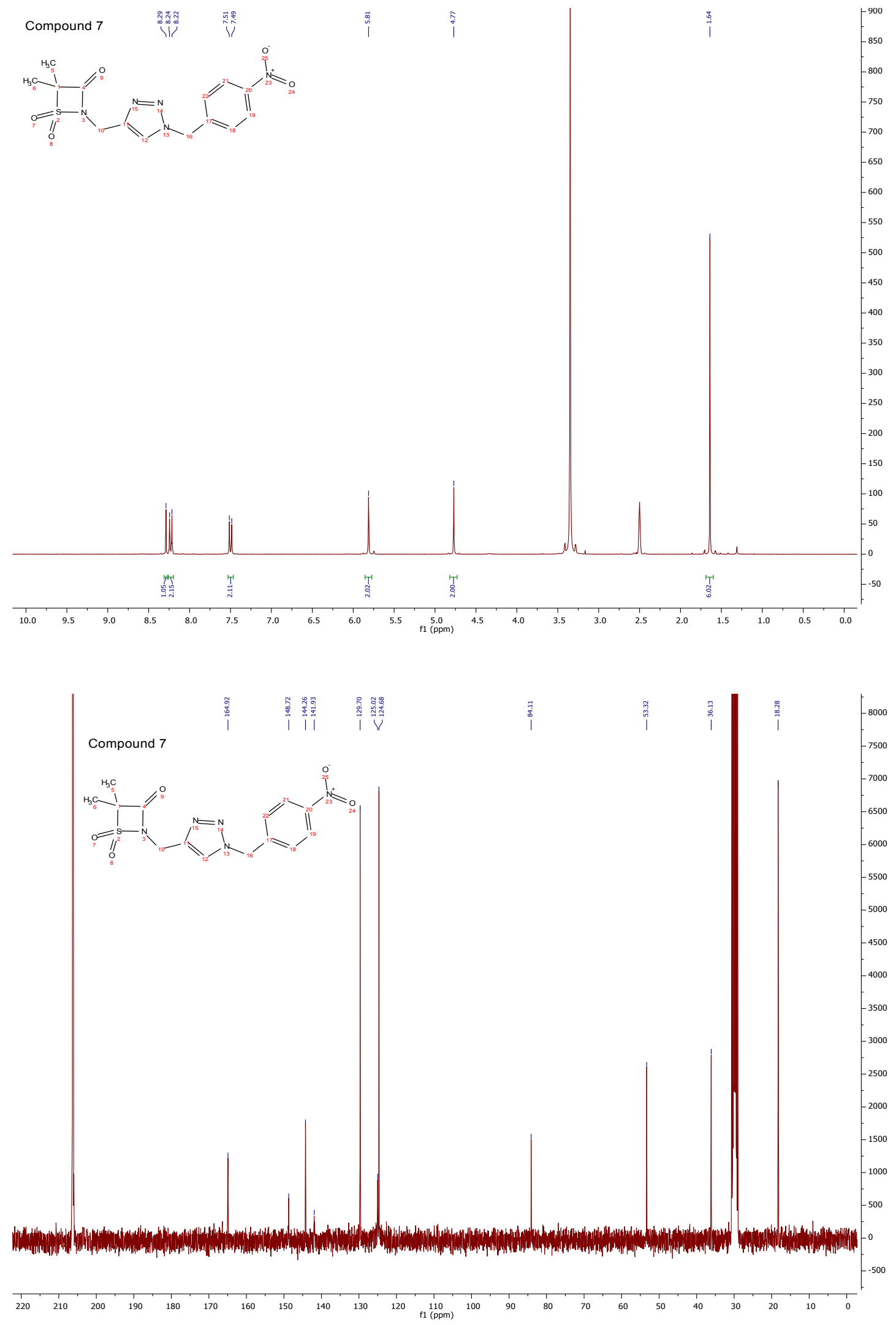

Figure S.8. $\mathrm{H}^{1} \mathrm{NMR}$ and $\mathrm{C}^{13} \mathrm{NMR}$ of compound 7.

S18 

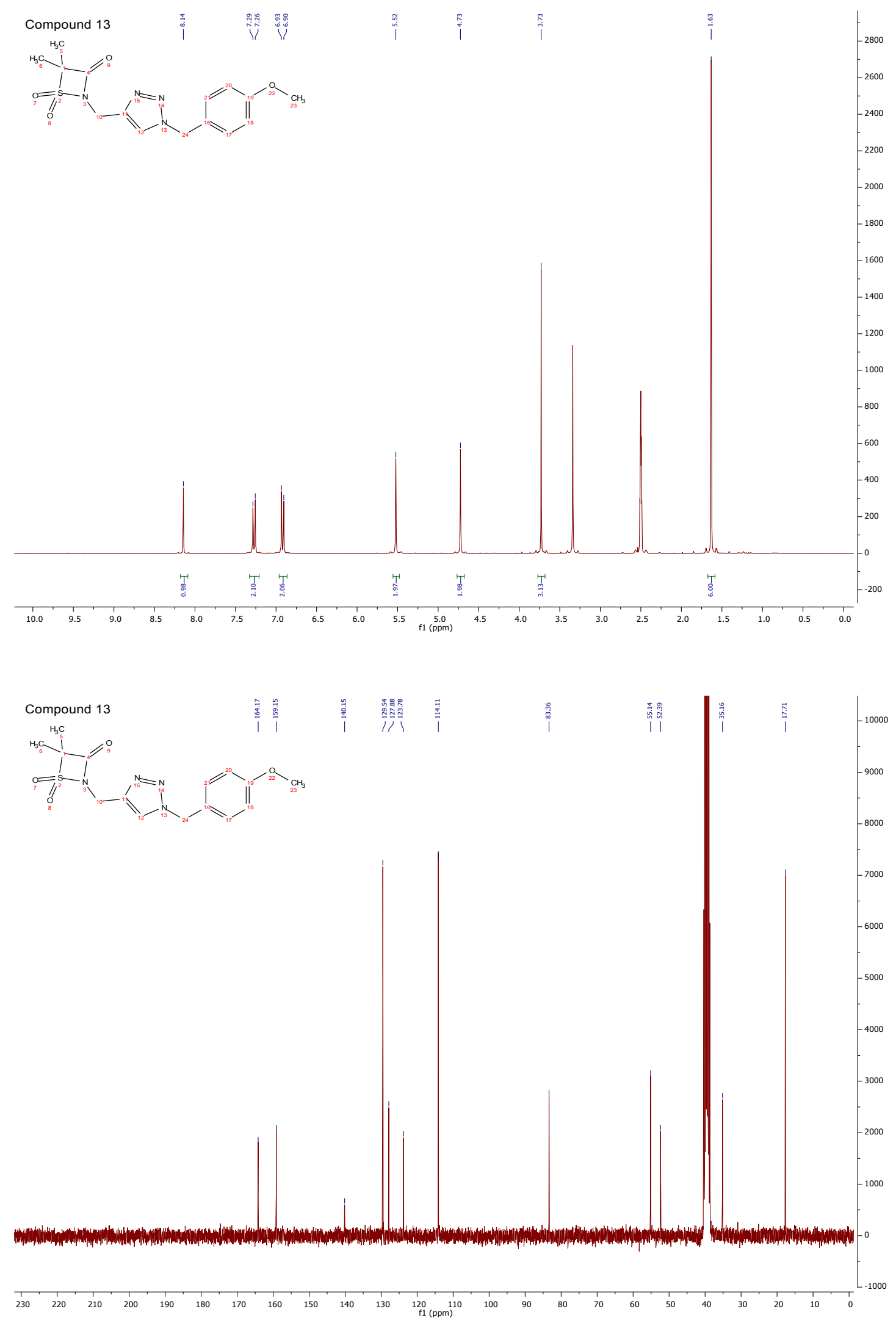

Figure S.9. $\mathrm{H}^{1} \mathrm{NMR}$ and $\mathrm{C}^{13} \mathrm{NMR}$ of compound 13. 

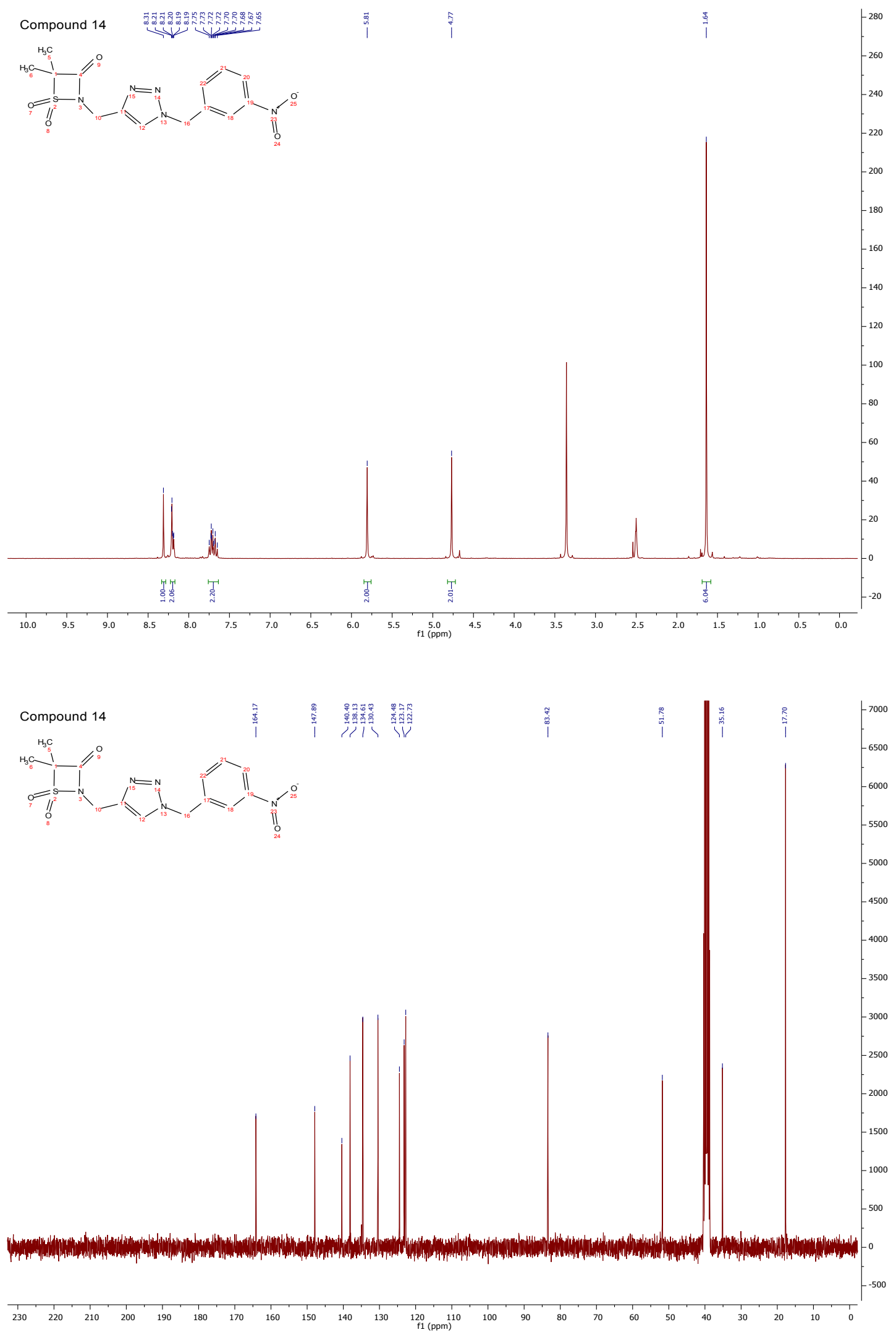

Figure S.10. H $\mathrm{H}^{1} \mathrm{NMR}$ and $\mathrm{C}^{13}$ NMR of compound 14.

S20 

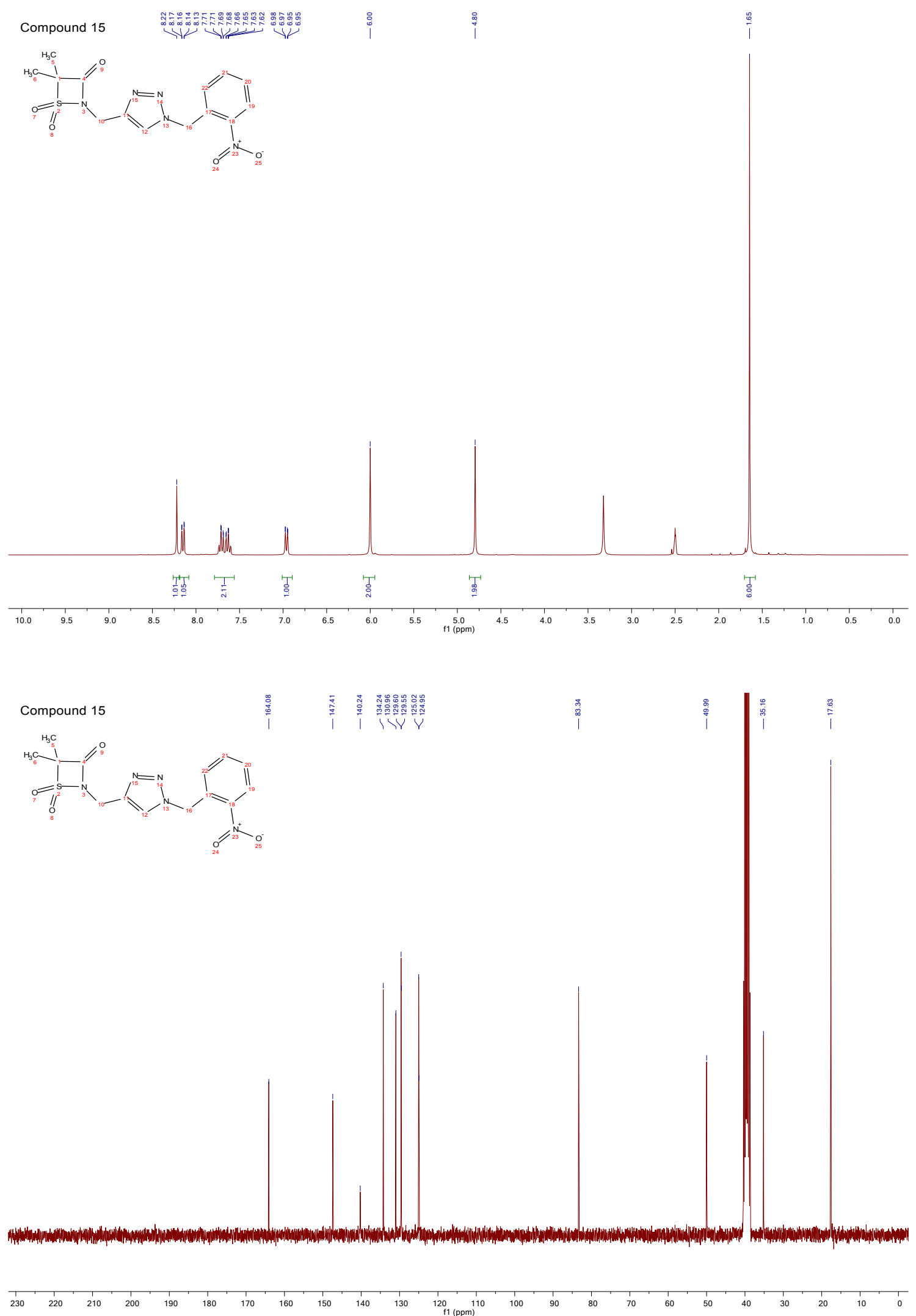

Figure S.11. $\mathrm{H}^{1} \mathrm{NMR}$ and $\mathrm{C}^{13} \mathrm{NMR}$ of compound 15. 

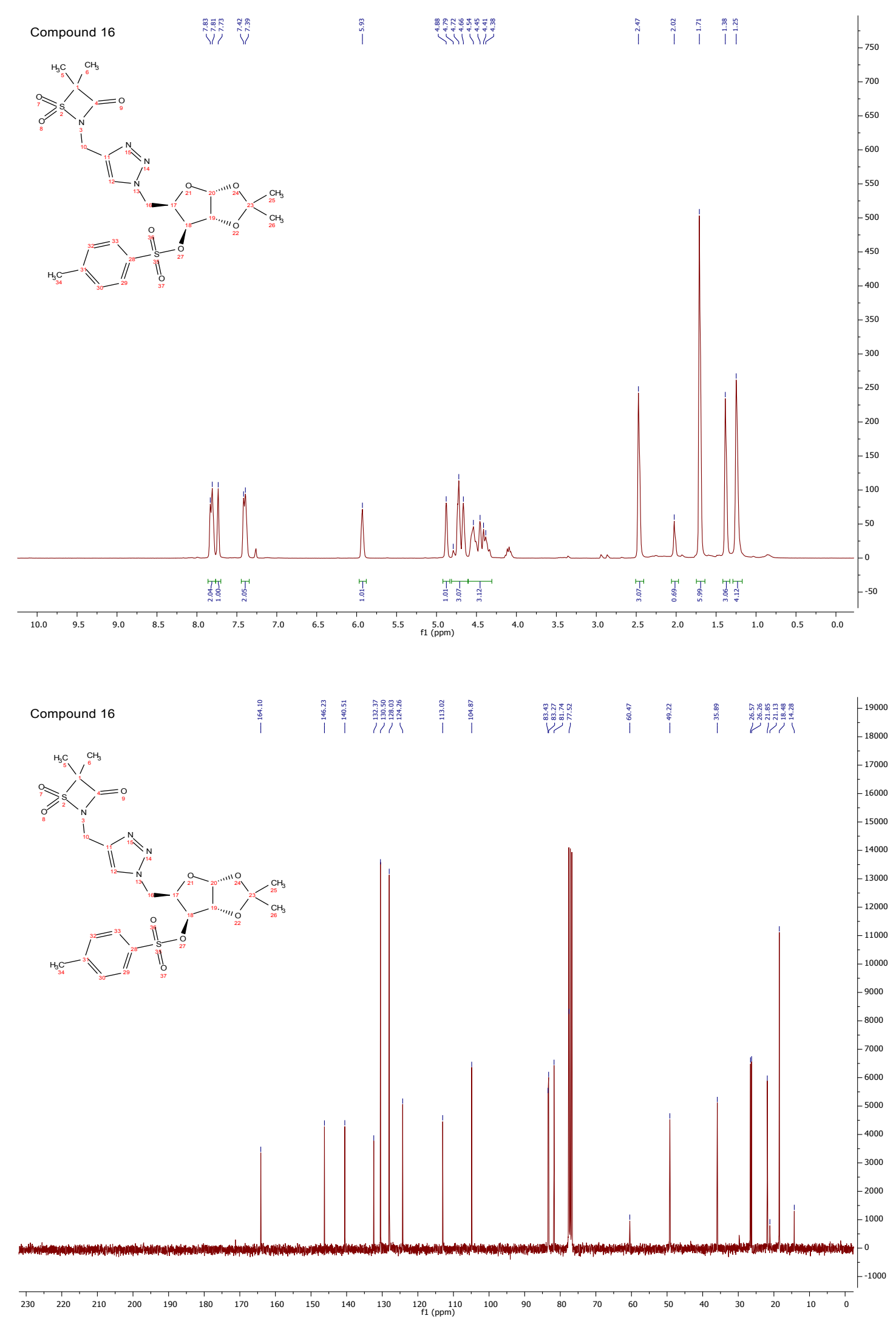

Figure S.12. $\mathrm{H}^{1} \mathrm{NMR}$ and $\mathrm{C}^{13} \mathrm{NMR}$ of compound $\mathbf{1 6}$. 

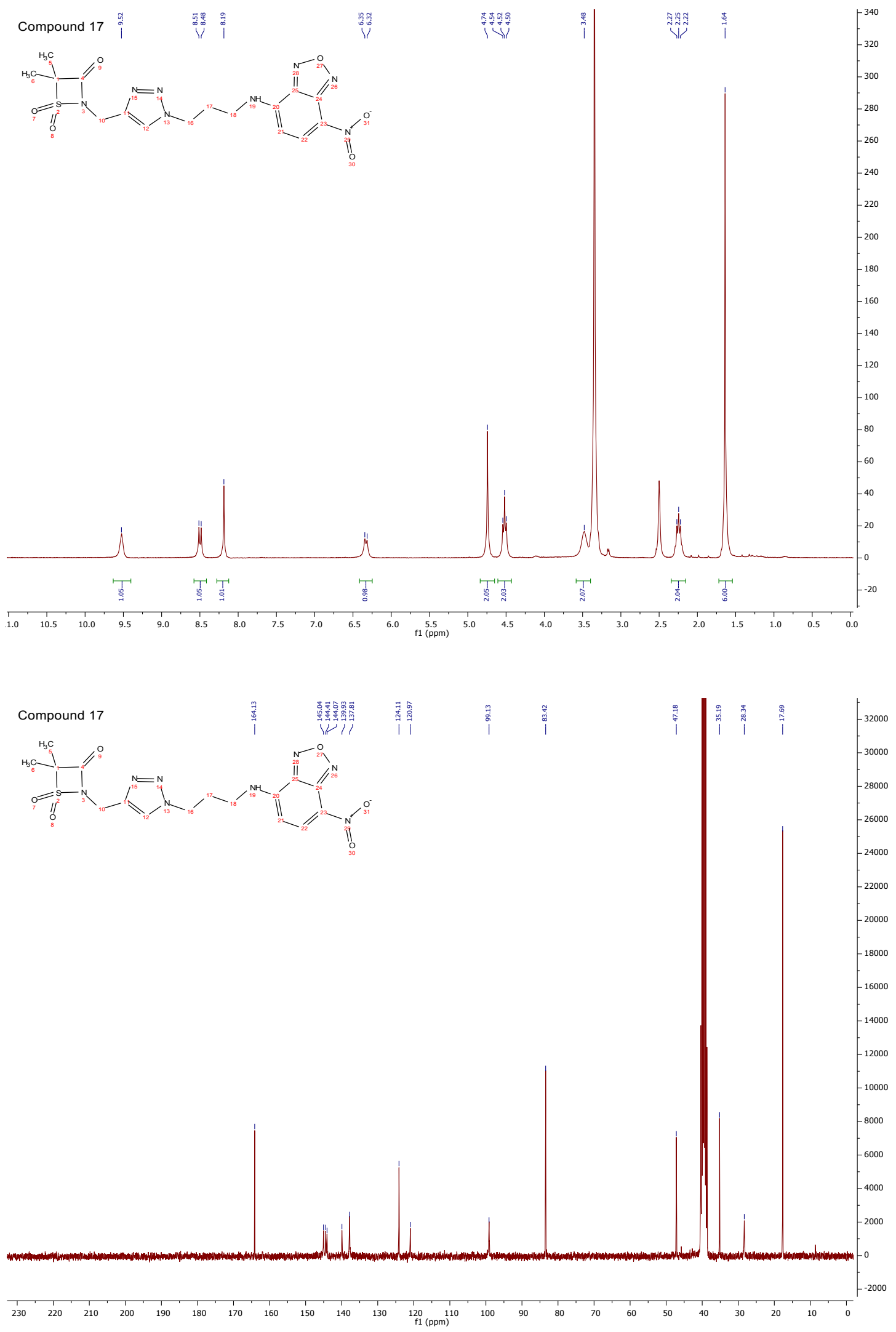

Figure S.13. H ${ }^{1}$ NMR and $C^{13}$ NMR of compound 17.

S23 

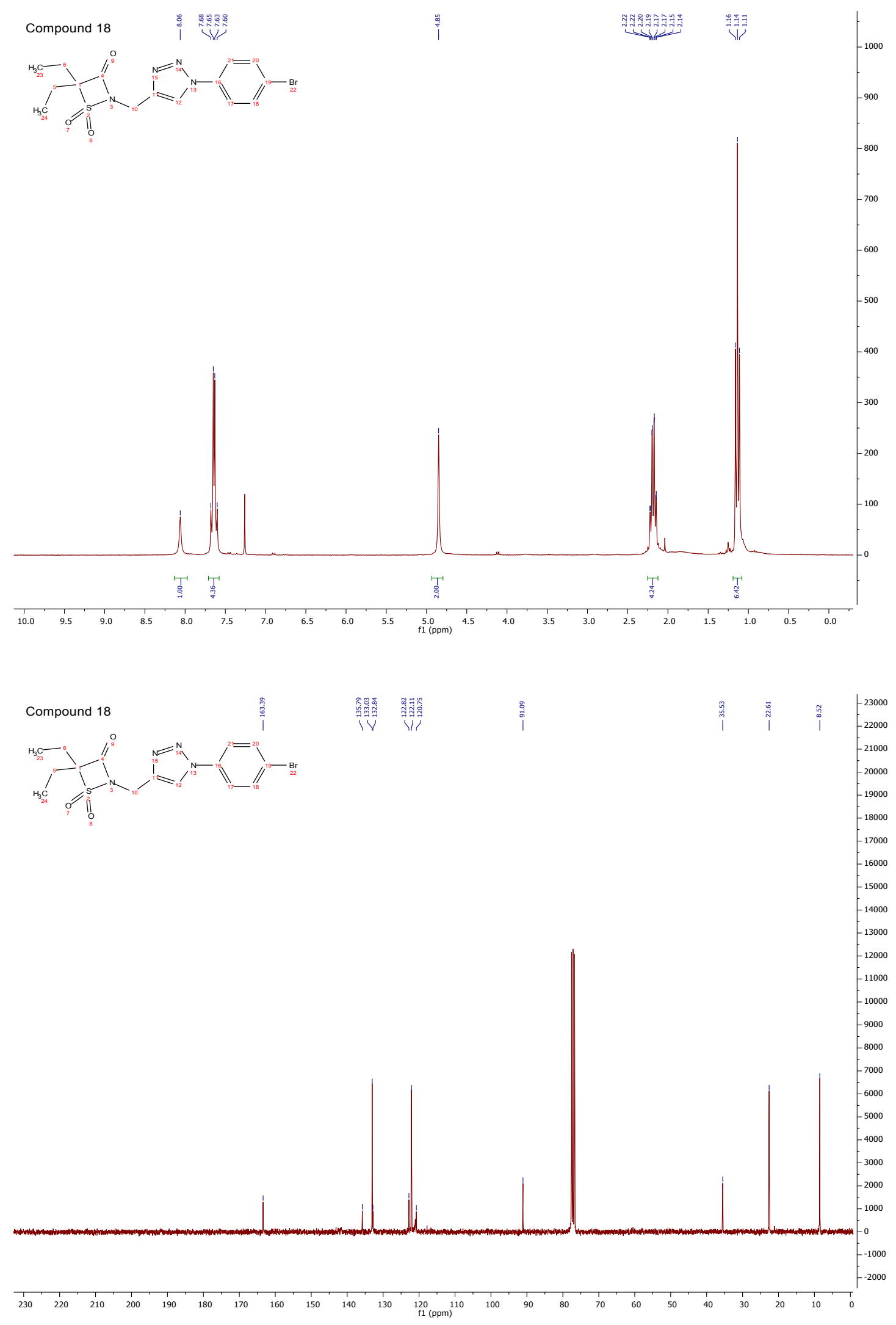

Figure S.14. $\mathrm{H}^{1} \mathrm{NMR}$ and $\mathrm{C}^{13} \mathrm{NMR}$ of compound 18. 

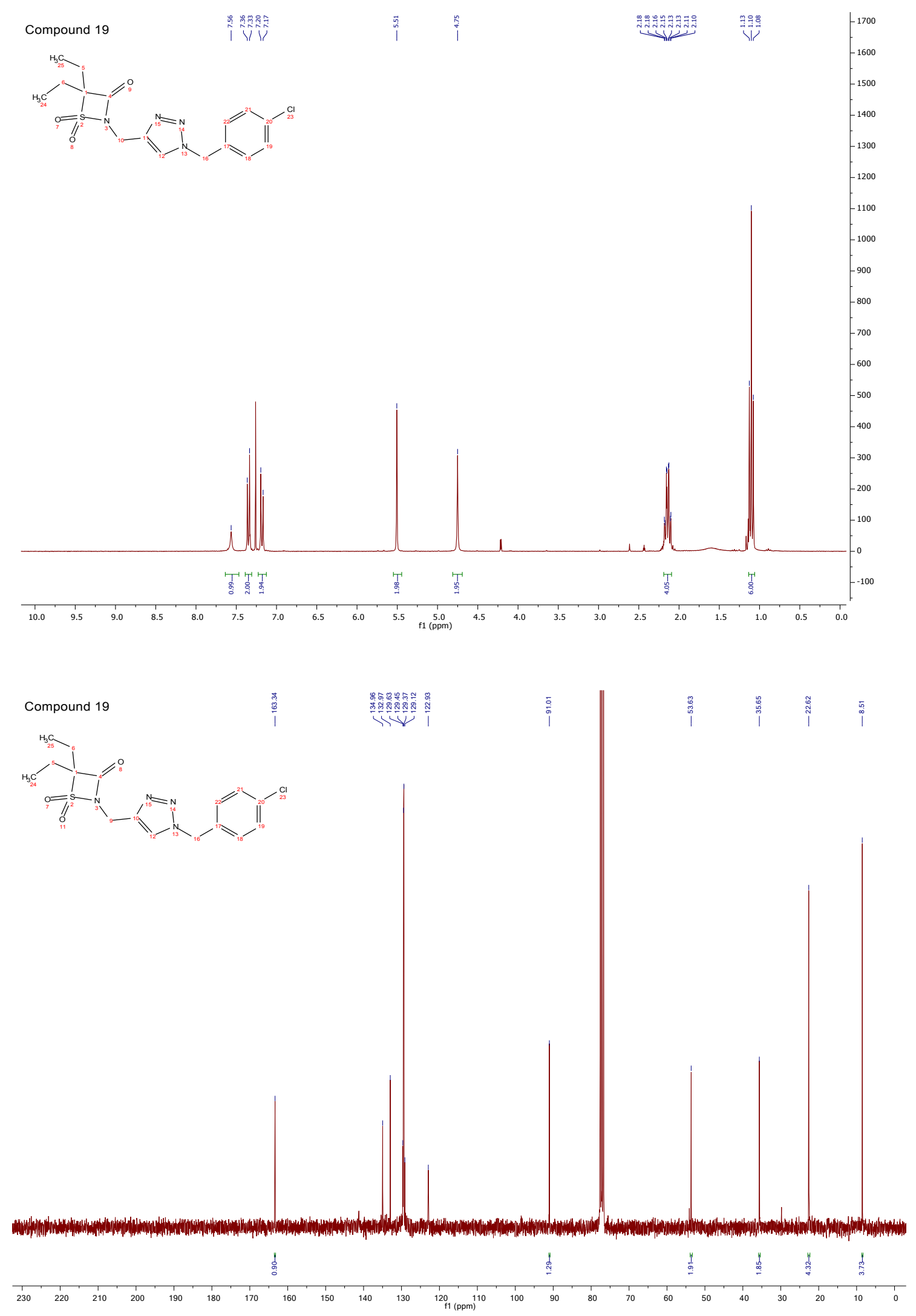

Figure S.15. $\mathrm{H}^{1} \mathrm{NMR}$ and $\mathrm{C}^{13} \mathrm{NMR}$ of compound $\mathbf{1 9}$. 

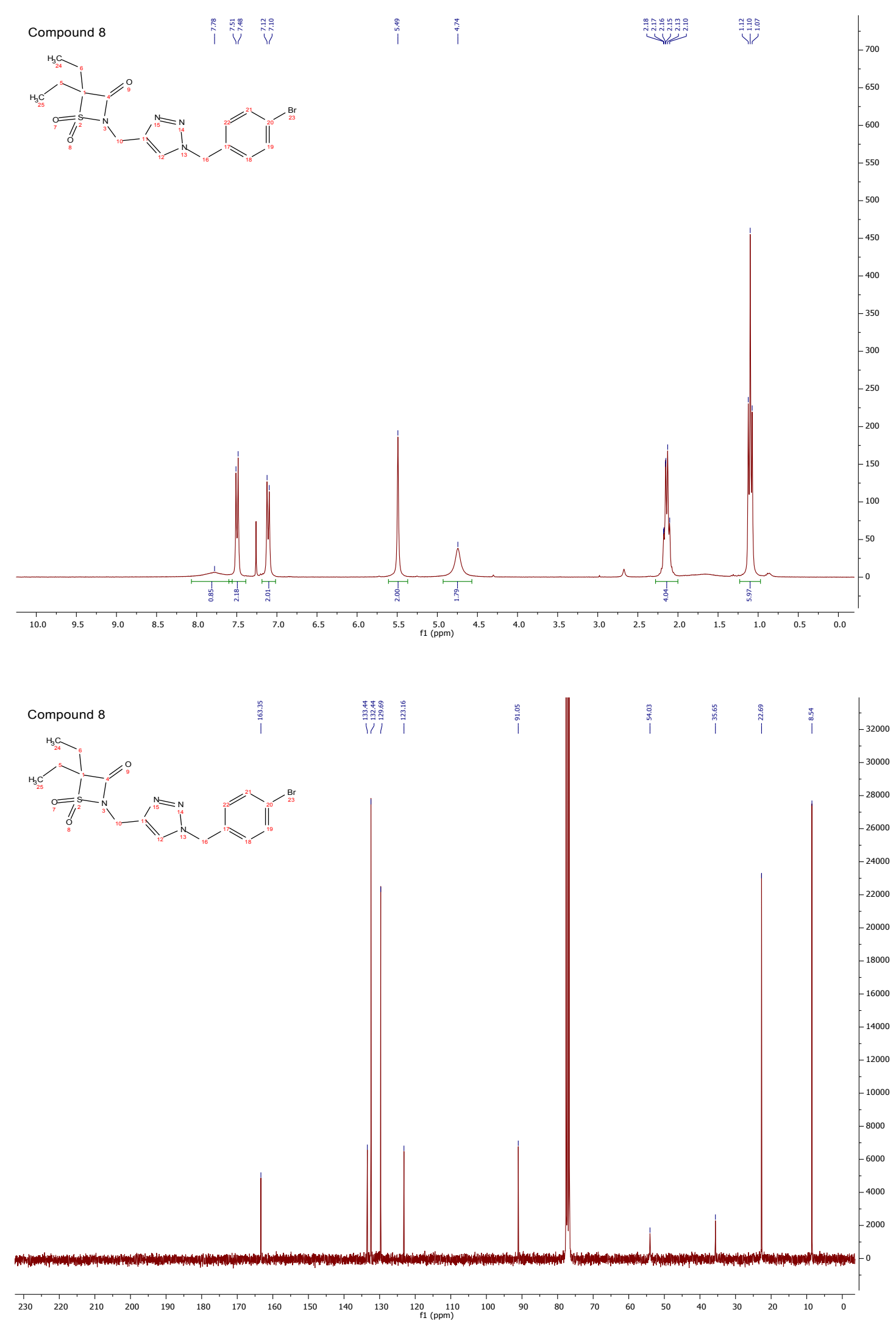

Figure S.16. $\mathrm{H}^{1} \mathrm{NMR}$ and $\mathrm{C}^{13} \mathrm{NMR}$ of compound 8. 

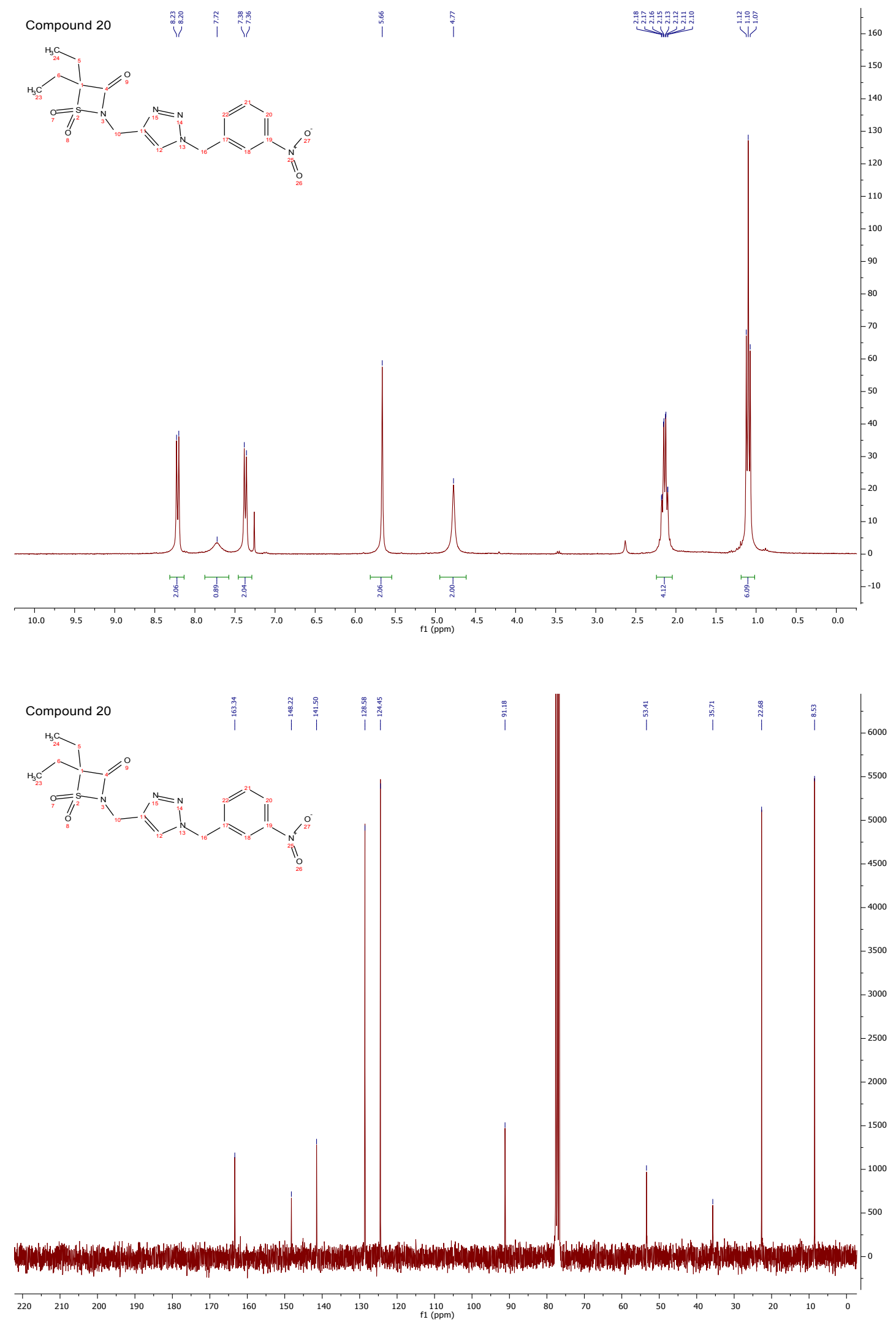

Figure S.17. $\mathrm{H}^{1}$ NMR and $\mathrm{C}^{13}$ NMR of compound 20.

S27 
Compound 21

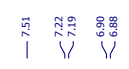

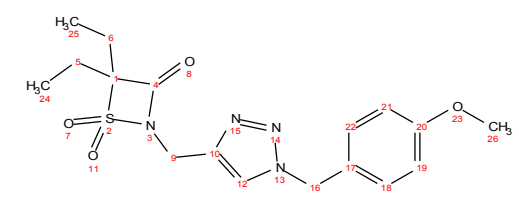

i i

ํㅏㄱ
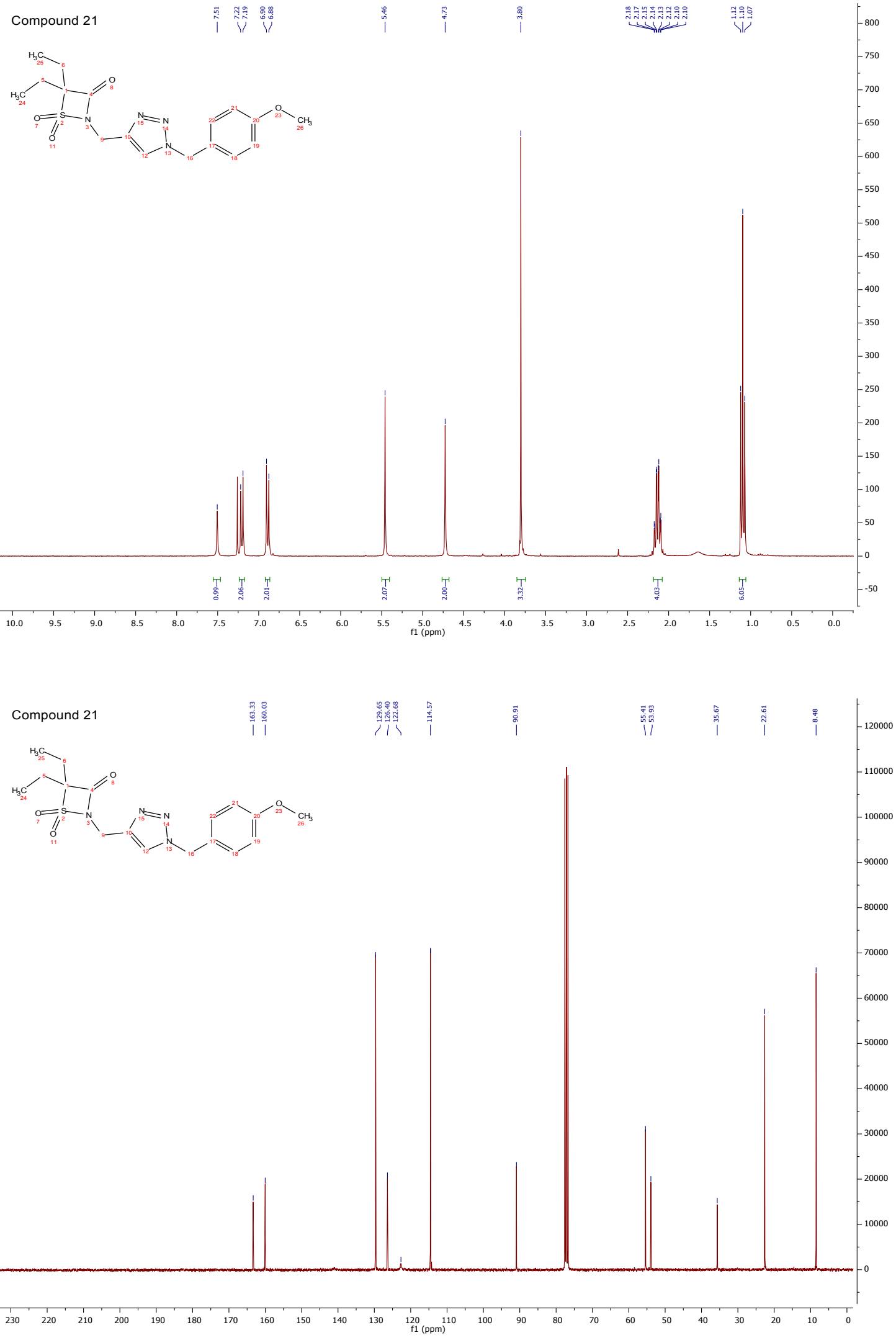

Figure S.18. $\mathrm{H}^{1} \mathrm{NMR}$ and $\mathrm{C}^{13} \mathrm{NMR}$ of compound 21.

S28 

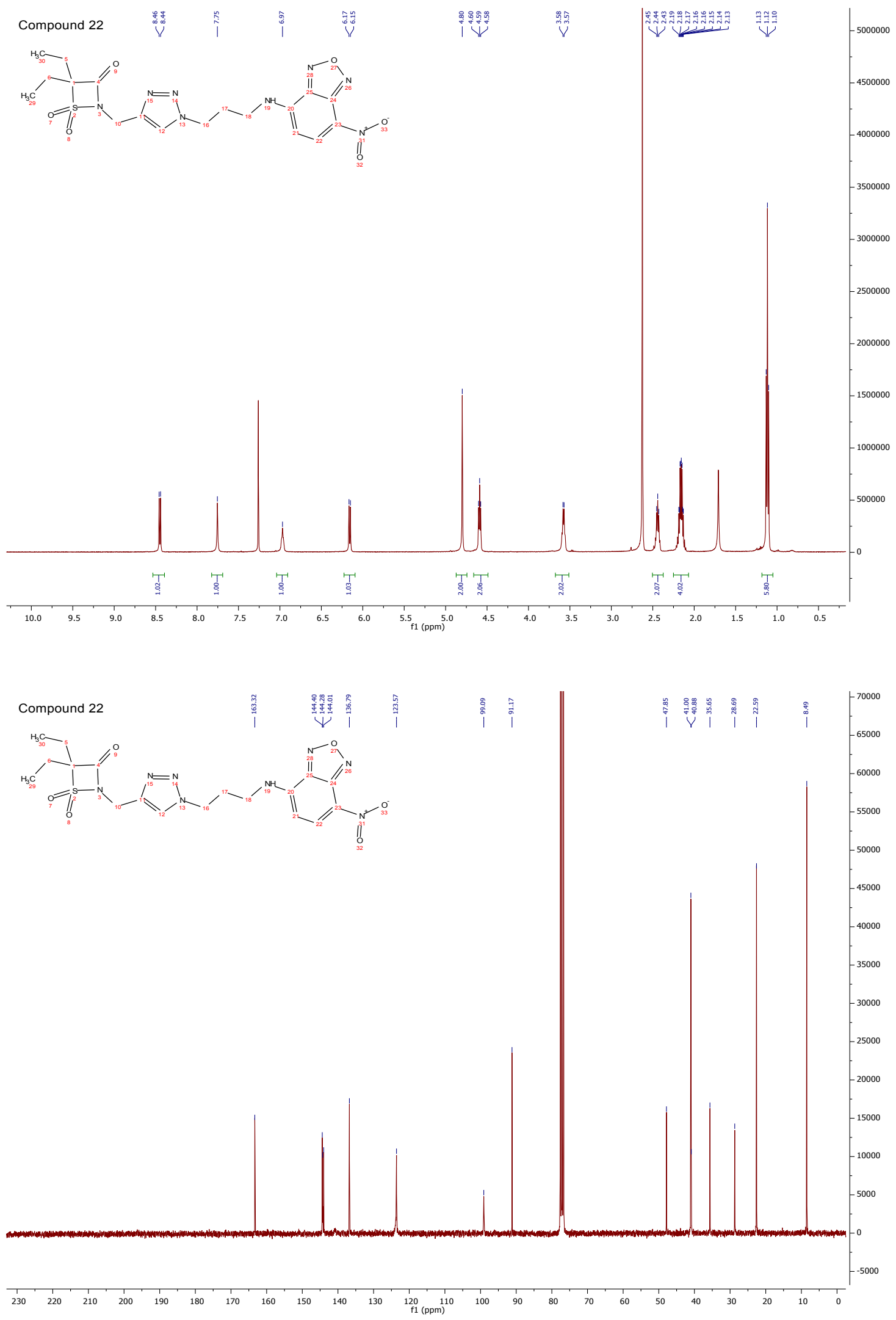

Figure S.19. $\mathrm{H}^{1} \mathrm{NMR}$ and $\mathrm{C}^{13} \mathrm{NMR}$ of compound 22.

S29 


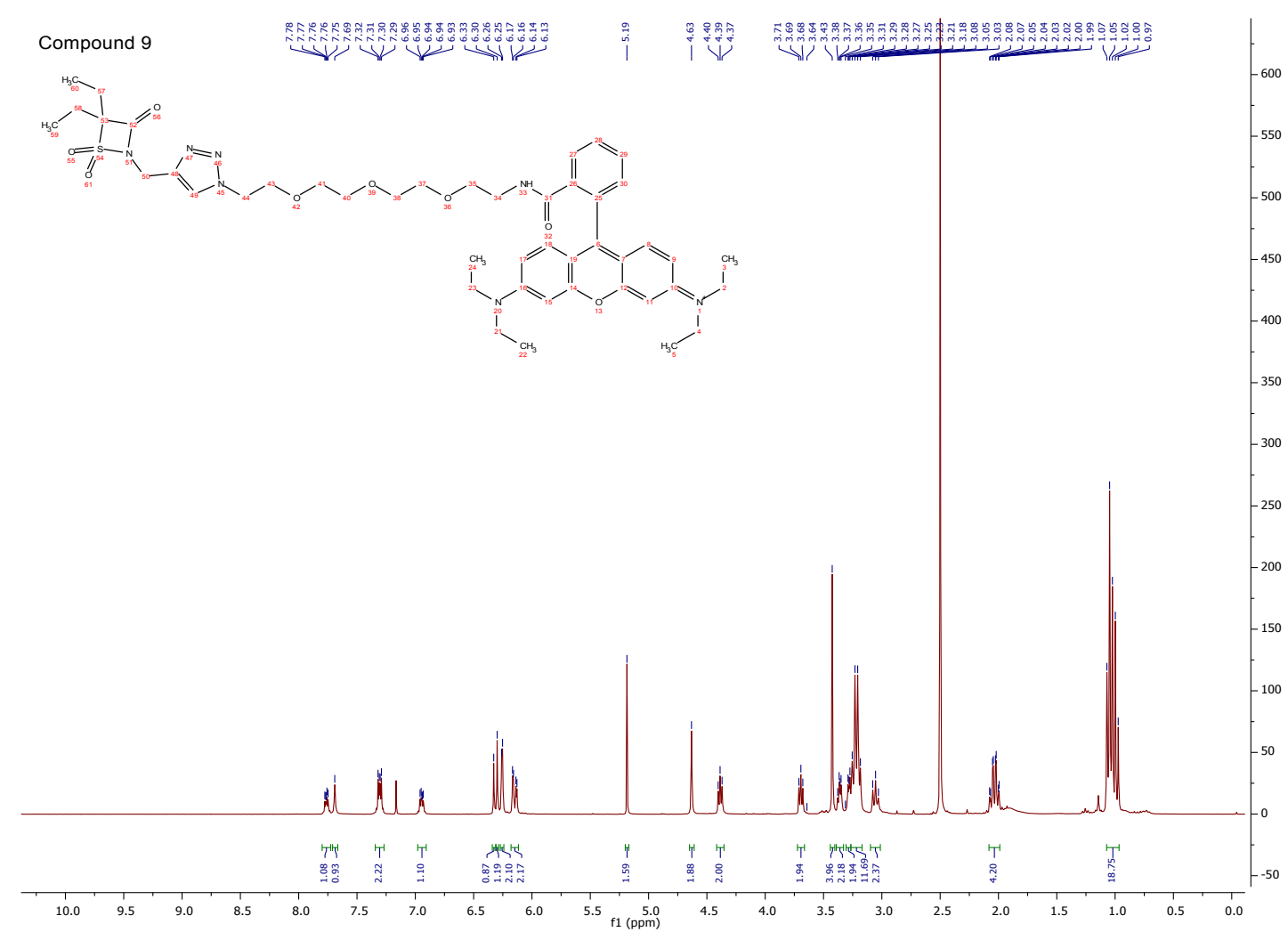

Figure S.20. $\mathrm{H}^{1}$ NMR of compound 9. 


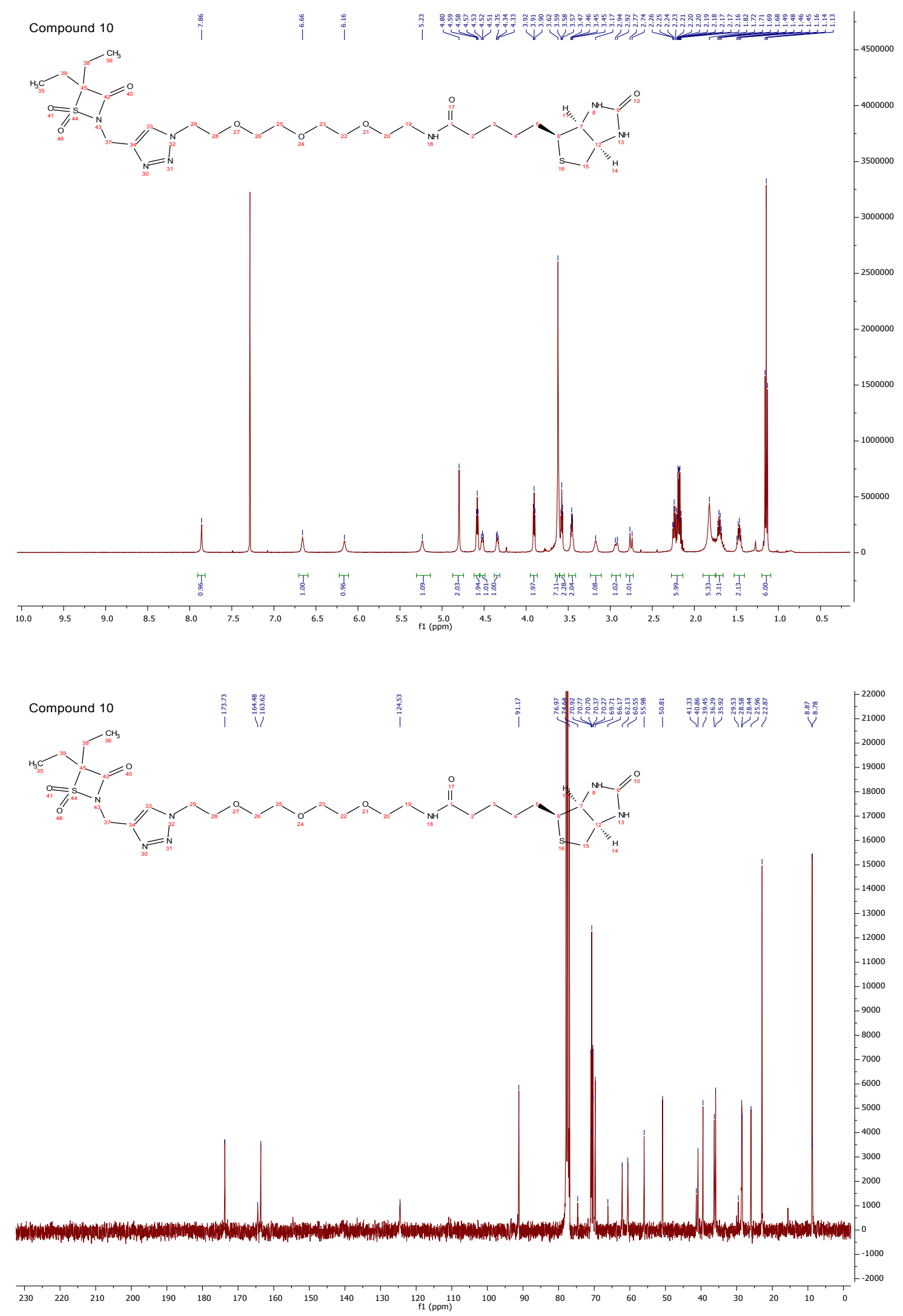

Figure S.21. $\mathrm{H}^{1} \mathrm{NMR}$ and $\mathrm{C}^{13} \mathrm{NMR}$ of compound $\mathbf{1 0}$. 


\section{X-Ray Crystallography - Crystallization, Structure Determination and Refinement}

Crystals of Porcine Pancreatic Elastase (PPE), were obtained as previously described. ${ }^{4,} 5$ In summary, PPE (SERVA Electrophoresis $\mathrm{GmbH}$, Heidelberg, Germany), was dissolved in Milli-Q water to a final concentration of $20 \mathrm{mg} \cdot \mathrm{mL}^{-1}(\sim 0.8$ $\mathrm{mM}$ ), and used for crystallization trials without further purification. $100 \mathrm{mM}$ stock solutions were prepared for ligands $\mathbf{5}$, 6, 7 and 8 in $100 \%(V / V)$ dimethyl sulfoxide (DMSO). PPE crystals were obtained at $2{ }^{\circ} \mathrm{C}$ using the sitting-drop vapor diffusion method by mixing equal volumes of protein and crystallization solution consisting of $70 \%(V / V)$ MPD (2-methyl2,4-pentanediol), $10 \mathrm{mM}$ sodium/potassium phosphate buffer $\mathrm{pH} 5.9$ (this solution was chosen based on previous crystallization reports of PPE). ${ }^{6} \mathrm{HNE}$ (Elastin Products Co., Inc. Owensville, Missouri, USA , No. SE563) was dissolved in $20 \mathrm{mM}$ Tris- $\mathrm{HCl} \mathrm{pH} 7.5$ and $50 \mathrm{mM}$ sodium chloride to the same final concentration as PPE, and was crystallized in 24\% PEG Smear Broad $(w / V), 0.1 \mathrm{M}$ Tris- $\mathrm{HCl} \mathrm{pH} \mathrm{7.2,} 0.1 \mathrm{M}$ potassium thiocyanate and $0.1 \mathrm{M}$ sodium bromide.

Complexes of PPE and HNE with inhibitors were obtained by co-crystallization. Elastases were first incubated with each inhibitor in 5X molar excess for 15 - 30 min (PPE) or 60 - 90 min (HNE), at room temperature, with final DMSO concentration around 3\% $(V / V)$. Crystals of putative complexes of both enzymes were grown under similar crystallization conditions as for the apo-protein, testing various concentrations and ratios of protein:precipitant and drop volumes (at 20 $\left.{ }^{\circ} \mathrm{C}\right)$. In some of the drops, nucleation had to be promoted using microseeding techniques. ${ }^{7}$

For X-ray diffraction data collection, PPE crystals were harvested from the drops and directly flash-cooled in liquid nitrogen, since $70 \%$ MPD is already cryoprotectant, whereas for HNE, ethylene glycol was added to the crystallization solution to a final concentration of 20\% $(V / V)$. Data were collected at beamlines ID23 and ID30A-3 at the European Synchrotron Radiation Facility (ESRF, Grenoble, France), and I03 and I24 at the Diamond Light Source (DLS, Didcot, Oxfordshire, UK). The programs XDS, ${ }^{8}$ POINTLESS ${ }^{9}$ and AIMLESS, ${ }^{10}$ all within the autoPROC pipeline, ${ }^{11}$ were used to integrate, determine space group and scale the data, respectively. STARANISO ${ }^{12}$ also within the autoPROC pipeline, was used to analyze the anisotropy of the data and, eventually, extend the resolution to a higher limit. Data collection and reduction statistics are depicted in Tables S1 and S2. Molecular replacement solutions for PPE and HNE datasets were obtained with PHASER,${ }^{13}$ as implemented in the PHENIX suite of programs, ${ }^{14,}, 15$ using the coordinates of PDB entries 4YM94, 5 for PPE and $1 \mathrm{HNE}$ for $\mathrm{HNE}^{16}$ devoid of any ligands and solvent molecules, as search models. Initial crystallographic refinement was performed with BUSTER-TNT ${ }^{17}$ using the macro "Missing Atoms" and "-L" flag ("presence of an unknown ligand"), to render clear electron density for the putative ligands. Iterative model building and refinement were carried out with programs $C O O T^{18}$ and $B U S T E R-T N T^{17}$ until model convergence and satisfactory overall quality statistics were achieved. Hydrogen atoms were added with zero occupancy before each refinement cycle with the program HYDROGENATE, which uses reduce from the MolProbity suite. ${ }^{19}$ Final refinements were performed with phenix.refine $^{14}$ from the PHENIX suite of programs. ${ }^{14}$ Structure validation was carried out with MolProbity ${ }^{19}$ as implemented in phenix.refine. Final refinement and validation statistics are shown in tables S1 and S2. All figures were rendered with PyMol. ${ }^{20}$

PPE:5-7 crystals contain one molecule in the asymmetric unit, with a Mathews coefficient ${ }^{21}\left(V_{\mathrm{M}}\right)$ of $1.8 \AA^{3} / \mathrm{Da}$, corresponding to approximately $33 \%$ of solvent content, whereas HNE contains three molecules in the asymmetric unit, $V_{\mathrm{M}}$ of $2.4 \AA^{3} / \mathrm{Da}$ and a solvent content $c a .48 \%$. PPE:5 has $R_{\text {crys }}$ of $13.3 \%\left(R_{\text {free }}\right.$ of $\left.16.3 \%\right)$ and comprises Val16 to Asn 245 , one ligand 5, 212 water molecules, one MPD, two phosphates and one sodium ion. Crystals of HNE:8 diffract to lower resolution than PPE; its final model shows a $R_{\text {crys }}$ of $21.52 \%\left(R_{\text {free }}\right.$ of $\left.25.72 \%\right)$ at $2.59 \AA$. The model contains 230 amino acid residues (Val16 - Asn245, following chymotrypsin numbering), one ligand 8, 110 waters, two ethylene glycol molecules and six bromide ions. Noteworthy, electron density for ligand $\mathbf{8}$ bound to Ser195 is only observed in chain C, likely due to crystal packing, as in chains A and B would show steric clashes with symmetry-related residues. We also observed N-linked sugar moieties at both potential glycosylation sites. At Asn109 and Asn159, clear electron density was visible for one $\beta$-N-acetyld-glucosamine (NAG) linked to one 1-fucose (FUC, $\alpha$-1,6-link) and an additional NAG ( $\beta$-1,4-link) in all chains, except for chain B, where the additional NAG is not present at Asn159. Figure S22 shows the electron density maps around ligands 6 and 7 for the other two X-ray structures of PPE complexes. 
Both PPE and HNE have a shallow active site cleft that is quite solvent exposed and therefore enables a broad range of different ligands to bind to the catalytic serine (Ser195). Figure S23 illustrates well the diversity of conformations adopted by various ligands in other reported HNE complexes.

Table S1. Data collection and refinement statistics for complexes PPE:5 and PPE:6.

\begin{tabular}{|c|c|c|}
\hline & PPE:5 & PPE:6 \\
\hline PDB Entry & $6 \mathrm{QBU}$ & 6QEN \\
\hline
\end{tabular}

\section{Data collection}

Synchrotron

Beamline

Wavelength (§)

Resolution range $(\AA)^{\mathrm{a}}$

Space group

Unit cell

$$
\begin{gathered}
a, b, c(\AA) \\
\alpha, \beta, \gamma\left(^{\circ}\right)
\end{gathered}
$$

Total no. of reflections

No. of unique reflections

Multiplicity

Completeness spherical (\%)

Completeness ellipsoidal (\%)

$<I / \sigma(I)>$

$R_{\text {merge }}(\%)^{\mathrm{b}}$

$R_{\text {pim }}(\%)^{c}$

$C C_{1 / 2}(\%)^{\mathrm{d}}$

Refinement

$R_{\text {cryst }}(\%)^{\text {e }}$

$R_{\text {free }}(\%)^{\mathbf{f}}$

RMSD bonds $(\AA ̊ \AA))^{\mathrm{g}}$

RMSD angles ( ${ }^{\circ}$ )

Protein residues

Ramachandran plot

Most favoured (\%)

Outliers (\%)

Rotamer outliers (\%)

Clashscore $^{\text {h }}$

MolProbity score
ESRF (Grenoble - France)

$$
\text { ID30A-3 }
$$

0.976

$$
\begin{aligned}
& 45.57-1.38 \\
& (1.45-1.38)
\end{aligned}
$$$$
P 22_{1} 2_{1}
$$

$45.57-1.53$

$$
(1.56-1.53)
$$

$50.55,57.55,74.59$

$90.0,90.0,90.0$

$\begin{array}{cc}154232(6552) & 129339(6576) \\ 38592(1929) & 32333(1617) \\ 4.0(3.4) & 4.0(4.1) \\ 84.3(28.2) & 97.2(99.9) \\ 91.8(57.6) & - \\ 11.4(1.2) & 13.3(2.1) \\ 5.4(73.3) & 5.0(49.2) \\ 2.9(44.6) & 2.6(25.7) \\ 99.9(57.8) & 99.9(81.9)\end{array}$

$13.32(21.31)$

$16.34(26.00)$

0.007

0.98

Val16 - Asn245
DLS (Oxford - UK)

I03

0.976

$\begin{array}{ll}34.05-1.20 & 34.05-1.41 \\ (1.30-1.20) & (1.44-1.41)\end{array}$

$P 2_{1} 2_{1} 2_{1}$

$51.13,57.71,74.65$

$90.0,90.0,90.0$

$\begin{array}{cc}198534(11131) & 164442(8329) \\ 49274(2466) & 42081(2116) \\ 4.0(4.5) & 3.9(3.9) \\ 70.0(15.6) & 98.0(98.4) \\ 93.5(70.2) & - \\ 14.5(1.5) & 16.7(2.2) \\ 3.4(75.0) & 3.2(43.6) \\ 1.9(39.1) & 1.8(24.7) \\ 99.9(65.7) & 99.9(86.1)\end{array}$

$14.20(21.65)$

$17.40(27.39)$

0.008

0.98

Val16 - Asn 245
97.9

0.0

0.0

0.81

0.78
97.5

0.0

0.5

2.72

1.16 
$B$-factors $\left(\AA^{2}\right)$

$\begin{array}{llll}\text { Protein } & 18.81 & - & 23.42\end{array}$

Ligands/ions

27.94

28.21

[a] Information in parenthesis refers to the last resolution shell.

[b] $\mathrm{R}_{\text {merge }}=\sum_{\text {hkl }} \sum_{\mathrm{i}} \mathrm{I} \mathrm{I}_{\mathrm{i}}(\mathrm{hkl})-\overline{\mathrm{I}(\mathrm{hkl}) \mathrm{l}} / \sum_{\mathrm{hkl}} \sum_{\mathrm{i}} \mathrm{i}_{\mathrm{i}}(\mathrm{hkl})$.

[c] $\mathrm{R}_{\mathrm{p} . \mathrm{im}}=\sum_{\mathrm{hkl}}\left[1 /(\mathrm{N}-1)^{\frac{1}{2}} \sum_{\mathrm{i}} \mathrm{I}_{\mathrm{i}}(\mathrm{hkl})-\overline{\mathrm{I}(\mathrm{hkl})} \mid / \sum_{\mathrm{hkl}} \sum_{\mathrm{i}} \mathrm{I}_{\mathrm{i}}(\mathrm{hkl})\right.$.

[d] CCl/2 as described in Karplus \& Diederichs (2012). Science, 336(6084): 1030-1033.

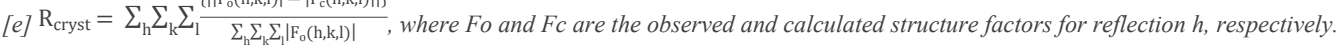

[f] Rfree was calculated the same way as Rcryst but using only $5 \%$ of the reflections which were selected randomly and omitted from refinement.

$[g]$ RMSD, root mean square deviation.

[h] Clashscore is the number of unfavourable all-atom steric overlaps $\geq 0.4 \AA$ per 1000 atoms. Word et al.,(1999). Mol Biol, 285(4):1711-33.

[i] MolProbity score provides a single number that represents the central MolProbity protein quality statistics; it is a log-weighted combination of clashscore, Ramachandran not favoured and bad side-chain rotamers, giving one number that reflects the crystallographic resolution at which those values would be expected.

Table S2. Data collection and refinement statistics for complexes PPE:7 and HNE:8.

\begin{tabular}{|c|c|c|}
\hline & PPE:7 & HNE:8 \\
\hline PDB Entry & 6QEO & 6SMA \\
\hline
\end{tabular}

\section{Data collection}

Synchrotron

Beamline

Wavelength ( $($ )

Resolution range $(\AA ̊)^{\mathrm{a}}$

Space group

Unit cell

$$
a, b, c(\AA)
$$$$
\alpha, \beta, \gamma\left({ }^{\circ}\right)
$$

Total no. of reflections

No. of unique reflections

Multiplicity

Completeness spherical (\%)

Completeness ellipsoidal (\%)

$$
<I / \sigma(I)>
$$

$\boldsymbol{R}_{\text {merge }}(\%)^{\mathrm{b}}$

$\boldsymbol{R}_{\text {pim }}(\%)^{c}$

$C C_{1 / 2}(\%)^{\mathrm{d}}$

Refinement

$\boldsymbol{R}_{\text {cryst }}(\%)^{\mathrm{e}}$

$R_{\text {free }}(\%)^{\mathrm{f}}$
ESRF (Grenoble - France)

ID23

0.967

$33.94-1.30$

$(1.35-1.30)$

$33.94-1.42$

$(1.44-1.42)$

$P 22_{1} 2_{1}$

$50.74,57.71,74.66$

$90.0,90.0,90.0$

210764 (6 935)

187811 (6 811)

$49091(2456)$

$$
4.3(2.8)
$$

88.9 (40.6)

$91.8(52.0)$

$13.4(1.2)$

$4.5(65.2)$

$2.4(44.4)$

$99.9(62.8)$

$13.01(21.55)$

$16.74(26.07)$
41396 (1 917)

4.5 (3.6)

$98.0(91.5)$

$15.7(2.2)$

$4.4(42.8)$

$2.2(24.6)$

$99.9(83.8)$
DLS (Oxford - UK)

$$
\begin{gathered}
\text { I24 } \\
1.649
\end{gathered}
$$$$
62.83-2.59
$$$$
(2.63-2.59)
$$

C2

$116.67,105.91,79.47$

$90.0,121.1,90.0$

$85806(4020)$

24564 (1 254)

$3.5(3.2)$

$95.1(97.3)$

$6.6(1.8)$

23.4 (126.4)

$13.3(75.5)$

$96.6(36.7)$

$21.52(29.68)$

$25.79(32.13)$ 
RMSD bonds $(\AA)^{\mathrm{g}}$

RMSD angles $\left({ }^{\circ}\right)$

Protein residues

Ramachandran plot

Most favoured (\%)

Outliers (\%)

Rotamer outliers (\%)

Clashscore $^{\mathrm{h}}$

MolProbity score ${ }^{i}$

$B$-factors $\left(\AA^{2}\right)$
0.009

1.17

Val16 - Asn245

97.5

0.0

0.5

1.59

1.01

17.70

22.94
0.002

0.527

Ile16 - Gln233

0.0

0.0

1.07

0.88

40.48

Ligands/ions

[a] Information in parenthesis refers to the last resolution shell.

[b] $\mathrm{R}_{\text {merge }}=\sum_{\text {hkl }} \sum_{\mathrm{i}} \mathrm{I}_{\mathrm{i}}(\mathrm{hkl})-\overline{\mathrm{I}(\mathrm{hkl}) \mid} / \sum_{\mathrm{hkl}} \sum_{\mathrm{i}} \mathrm{I}_{\mathrm{i}}(\mathrm{hkl})$.

[c] $\mathrm{R}_{\text {p.i.m }}=\sum_{\text {hkl }}\left[1 /(\mathrm{N}-1)^{\frac{1}{2}} \sum_{\mathrm{i}}\left|\mathrm{I}_{\mathrm{i}}(\mathrm{hkl})-\overline{\mathrm{I}(\mathrm{hkl})}\right| / \sum_{\text {hkl }} \sum_{\mathrm{i}} \mathrm{I}_{\mathrm{i}}(\mathrm{hkll})\right.$.

[d] CC1/2 as described in Karplus \& Diederichs (2012). Science, 336(6084): 1030-1033.

[e] $\mathrm{R}_{\mathrm{cryst}}=\sum_{\mathrm{h}} \sum_{\mathrm{k}} \sum_{\mathrm{l}} \frac{\left\{\mathrm{F}_{\mathrm{o}}(\mathrm{h}, \mathrm{k}, \mathrm{l})|-| \mathrm{F}_{\mathrm{c}}(\mathrm{h}, \mathrm{k}, \mathrm{l}) \mid \mathrm{l}\right.}{\sum_{\mathrm{h}} \sum_{\mathrm{k}} \sum_{1} \mid \mathrm{F}_{\mathrm{o}}(\mathrm{h}, \mathrm{k}, \mathrm{l}, \mathrm{l})}$, where Fo and Fc are the observed and calculated structure factors for reflection $h$, respectively.

[f] Rfree was calculated the same way as Rcryst but using only 5\% of the reflections which were selected randomly and omitted from refinement.

[g] RMSD, root mean square deviation.

[h] Clashscore is the number of unfavourable all-atom steric overlaps $\geq 0.4 A$ per 1000 atoms. Word et al.,(1999). Mol Biol, $285(4): 1711-33$.

[i] MolProbity score provides a single number that represents the central MolProbity protein quality statistics; it is a log-weighted combination of clashscore, Ramachandran not favoured and bad side-chain rotamers, giving one number that reflects the crystallographic resolution at which those values would be expected.

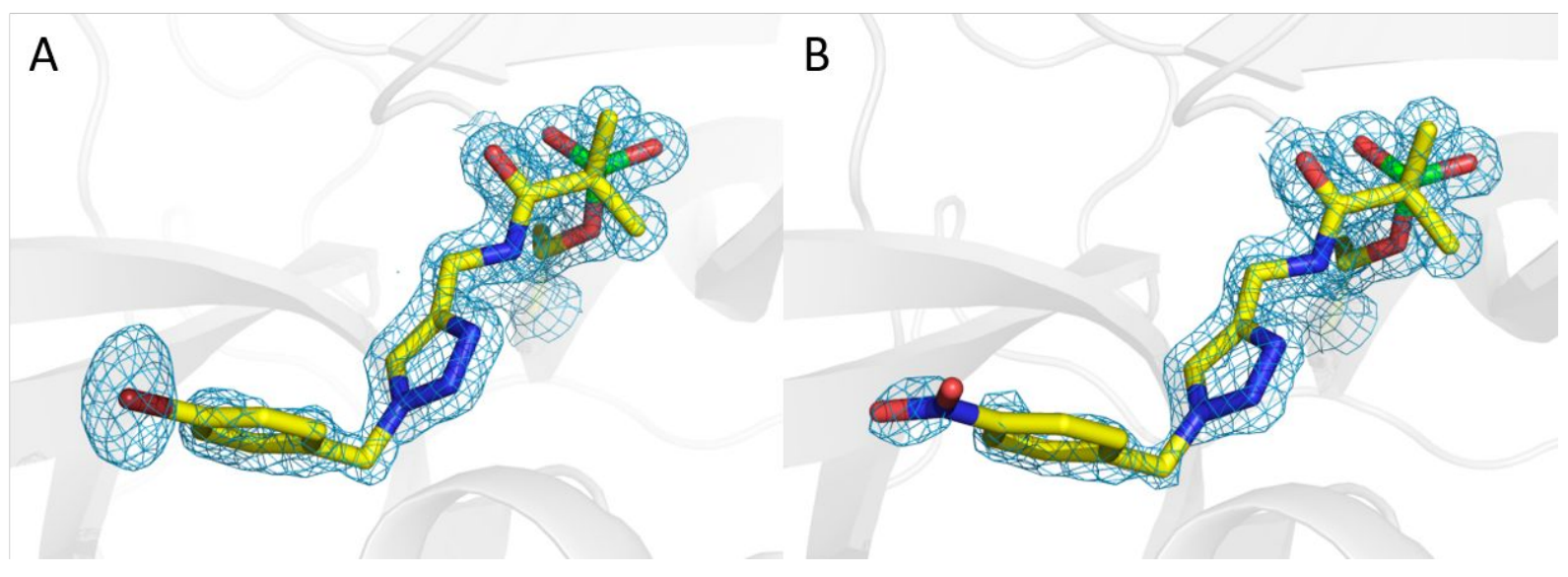

Figure S22. Electron density maps around the covalently bound ligands 6 (A) and 7 (B) to PPE; $|2 \mathrm{Fo}-\mathrm{Fc}|$ maps are depicted in blue mesh for PPE complexes. Color code: carbon in yellow, oxygen in red, nitrogen in blue, sulfur in green, and $\mathrm{Br}$ atoms in dark red. 


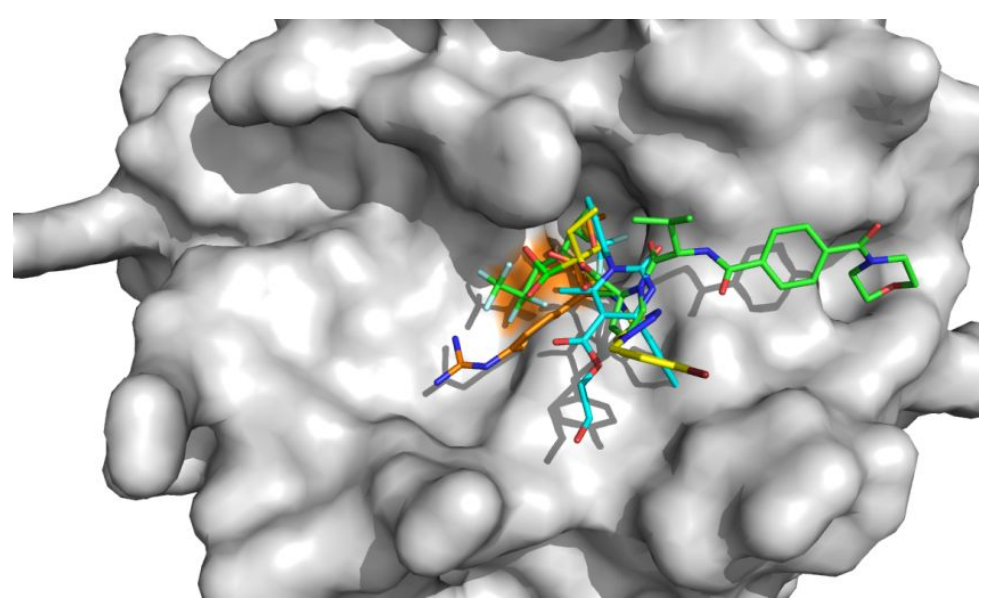

Figure S23. Surface of HNE:8 complex with aligned ligands from other HNE complexes. All ligands are displayed in sticks with carbon atoms colored according to their PDB code: yellow- HNE herein reported (6SMA), green- 1B0F, ${ }^{22}$ light blue- $3 \mathrm{Q}^{2} 7^{23}$ and orange- $8 \mathrm{EST}^{24}$ (O- red, N- blue, S- green, and Br-brown); the surface of catalytic serine (Ser195) is represented in orange. 


\section{Computational Methods}

3-oxo- $\beta$-sultams 1 and 5 (and their tautomeric forms) were optimized at the Beck 3-Lee-Yang-Parr (B3LYP) level of theory as implemented in Gaussian $16 \mathrm{Rev}$ A.03 package, using the $6-311++\mathrm{G}(\mathrm{d}, \mathrm{p})$ basis set. All geometries were characterised as minima by using the sign of the eigenvalues of the force-constant matrix obtained from a frequency calculation (no imaginary frequencies were found) at this level of theory. Gauss view molecular visualizing program package was used to visualize vibrational wavenumber, electronic structure, frontier molecular orbitals (HOMO and LUMO) and other molecular properties. ${ }^{25}$

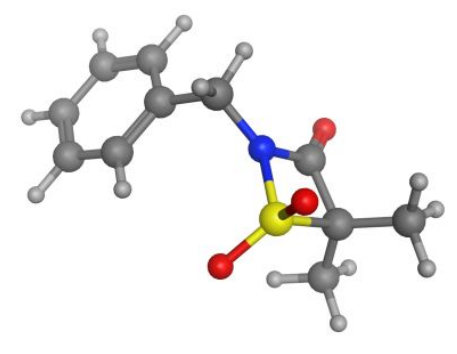

Compound 1

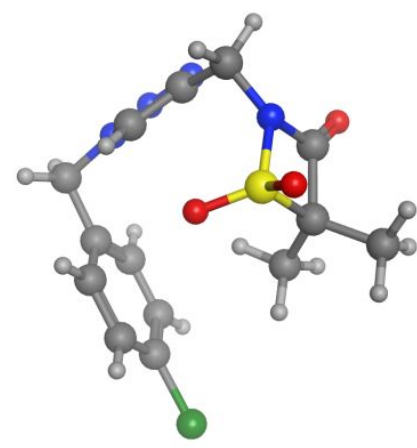

Compound 5

Figure S24. Optimized structures of compounds 1 and 5, respectively, at the B3LYP/6-311++G(d,p) level of theory. 
Table S3. HOMO, LUMO, Mulliken charges, distances (A), angles and dihedral angles (between atoms inside the 3-oxo- $\beta$-sultam ring).

\begin{tabular}{ccc} 
& Compound $\mathbf{1}$ & Compound $\mathbf{5}$ \\
\hline HOMO $(\mathrm{eV})$ & -0.26408 & -0.26579 \\
LUMO $(\mathrm{eV})$ & -0.03298 & -0.04796 \\
Mulliken charges: $\mathrm{S}$ & 0.488 & 0.426 \\
Mulliken charges: C & -0.234 & -0.125 \\
$\mathrm{~d}(\mathrm{~N}-\mathrm{S})$ & 1.73 & 1.73 \\
$\mathrm{~d}(\mathrm{~S}-\mathrm{C})$ & 1.88 & 1.88 \\
$\mathrm{~d}(\mathrm{C}-\mathrm{C})$ & 1.55 & 1.55 \\
$\mathrm{~d}(\mathrm{C}-\mathrm{N})$ & 1.38 & 1.38 \\
$\mathrm{a}(\mathrm{NSC})$ & 77.0 & 77.1 \\
$\mathrm{a}(\mathrm{SCC})$ & 85.5 & 85.6 \\
$\mathrm{a}(\mathrm{CCN})$ & 100.5 & 100.5 \\
$\mathrm{a}(\mathrm{CNS})$ & 96.9 & 96.8 \\
$\mathrm{dh}(\mathrm{NSCC})$ & 1.5 & 1.1 \\
$\mathrm{dh}(\mathrm{SCCN})$ & -1.8 & -1.4 \\
$\mathrm{dh}(\mathrm{CCNS})$ & 2 & 1.5 \\
$\mathrm{dh}(\mathrm{CNSC})$ & -1.7 & -1.2 \\
\hline
\end{tabular}




\section{Biological Assays}

\subsection{Enzymatic Inhibition Assays - Methodology}

Inhibition Assay for Human Neutrophil Elastase. HNE assays were carried out in a total volume of $200 \mu \mathrm{L}$ per well. Each assay well contained $155 \mu \mathrm{L}$ of $0.1 \mathrm{M}$ HEPES pH 6.9, $20 \mu \mathrm{L}$ of HNE (stock solution $1.7 \mu \mathrm{M}$ in $0.05 \mathrm{M}$ acetate buffer, $\mathrm{pH} 5.5)$ and $5 \mu \mathrm{L}$ of the tested compound. After incubation at room temperature for 30 minutes, $20 \mu \mathrm{L}$ of fluorogenic substrate (MeO-Suc-Ala-Ala-Pro-Val-AMC, Merck, Germany) is added. DMSO was used as control. Enzymatic inhibition assays were carried out at $25{ }^{\circ} \mathrm{C}$ for a period of 30 minutes. The reaction was monitored with a FLUOstar Omega (BMG Lactech, Germany) microplate reader, at the excitation wavelength of $360 \mathrm{nM}$ and emission wavelength of $460 \mathrm{nM}$. $\mathrm{IC}_{50} \mathrm{~S}$ were determined by non-linear regression using GraphPad PRISM software. For all experiments, stock solutions of the tested compounds were prepared and diluted in DMSO.

Inhibition Assay for Chymotrypsin. Inhibition assays for chymotrypsin (Calbiochem) were performed in $0.05 \mathrm{M}$ Tris$\mathrm{HCl}, 0.138 \mathrm{M} \mathrm{NaCl}, \mathrm{pH} 8.0$ with $30 \mathrm{nM}$ human pancreas chymotrypsin, test compounds in pre-determined concentrations, and $100 \mu \mathrm{M}$ substrate (Suc-Ala-Ala-Pro-Phe-7-amino-4-methylcoumarin, Bachem). DMSO was used as control. The reaction was monitored like for HNE.

Inhibition Assay for Urokinase. Inhibition assays for urokinase (Calbiochem) were performed in $0.05 \mathrm{M}$ Tris- $\mathrm{HCl}, 0.138$ $\mathrm{M} \mathrm{NaCl}, \mathrm{pH} 8.0$, with $30 \mathrm{U} / \mathrm{mL}$ human urine urokinase, test compounds in pre-determined concentrations, and $50 \mu \mathrm{M}$ substrate (Z-Gly-Gly-Arg-AMC.HCl, Bachem). DMSO was used as control. The reaction was monitored like for HNE.

Inhibition Assay for Trypsin. Inhibition assays for trypsin (Calbiochem) were performed in $0.05 \mathrm{M}$ Tris- $\mathrm{HCl}, 0.138 \mathrm{M}$ $\mathrm{NaCl}, \mathrm{pH} 8.0$, with 30nM human pancreas Trypsin, test compounds in pre-determined concentrations, and $50 \mu \mathrm{M}$ substrate (Z-Gly-Gly-Arg-AMC.HCl, Bachem). DMSO was used as control. The reaction was monitored like for HNE.

Inhibition Assay for Thrombin. Inhibition assays for thrombin (Calbiochem) were performed in $0.01 \mathrm{M}$ sodium phosphate, $0.138 \mathrm{M} \mathrm{NaCl}, 0.1 \%$ PEG 6000 , $\mathrm{pH} 7.0$, with $1.7 \mathrm{U} / \mathrm{mL}$ human plasma thrombin, test compounds in predetermined concentrations, and $50 \mu \mathrm{M}$ substrate (Z-Gly-Gly-Arg-AMC.HCl, Bachem). DMSO was used as control. The reaction was monitored like for HNE.

Inhibition Assay for Kallikrein. Inhibition assays for kallikrein (Calbiochem) were performed in $0.05 \mathrm{M}$ Tris- $\mathrm{HCl}, 0.138$ $\mathrm{M} \mathrm{NaCl}, \mathrm{pH} 8.0$, with $2 \mathrm{nM}$ human plasma kallikrein, test compounds in pre-determined concentrations, and $50 \mu \mathrm{M}$ substrate (H-Pro-Phe-Arg-AMC acetate salt, Bachem). DMSO was used as control. A positive control was also used (Gabexate mesylate, Aldrich). The reaction was monitored like for HNE. 


\subsubsection{Enzymatic Inhibition - Human Neutrophil Elastase}
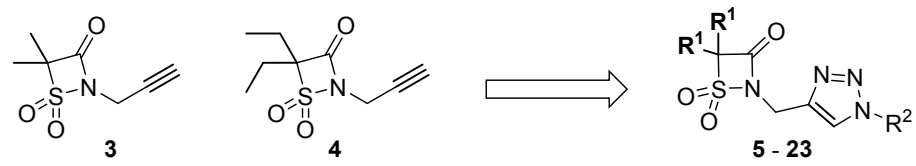

$I_{50}=3.27 \pm 1.09 \mu \mathrm{M} \quad I C_{50}=0.873 \pm 0.160 \mu \mathrm{M}$

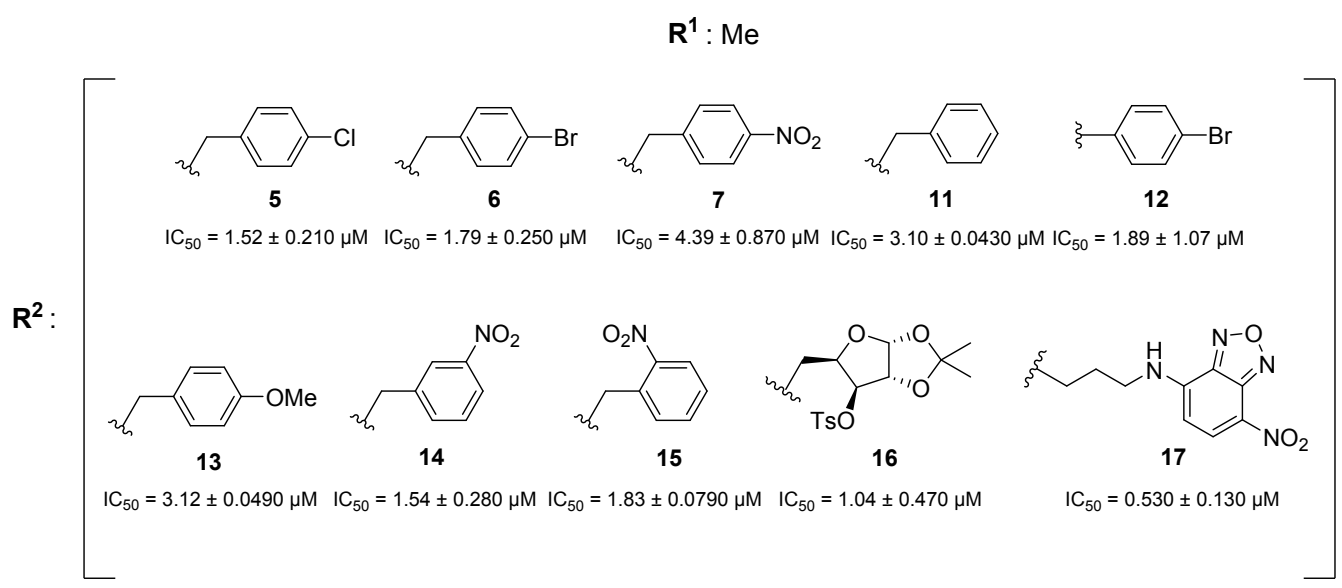

$\mathbf{R}^{1}: \mathrm{Et}$

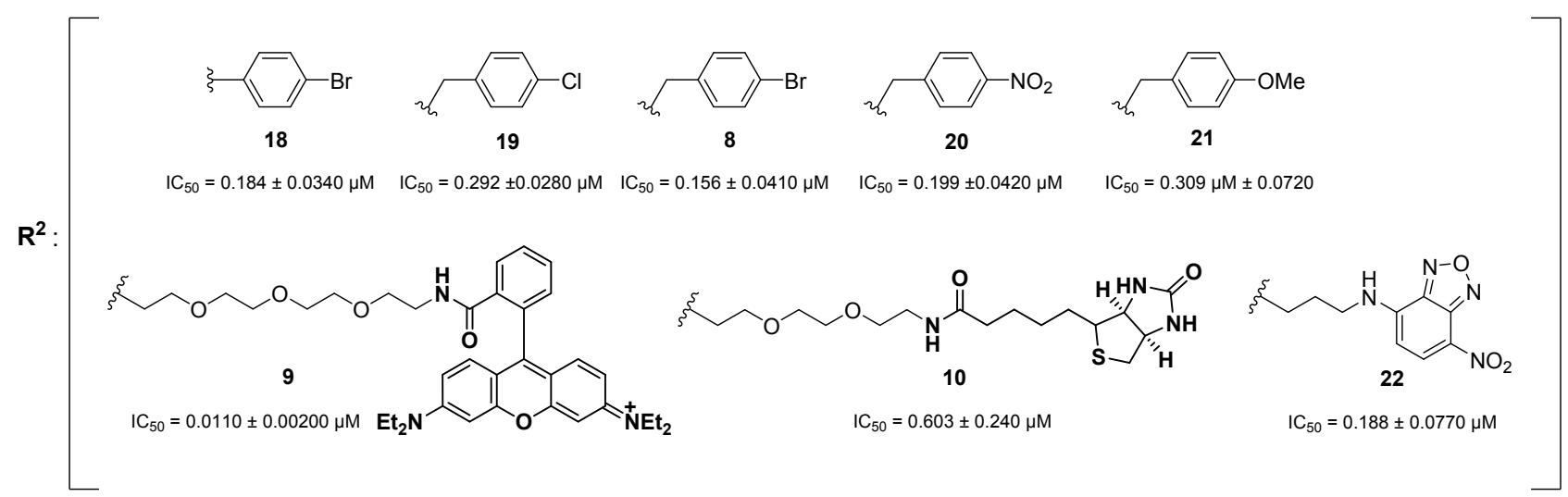

Scheme S2. Full library of 3-Oxo- $\beta$-Sultams and their respective $\mathrm{IC}_{50}$ values for HNE inhibition. 


\subsubsection{Enzymatic Inhibition - Biochemical Selectivity Evaluation Results}

Selected Serine Hydrolases, namely Thrombin, Urokinase, Trypsin, Kallikrein and Chymotrypsin, were used for assessment of biochemical selectivity using the methodology described in section 5.1. The results are given in Table S4.

Table S4. Biochemical selectivity against selected enzymes $(n=3)$.

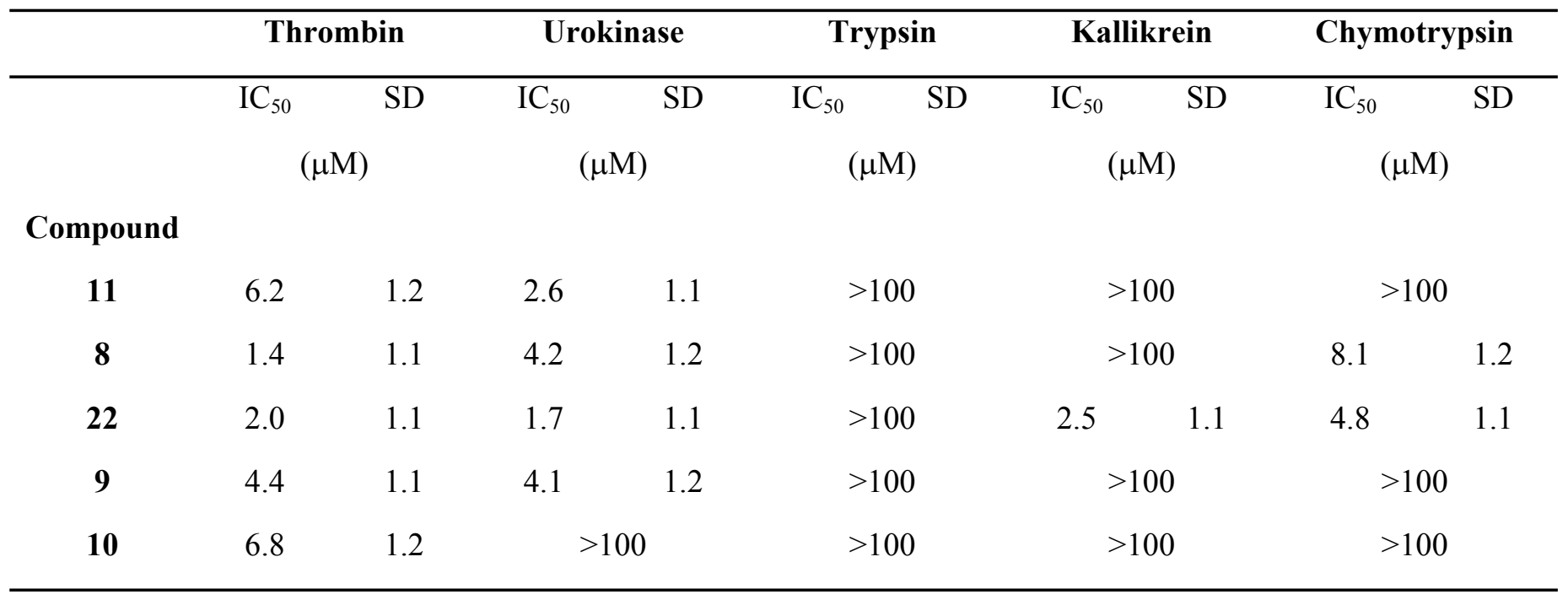

\subsection{Progress curve determination for $\mathrm{HNE}$}

The rates of inhibition of HNE by compound 9 were determined by the progress curve method. ${ }^{26}$ Inactivation of HNE was assayed at $25^{\circ} \mathrm{C}$. Each assay well contained $155 \mu \mathrm{L}$ of $0.1 \mathrm{M}$ HEPES pH 6.9, $20 \mu \mathrm{L}$ of HNE (stock solution $1.7 \mu \mathrm{M}$ in 0.05 $\mathrm{M}$ acetate buffer, $\mathrm{pH} 5.5$ ) and $5 \mu \mathrm{L}$ of the tested compound. $20 \mu \mathrm{L}$ of fluorogenic substrate (MeO-Suc-Ala-Ala-Pro-ValAMC, Merck, Germany) is the added. DMSO was used as control. Enzymatic inhibition assays were carried out at $25^{\circ} \mathrm{C}$ for a period of 30 minutes. The reaction was monitored with a FLUOstar Omega (BMG Lactech, Germany) microplate reader, at the excitation wavelength of $360 \mathrm{~nm}$ and emission wavelength of $460 \mathrm{~nm}$. The pseudo-first order rate constants, kobs, for the inhibition of HNE were determined according to the slow-tight binding inhibition model and involved the fitting of product concentration as a function of time to Equation 1 by non-linear regression analysis,

$$
\mathrm{A}=v_{\mathrm{s}} \mathrm{t}+\left(v_{\mathrm{i}}-\mathrm{v}_{\mathrm{s}}\right)\left(1-\mathrm{e}^{-k \mathrm{obst}}\right) / \mathrm{k}_{\mathrm{obs}}+\mathrm{A}_{\mathrm{o}}
$$

\section{(Equation 1)}

where $\mathrm{A}$ is the fluorescence units, $\mathrm{A}_{0}$ is the fluorescence units at $\mathrm{t}=0$, vi is the initial rate of change of absorbance, $\mathrm{v}_{\mathrm{s}}$ is the steady-state rate and $k_{\mathrm{obs}}$ is the first-order rate constant for the approach to the steady-state. As a linear dependence of $k_{\mathrm{obs}}$ on inhibitor concentration was observed, correction for substrate concentration and Michaelis constant yielded the secondorder rate constant for inhibition, $\left(k_{\text {inact }} / K_{\mathrm{i}}\right)$, as the slope, and the first-order rate for the dissociation of the $\mathrm{E} \cdot \mathrm{I}$ complex, $k_{\text {off }}$, as the intercept (Equation 2) 


$$
k_{\text {obs }}=k_{\text {off }}+\left(k_{\text {inact }} / K_{\mathrm{i}}\right)[\mathrm{I}] /\left(1+[\mathrm{S}] / K_{\mathrm{m}}\right)
$$

(Equation 2)

Under these conditions, the pseudo first-order rate constant for the approach to the steady-state, $\mathrm{k}_{\mathrm{obs}}$, presented a linear dependence with probe concentration, consistent with the simple time-dependent inhibition via a slow association mechanism, and corresponding to a second-order rate constant, kon, of $165 \mathrm{M}^{-1} \mathrm{~s}^{-1}$. In contrast, the intercept of the plot of $\mathrm{k}_{\mathrm{obs}} \mathrm{vs}$ the concentration of the probe $\mathbf{9}$, corresponding to the dissociation rate constant $\mathrm{k}_{\text {off }}$, is negligible, suggesting that hydrolysis of the covalent enzyme-inhibitor complex is very slow (Figure S25).
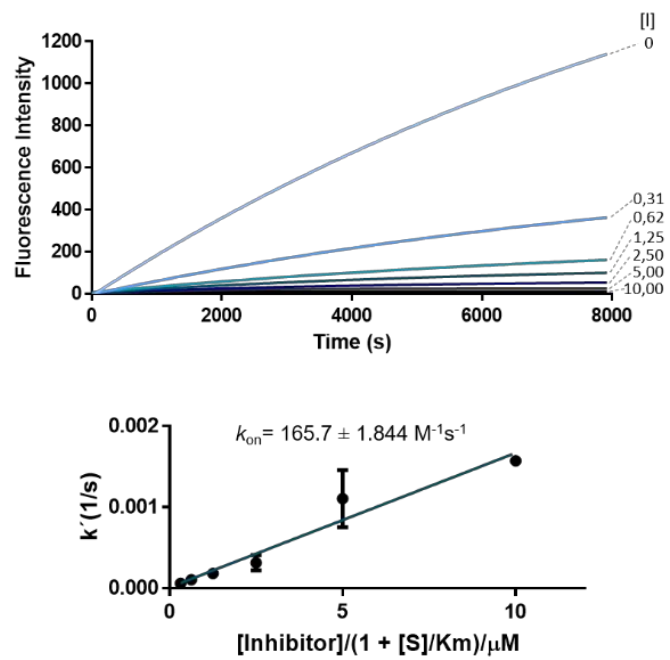

Figure S25. Progress curve analysis for compound 9. 


\subsection{Cell Culture}

Cells were cultured at $37{ }^{\circ} \mathrm{C}$ under a humidified $5 \%$ carbon dioxide atmosphere. Culture media were supplemented with $10 \%$ fetal bovine serum (FBS), penicillin (50 IU/mL), streptomycin $(50 \mu \mathrm{g} / \mathrm{mL})$, and glutamine $(2 \mathrm{mM})$, unless otherwise specified. U937 cells were cultured in tissue culture flasks using RPMI-1640. Cells were seeded at $2 \times 10^{5}$ viable cells $/ \mathrm{mL}$ and cultured by addition of fresh media every 2 to 3 days, maintaining cell density below $2 \times 10^{6}$ viable cells $/ \mathrm{mL}$. HEK293T cells were cultured in tissue culture plates using DMEM. A subcultivation ratio of 1:3 to 1:5 was used for passaging cells every 2 to 3 days when the cells reached approximately $80 \%$ confluency.

For SILAC experiments, the culture medium for SILAC U937 cells was SILAC RPMI supplemented with 10\% dialyzed FBS, penicillin, streptomycin, and glutamine (concentrations as above). "Light" medium was supplemented with Larginine- $\mathrm{HCl}$ and L-lysine- $\mathrm{HCl}$ (each at $100 \mu \mathrm{g} / \mathrm{mL}$ ); "Heavy" medium was supplemented with $\left[{ }^{13} \mathrm{C}_{6},{ }^{15} \mathrm{~N}_{4}\right] \mathrm{L}$-arginine- $\mathrm{HCl}$ and $\left[{ }^{13} \mathrm{C}_{6},{ }^{15} \mathrm{~N}_{2}\right] \mathrm{L}-1 y \operatorname{sine}-\mathrm{HCl}$ (each at $100 \mu \mathrm{g} / \mathrm{mL}$ ). SILAC U937 cells were generated by culturing cells in for a minimum of 5-8 passages. Aliquots were frozen in the corresponding SILAC medium supplemented with 10\% DMSO and stored in liquid nitrogen where required. After thawing, cells were passaged a minimum of three times before being used in experiments.

\subsection{Gel-based Assays}

\subsubsection{Methodology}

Gel-based ABPP. Whole cell lysates were normalized to $1 \mathrm{mg} / \mathrm{mL}$ of protein using a protein concentration assay (DC assay, BioRad). For labeling experiments, $1 \mu \mathrm{L}$ of the tested probe (50X concentrated) or DMSO was incubated for 30 minutes with $50 \mu \mathrm{L}$ of lysate at room temperature. For competitive experiments, $1 \mu \mathrm{L}$ of competitor (50X concentrated) was added and incubated for 30 minutes, followed by $1 \mu \mathrm{L}$ of probe (50X concentrated) for an additional 30 minutes. The reaction was quenched by adding $4 \mathrm{X}$ gel loading buffer $(17 \mu \mathrm{L})$. Proteins were resolved by SDS-PAGE $(10 \%$ acrylamide gel, constant $300 \mathrm{~V}$, approx $850-900 \mathrm{~V} \cdot \mathrm{hr}$ ). In-gel fluorescence scanning was performed on a ChemiDoc MP imager (BioRad, excitation: Green Epi, emission: 605/50).

Click-chemistry for gel-based assays. A freshly prepared "click" reagent mixture containing TBTA (3.0 $\mu \mathrm{L} / \mathrm{sample}, 1.7$ $\mathrm{mM}$ in 1:4 DMSO:t-BuOH), CuSO4 $(1.0 \mu \mathrm{L} / \mathrm{sample}, 50 \mathrm{mM}$ in H2O), TCEP $(1.0 \mu \mathrm{L} / \mathrm{sample}, 50 \mathrm{mM}$ in DPBS and rhodamine azide $(1.0 \mu \mathrm{L} /$ sample, $1.25 \mathrm{mM}$ in DMSO). After incubating for $1 \mathrm{~h}$ at room temperature, each reaction was quenched with $4 \times$ SDS loading buffer $(17 \mu \mathrm{L})$ and processed as described above.

\subsubsection{Additional Results - Preliminary Probe Evaluation}

Purified HNE range of detection tests. Decreasing concentrations (500 to $31.25 \mathrm{nM}$ ) of purified enzyme (ThermoFisher Scientific) were incubated with the rhodamine ABP $9(50 \mu \mathrm{M})$ and the alkyne ABP $4(50 \mu \mathrm{M})$ (Figure S26). For the rhodamine derivative, concentration-dependent labeling of HNE was observed, indicating that this probe is suitable for ingel detection of HNE. The alkyne probe was clicked with rhodamine azide post-labeling and resulted in a substantially weaker signal than that of the rhodamine derivative, with HNE only visible in the highest concentrations tested. Further studies were therefore performed using the rhodamine probe 9. 


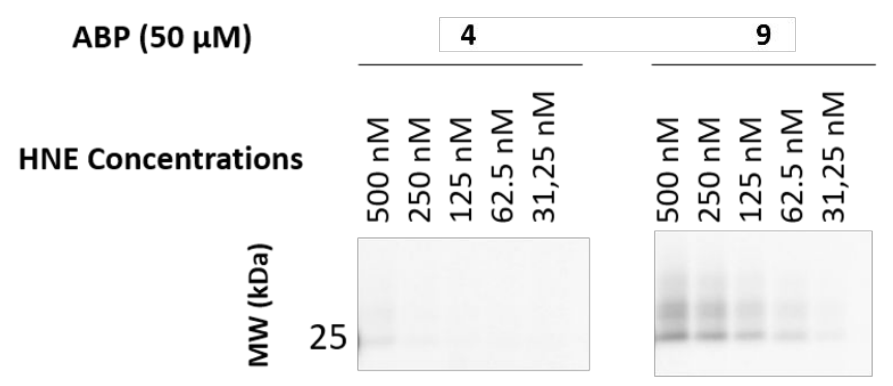

Figure S26. Labeling of decreasing concentrations of commercially available HNE with compounds 4 and 9 (50 $\mu \mathrm{M})$.

Labeling of decreasing HNE concentrations in whole proteome. Compound 9 was incubated with HEK293T lysates spiked with decreasing concentrations of purified HNE prior to probe incubation (Figure S27). HNE labeling was observed with concentration-dependent signal for all tested concentrations, but labeling was not exclusive, with a several off-targets being observed. It is noteworthy that a band of approximately $50 \mathrm{kDa}$ molecular weight showed increasing labeling as HNE concentration decreased, suggesting this protein could be an HNE substrate. These results demonstrate that 3-oxo- $\beta$-sultams can be used for the detection of HNE in complex proteomes.

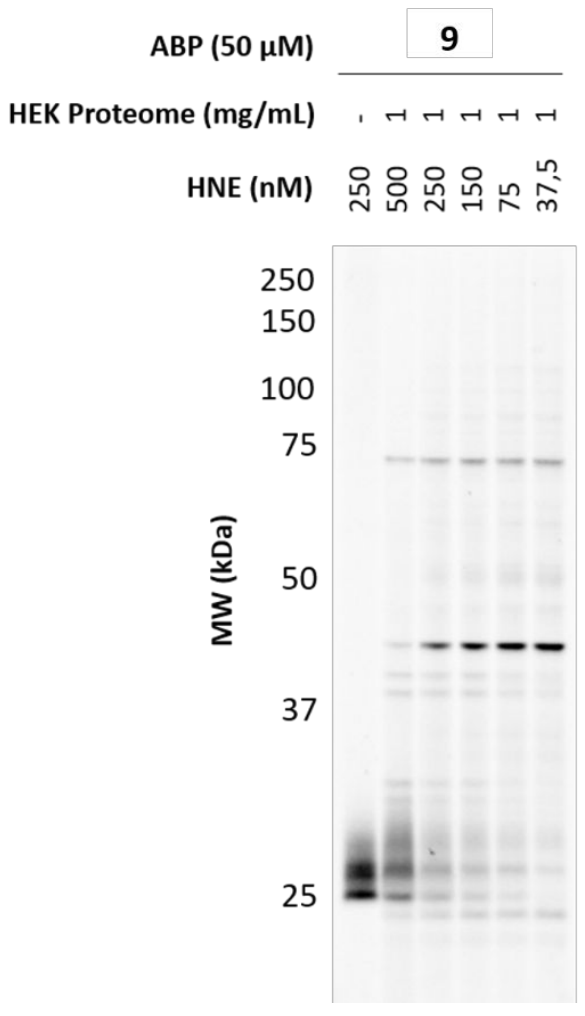

Figure S27. Labeling of decreasing concentrations of HNE spiked into HEK293T proteome by compound 9. 


\subsection{Mass-spectrometry-based Assays: ABPP-MudPIT-SILAC}

Complete proteomics identification and quantification data are available as a separate spreadsheet.

Proteome treatment with ABP. SILAC U937 whole cell lysates were normalized to a concentration of $1 \mathrm{mg} / \mathrm{mL}$ and 500 $\mu \mathrm{L}$ was used. ABP 10 was tested at a low $(10 \mu \mathrm{M})$ and high $(50 \mu \mathrm{M})$ concentration. Three replicate experiments were performed for each condition described. For enrichment experiments, "light" samples were treated with DMSO, and "heavy" samples probe $\mathbf{1 0}$ for $30 \mathrm{~min}$ at room temperature. For competition experiments, "light" samples were pre-treated with DMSO and "heavy" samples with competitor 9 for 30 min, at room temperature, then ABP $\mathbf{1 0}$ was added to both samples for another $30 \mathrm{~min}$. Light and heavy samples were quenched and mixed by addition to pre-chilled (ice) methanol (2 mL).

Preparation of samples for MudPIT analysis. The subsequent steps for protein precipitation were performed using chilled buffers kept on ice. $\mathrm{CHCl}_{3}(0.5 \mathrm{~mL})$ and DPBS $(1 \mathrm{~mL})$ were added sequentially and the cloudy mixture was vortexed and centrifuged $\left(5,000 \times \mathrm{g}, 15 \mathrm{~min}, 4^{\circ} \mathrm{C}\right)$. The organic and aqueous layers were aspirated leaving a protein disc that had formed between the organic and aqueous phases. The protein disc was washed with cold 1:1 $\mathrm{MeOH}: \mathrm{CHCl}_{3}(3 \times 1 \mathrm{~mL})$ and then dispersed by sonication back into 4:1 $\mathrm{MeOH}: \mathrm{CHCl}_{3}(2.5 \mathrm{~mL})$. A protein pellet was obtained by centrifugation $(5000 \times \mathrm{g}, 10$ $\left.\min , 4{ }^{\circ} \mathrm{C}\right)$ and the supernatant removed. The remaining pellet was resuspended in a freshly prepared solution of urea (500 $\mu \mathrm{L}, 6 \mathrm{M}$ in DPBS), TCEP $\left(50 \mu \mathrm{L}, 100 \mathrm{mM}\right.$ in DBPS, basified with $\left.\mathrm{K}_{2} \mathrm{CO}_{3}\right)$ was added, and the suspension incubated with shaking $\left(30 \mathrm{~min}, 37^{\circ} \mathrm{C}\right)$ to redissolve proteins. Proteins were alkylated with iodoacetamide ( $70 \mu \mathrm{L}, 400 \mathrm{mM}$ in DPBS) for $30 \mathrm{~min}$ at room temperature, in the dark. SDS was added (10\% in DPBS) and the sample diluted with DPBS (5 mL). Prewashed streptavidin-beads ( $100 \mu \mathrm{L} /$ sample, $0.25 \%$ SDS in DPBS) were added and the samples were rotated for $2.5 \mathrm{~h}$. beads were then pelleted by centrifugation $(1,000 \times \mathrm{g}, 2 \mathrm{~min})$ and sequentially washed with $0.25 \% \mathrm{SDS}(3 \times 10 \mathrm{~mL})$. Beads were transferred to a low-binding 1.7-mL tube, and further washed with DPBS $(3 \times 1 \mathrm{~mL})$ and Millipore $\mathrm{H} 2 \mathrm{O}(3 \times 1 \mathrm{~mL})$. Trypsin solution (20 $\mu \mathrm{g}$ sequencing-grade modified trypsin, [Promega], in $2 \mathrm{~mL} 2 \mathrm{M}$ urea, buffered with $100 \mathrm{mM}$ TEAB) was added to each sample and on-bead digestion proceeded overnight with shaking $\left(14 \mathrm{~h}\right.$ at $\left.37^{\circ} \mathrm{C}\right)$. The mixture was filtered using a Bio-Spin column, eluting into a fresh low-binding tube and quenched with formic acid (16 $\mu \mathrm{L})$. Samples were stored at $20{ }^{\circ} \mathrm{C}$ prior to MudPIT analysis.

MudPIT analysis of tryptic peptides. Peptides were analyzed by LC-MS/MS on a ThermoFinnigan LTQ mass spectrometer (Thermo Scientific) according to previously described methods (Weerapana et al, 2007). Peptides from onbead tryptic digests were pressure loaded onto a $250 \mu \mathrm{m}$ (inner diameter) fused silica capillary column packed with $4 \mathrm{~cm}$ $\mathrm{C} 18$ resin $(5 \mu \mathrm{m}$, Phenomenex). Peptides were then eluted onto a $100 \mu \mathrm{m}$ (inner diameter) fused silica capillary column packed with $3 \mathrm{~cm}$ strong cation exchange (SCX) resin followed by $10 \mathrm{~cm} \mathrm{C18} \mathrm{resin.} \mathrm{Chromatographic} \mathrm{separation} \mathrm{of} \mathrm{the}$ peptide mixture was achieved using a 5-step multidimensional LC-MS (MudPIT) (Washburn et al., 2001) protocol consisting of $0 \%, 25 \%, 50 \%, 80 \%$ and $100 \%$ salt bumps of $\mathrm{NH}_{4} \mathrm{OAc}(500 \mathrm{mM})$ salt bumps followed by an increasing gradient of $\mathrm{CH}_{3} \mathrm{CN}\left(0.1 \% \mathrm{HCO}_{2} \mathrm{H}\right)$ in $\mathrm{H}_{2} \mathrm{O}$.

Protein identification and quantification. RAW files were directly uploaded to the Integrated Proteomics Pipeline (IP2) for analysis, where they were searched using ProLuCID against a human reverse-concatenated non-redundant (gene-centric) FASTA database, assembled from the Uniprot database. The precursor-ion mass tolerance was set to $50 \mathrm{ppm}$. Oxidation on methionine $(+15.9949)$ was specified as a variable modification and iodoacetamide alkylation $(+57.0215)$ on cysteine as a static modification. Matched MS2 spectra from ProLuCID searches were assembled by protein and filtered using DTASelect (version 2.0.47) which allowed only half-tryptic or fully-tryptic peptides for identification and quantification. Peptides were restricted to a specified false positive rate of $1 \%$. SILAC ratios were quantified using CIMAGE software (described in Weerapana et al., 2010). ${ }^{27}$ Briefly, the software extracts MS1 ion chromatograms ( $\left.\pm 20 \mathrm{ppm}\right)$ from 'light' and 'heavy' target peptide masses $(\mathrm{m} / \mathrm{z})$ using a retention time window $( \pm 10 \mathrm{~min})$ centered at the time the peptide ion was 
identified by MS/MS fragmentation; the ratio of light and heavy peptide peak areas are then calculated. To ensure the correct peak-pair is used for quantification, CIMAGE applies a co-elution correlation score filter $\left(\mathrm{R}^{2} \geq 0.8\right)$ for heavy and light peptide peaks to exclude target peptides with poor co-elution profiles. Furthermore, an envelope correlation score filter is applied to ensure the experimentally observed high-resolution MS1 spectrum matches $\left(\mathrm{R}^{2}>0.8\right)$ the predicted isotopic distribution. Peptide SILAC ratios are capped at a maximum of 20 to mitigate the effects of the large dynamic range of protein levels; this is also the ratio assigned to "singletons"- peptides that exclusively had extracted ion signal for one of the isotopes but not the other.

SILAC ratios for proteins were calculated from the peptide ratios generated by CIMAGE. Log2-transformed SILAC ratios were first analyzed on a per sample level. A SILAC ratio of $\geq 3.0$ was chosen as a cutoff for defining enriched and competed targets. Peptides were grouped by sequence and the median value used for further analysis. In cases where a maximum ratio was observed along with ratios less than the cutoff, the maximum ratio was excluded from calculations, since the prior probability of outlier "singletons" is known to be high. Peptides were then grouped by protein and the median SILAC ratio was used for further calculations. Protein $\log 2$-SILAC ratios were grouped by experimental replicate, then the mean of 3 replicates was calculated and transformed back into base 10. Proteins ratio values retained for further analysis were required to be quantified in at least 2 replicates and represented by at least 2 sequence-unique quantified peptides. Saturable targets were defined as proteins that had SILAC ratio of $\geq 3.0$ in both enrichment and competition experiments.
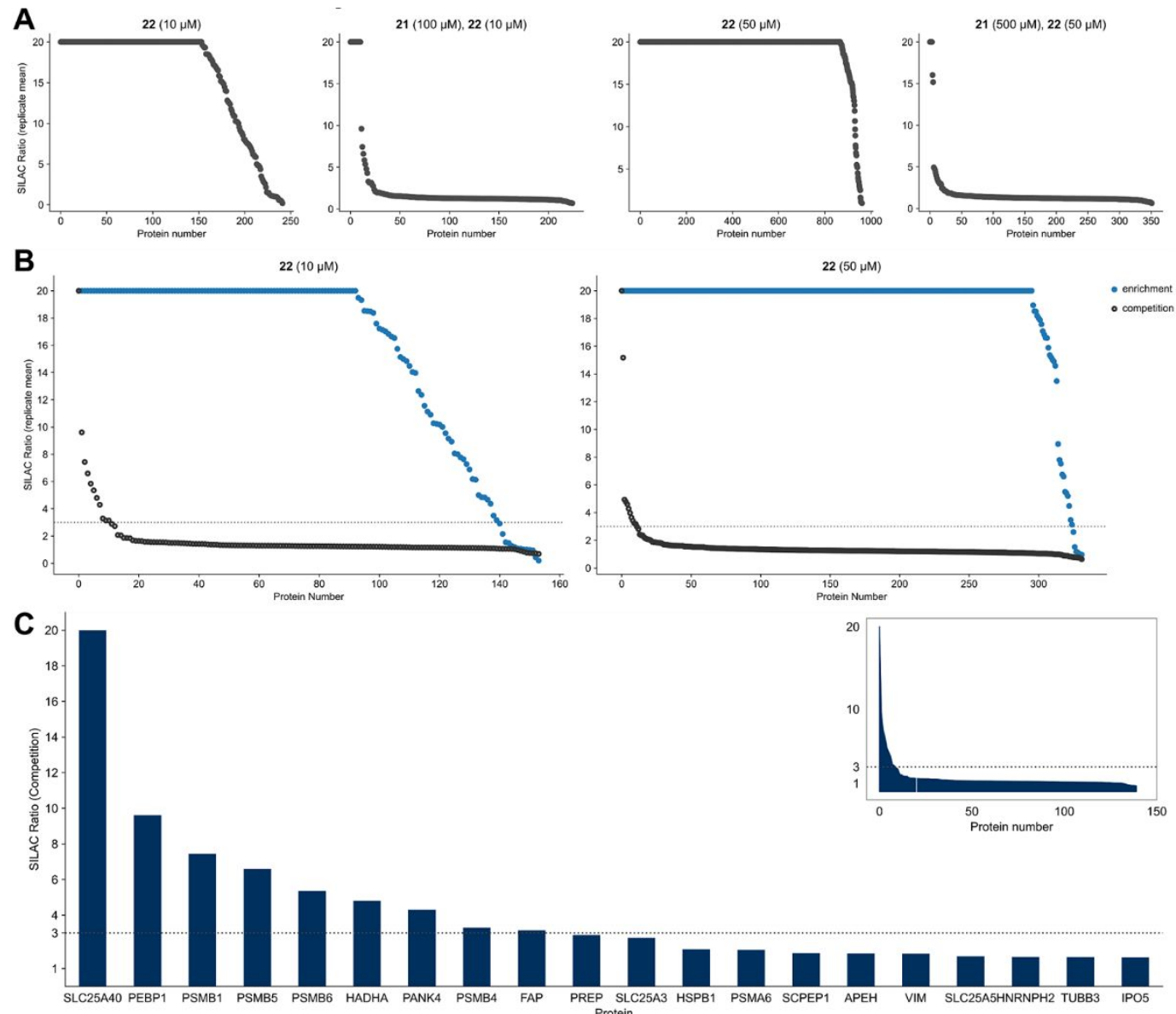

Figure S28. Waterfall plots of SILAC ratios. A) Mean SILAC ratios for each enrichment (10, 10 and $50 \mu \mathrm{M})$ and competition experiment $(9,100$ and $500 \mu \mathrm{M})$. B) Mean SILAC ratios for proteins that were reproducibly quantified in both corresponding enrichment and competition experiments. The dotted line (SILAC ratio $\geq 3.0)$ indicates the threshold for a protein to be considered enriched or competed in the respective experiment. C) Plot 
of top 20 SILAC competition ratios (larger values indicate stronger competition) of enriched proteins, defined as having SILAC ratios of $\geq 3$ in enrichment experiments (probe 10, $10 \mu \mathrm{M} / \mathrm{DMSO}$ control, see Supplementary Proteomics Tables for full details); inset shows SILAC competition ratios for all enriched proteins. U937 whole lysates were pre-incubated with excess $9(100 \mu \mathrm{M})$, followed by biotinylated ABP $10(10 \mu \mathrm{M})$. Targets were defined as enriched proteins that had SILAC competition ratios of $\geq 3$ (dotted line). Bars represent the mean of at least two valid SILAC competition ratios out of three replicates performed. 


\section{References}

[1] Tsang, W. Y., Ahmed, N., Harding, L. P., Hemming, K., Laws, A. P., and Page, M. I. (2005) Acylation versus sulfonylation in the inhibition of elastase by 3-oxo- $\beta$-sultams, $J$ Am Chem Soc 127, 8946-8947.

[2] Tsang, W. Y., Ahmed, N., Hemming, K., and Page, M. I. (2007) Reactivity and selectivity in the inhibition of elastase by 3-oxo- $\beta$-sultams and in their hydrolysis, Org Biomol Chem 5, 3993-4000.

[3] Glasl, D., Otto, H.-H., and Rihs, G. (1997) Properties and Reactions of Substituted 1,2-Thiazetidine 1,1-Dioxides: Synthesis of N-Substituted 4,4-dimethyl-1,2-thiazetidin-3-one 1,1-dioxides, and a new base-catalyzed rearrangement to thiazolidin-4-one 1,1-dioxides, Helv Chim Acta 80, 671-683.

[4] Hofbauer, S., Brito, J. A., Mulchande, J., Nogly, P., Pessanha, M., Moreira, R., and Archer, M. (2015) Stabilization of porcine pancreatic elastase crystals by glutaraldehyde cross-linking, Acta Crystallogr F Struct Biol Commun 71, 13461351.

[5] Ruivo, E. F., Goncalves, L. M., Carvalho, L. A., Guedes, R. C., Hofbauer, S., Brito, J. A., Archer, M., Moreira, R., and Lucas, S. D. (2016) Clickable 4-Oxo- $\beta$-lactam-Based Selective Probing for Human Neutrophil Elastase Related Proteomes, ChemMedChem 11, 2037-2042.

[6] Tsunemi, M., Matsuura, Y., Sakakibara, S., and Katsube, Y. (1996) Crystal structure of an elastase-specific inhibitor elafin complexed with porcine pancreatic elastase determined at 1.9 A resolution, Biochemistry 35, 11570-11576.

[7] Thaller, C., Weaver, L. H., Eichele, G., Wilson, E., Karlsson, R., and Jansonius, J. N. (1981) Repeated seeding technique for growing large single crystals of proteins, J Mol Biol 147, 465-469.

[8] Kabsch, W. (2010) XDS, Acta Crystallogr D Biol Crystallogr 66, 125-132.

[9] Evans, P. R. (2011) An introduction to data reduction: space-group determination, scaling and intensity statistics, Acta Crystallogr D Biol Crystallogr 67, 282-292.

[10] Evans, P. R., and Murshudov, G. N. (2013) How good are my data and what is the resolution?, Acta Crystallogr D Biol Crystallogr 69, 1204-1214.

[11] Vonrhein, C., Flensburg, C., Keller, P., Sharff, A., Smart, O., Paciorek, W., Womack, T., and Bricogne, G. (2011) Data processing and analysis with the autoPROC toolbox, Acta Crystallogr D Biol Crystallogr 67, 293-302.

[12] Tickle, I.J., Flensburg, C., Keller, P., Paciorek, W., Sharff, A., Vonrhein, C., and Bricogne, G. (2018) STARANISO, Global Phasing Ltd., Cambridge,United Kingdom.

[13] McCoy, A. J., Grosse-Kunstleve, R. W., Adams, P. D., Winn, M. D., Storoni, L. C., and Read, R. J. (2007) Phaser crystallographic software, $J$ Appl Crystallogr 40, 658-674.

[14] Adams, P. D., Afonine, P. V., Bunkoczi, G., Chen, V. B., Davis, I. W., Echols, N., Headd, J. J., Hung, L. W., Kapral, G. J., Grosse-Kunstleve, R. W., McCoy, A. J., Moriarty, N. W., Oeffner, R., Read, R. J., Richardson, D. C., Richardson, J. S., Terwilliger, T. C., and Zwart, P. H. (2010) PHENIX: a comprehensive Python-based system for macromolecular structure solution, Acta Crystallogr D Biol Crystallogr 66, 213-221.

[15] Afonine, P. V., Grosse-Kunstleve, R. W., Echols, N., Headd, J. J., Moriarty, N. W., Mustyakimov, M., Terwilliger, T. C., Urzhumtsev, A., Zwart, P. H., and Adams, P. D. (2012) Towards automated crystallographic structure refinement with phenix.refine, Acta Crystallogr D Biol Crystallogr 68, 352-367.

[16] Navia, M. A., McKeever, B. M., Springer, J. P., Lin, T. Y., Williams, H. R., Fluder, E. M., Dorn, C. P., and Hoogsteen, K. (1989) Structure of human neutrophil elastase in complex with a peptide chloromethyl ketone inhibitor at 1.84-A resolution, Proc Natl Acad Sci U S A 86, 7-11.

[17] Blanc, E., Roversi, P., Vonrhein, C., Flensburg, C., Lea, S. M., and Bricogne, G. (2004) Refinement of severely incomplete structures with maximum likelihood in BUSTER-TNT, Acta Crystallogr D Biol Crystallogr 60, $2210-2221$.

[18] Emsley, P., Lohkamp, B., Scott, W. G., and Cowtan, K. (2010) Features and development of Coot, Acta Crystallogr D Biol Crystallogr 66, 486-501. 
[19] Chen, V. B., Arendall, W. B., 3rd, Headd, J. J., Keedy, D. A., Immormino, R. M., Kapral, G. J., Murray, L. W., Richardson, J. S., and Richardson, D. C. (2010) MolProbity: all-atom structure validation for macromolecular crystallography, Acta Crystallogr D Biol Crystallogr 66, 12-21.

[20] Schrödinger, L. The PyMOL Molecular Graphics System, Version 2.0.

[21] Matthews, B. W. (1968) Solvent content of protein crystals, J Mol Biol 33, 491-497.

[22] Cregge, R. J., Durham, S. L., Farr, R. A., Gallion, S. L., Hare, C. M., Hoffman, R. V., Janusz, M. J., Kim, H. O., Koehl, J. R., Mehdi, S., Metz, W. A., Peet, N. P., Pelton, J. T., Schreuder, H. A., Sunder, S., and Tardif, C. (1998) Inhibition of human neutrophil elastase. 4. Design, synthesis, X-ray crystallographic analysis, and structure-activity relationships for a series of P2-modified, orally active peptidyl pentafluoroethyl ketones, J Med Chem 41, 2461-2480.

[23] Hansen, G., Gielen-Haertwig, H., Reinemer, P., Schomburg, D., Harrenga, A., and Niefind, K. (2011) Unexpected active-site flexibility in the structure of human neutrophil elastase in complex with a new dihydropyrimidone inhibitor, $J$ Mol Biol 409, 681-691.

[24] Powers, J. C., Oleksyszyn, J., Narasimhan, S. L., and Kam, C. M. (1990) Reaction of porcine pancreatic elastase with 7-substituted 3-alkoxy-4-chloroisocoumarins: design of potent inhibitors using the crystal structure of the complex formed with 4-chloro-3-ethoxy-7-guanidinoisocoumarin, Biochemistry 29, 3108-3118.

[25] Frisch, M. J., Trucks, G. W., Schlegel, H. B., Scuseria, G. E., Robb, M. A., Cheeseman, J. R., Scalmani, G., Barone, V., Petersson, G. A., Nakatsuji, H., Li, X., Caricato, M., Marenich, A. V., Bloino, J., Janesko, B. G., Gomperts, R., Mennucci, B., Hratchian, H. P., Ortiz, J. V., Izmaylov, A. F., Sonnenberg, J. L., Williams, Ding, F., Lipparini, F., Egidi, F., Goings, J., Peng, B., Petrone, A., Henderson, T., Ranasinghe, D., Zakrzewski, V. G., Gao, J., Rega, N., Zheng, G., Liang, W., Hada, M., Ehara, M., Toyota, K., Fukuda, R., Hasegawa, J., Ishida, M., Nakajima, T., Honda, Y., Kitao, O., Nakai, H., Vreven, T., Throssell, K., Montgomery Jr., J. A., Peralta, J. E., Ogliaro, F., Bearpark, M. J., Heyd, J. J., Brothers, E. N., Kudin, K. N., Staroverov, V. N., Keith, T. A., Kobayashi, R., Normand, J., Raghavachari, K., Rendell, A. P., Burant, J. C., Iyengar, S. S., Tomasi, J., Cossi, M., Millam, J. M., Klene, M., Adamo, C., Cammi, R., Ochterski, J. W., Martin, R. L., Morokuma, K., Farkas, O., Foresman, J. B., and Fox, D. J. (2016) Gaussian 16 Rev. C.01, Wallingford, CT.

[26] Morrison, J. F., and Walsh, C. T. (1988) The behavior and significance of slow-binding enzyme inhibitors, Adv Enzymol Relat Areas Mol Biol 61, 201-301.

[27] Weerapana, E., Wang, C., Simon, G. M., Richter, F., Khare, S., Dillon, M. B. D., Bachovchin, D. A., Mowen, K., Baker, D., and Cravatt, B. F. (2010) Quantitative reactivity profiling predicts functional cysteines in proteomes, Nature 468, 790-795. 